\title{
Sobre Avaliação Parcial de Meta-Interpretadores Geração de Núcleos Específicos de Sistemas Especialistas
}

\author{
Joầo Luiz Franco
}

Orientação:

Profa. Dra. Maria Carolina Monard

Dissertação apresentada ao Instituto de Ciências Matemáticas de São Carlos - USP, como parte dos requisitos para obtenção do título de Mestre em Ciências de Computação e Matemática Computacional. 


\section{Agradecimentos}

a Carolina, pelo carinho, incentivo, dedicação e pelo grande auxilio, tanto na graduação como no mestrado.

às amigas Solange, Júlia e Inés, pela participação neste trabalho, com críticas, sugestōes e muito carinho.

aos amigos Mauro, Takiai, Pedrão, Cal, Luiz, Ricardo, Pacheco, Bráulio, João; às amigas Cristina, Silvely e Ana; a todos os companheiros da pós-graduação.

a João, Adão, Domingão e aos amigos de São Carlos.

a Sandra, pela amizade sincera e pelos momentos mais felizes.

a Beth e Laura, pela dedicação ao trabalho e pelo carinho que tratam a todos.

a Dolores, Silvana, Giselda, Rose, Carmem e a todos aqueles funcionários que nos tratam com afeto e alegria.

a minha familia, pelo carinho e apoio.

ao CNPq e à CAPES, pelo apoio financeiro. 


\section{Resumo}

Para facilitar a tarefa de implementação de sistemas, as linguagens de programação devem ter uma major expressividade. No entanto, o aumento do poder de expressão das linguagens frequentemente diminui a eficiência dos programas desenvolvidos a partir delas.

A linguagem Prolog tem um poder de expressão considerável. Além disso, essa expressividade pode ser facilmente aumentada. Porém, esse aumento de expressividade diminui consideravelmente a eficiência de execução. Neste trabalho, são abordados dois métodos para aumentar a eficiência de programas Prolog sem diminuir a expressividade da linguagem.

A facilidade de meta-programação é uma caracteristica muito poderosa da linguagem Prolog. No entanto, introduz um nível extra de interpretação durante a execução do programa. Um dos métodos apresentados - a Avaliação Parcial — pode ser utilizada para remover o nível extra de interpretação, viabilizando a utilização de metaprogramação - principalmente na implementação de Sistemas Especialistas. Neste trabalho, é discutido e implementado um avaliador parcial de meta-interpretadores, além de mostrar como ele pode ser utilizado com diferentes tipos de meta-interpretadores.

O outro método abordado - Especialização de Programas - é utilizado para construir programas específicos a partir de um programa geral. Isto é feito retirando-se do programa geral as cláusulas desnecessárias para uma aplicação específica. Neste trabalho, apresenta-se uma implementação onde a Especialização de Programas é utilizada para gerar Núcleos de Sistemas Especialistas específicos a partir de um Núcleo de Sistemas Especialistas geral. 


\begin{abstract}
One of the aims of the Fifth Generation Computer Project is to enable the efficent development of complex, large-scale knowledge processing programs, by augmenting the expressive power of programming languages as well as the execution efficiency of programs written in those languages.

The logic programming language Prolog - adopted for use in this project - has considerable expressive power itself although does not always provide satisfactory execution efficiency.

Meta-programming is a strong paradigm for software development due to its conceptual clarity. A meta program is one which uses another programthe object program - as data. Meta-programming in Prolog is particularly attractive because the object language and the meta language are identical. However, meta programs are inefficient because of layers of interpretation.

In this work we present two methods to improve the efficiency of Prolog programs.

The first one solves the problem o flayers of interpretation by partial evaluation of metaprograms with respect to object programs. We describe the basic ideas underlying partial evaluation, the Prolog implementation of a partial evaluator for Prolog programs and its application to metaprogramming. The difficulties in implementing a general partial evaluator systems for Prolog are also discussed.

The second method proposed and implemented in this work to improve the efficiency of Prolog programs, is related to the construction of a more specific program from an existing, general Prolog program. This is achieved by withdrawing clauses that are in the general program but which will never be executed by the more specific program being constructed.
\end{abstract}




\section{Conteúdo}

1 Introdução 1

1.1 O Projeto Computador de Quinta Geração . . . . . . . . . . . . . . 1

1.2 Geração Automática de Programas Específicos . . . . . . . . . . . . 2

1.3 Avaliação Parcial ............................ 2

1.4 Motivação do Trabalho . . . . . . . . . . . . . . 3

1.5 Organização do Trabalho ................... 3

2 Um Ambiente para Auxiliar a Construção de Núcleos de Sistemas Especialistas $\quad 5$

2.1 Considerações Iniciais $\ldots \ldots \ldots \ldots \ldots \ldots \ldots$

2.2 Sistemas Especialistas e Sistemas de Conhecimento . . . . . . . . . 5

2.3 Estrutura Básica de um Sistema Especialista . . . . . . . . . . 7

2.4 Desenvolvimento de um Sistema Especialista . . . . . . . . . . . . 8

2.5 Considerações sobre Núcleos de Sistemas Especialistas . . . . . . . . 8

2.6 Descrição do Ambiente . . . . . . . . . . . . . . . . 9

2.7 Consideraçôes Finais . . . . . . . . . . . . . . 10

3 GENESE - Um Gerador de Núcleos Especificos de Sistemas Especialistas $\quad 13$

3.1 Considerações Iniciais $\ldots \ldots \ldots \ldots \ldots$

3.2 Objetivos Gerais ........................ 13

3.3 Proposta de Implementação . . . . . . . . . . . . . . . 15

3.4 A Árvore de Relacionamento entre as Cláusulas . . . . . . . . . . . . 15

3.5 O Módulo de Interface com o Implementador do Núcleo Geral . . . . . . 18 
3.6 Representação Interna . . . . . . . . . . . . . . 19

3.7 Módulo de Interface com o Implementador da Base de Conhecimento . 20

3.8 Interface com o Usuário . . . . . . . . . . . . . . . 21

3.8.1 Definição de Menus. . . . . . . . . . . . . . . . 21

3.8.2 Manipulação de Perguntas. . . . . . . . . . . . . 22

3.8.3 Inserção e Retirada de Elementos na Lista de Opções . . . . . 23

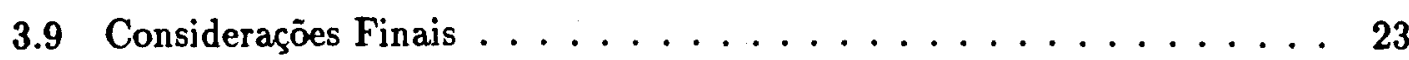

4 Exemplos de Funcionamento do Sistema GENESE 24

4.1 Considerações Iniciais $\ldots \ldots \ldots \ldots \ldots \ldots . \ldots \ldots$

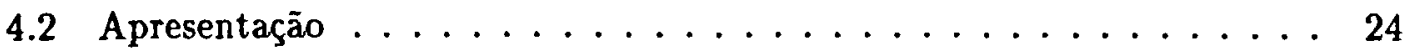

4.3 O Módulo de Interface com o Implementador da Base de Conhecimento 26

4.4 O Módulo de Interface com o Implementador do Núcleo Geral . . . . . 27

4.4 .1 Manipulação de Árvores . . . . . . . . . . . . . 28

4.4.2 Manipulação de Sub-regras . . . . . . . . . . . . 33

4.4.3 Manipulação de Perguntas . . . . . . . . . . . . . . . 39

4.5 Considerações Finais $\ldots \ldots \ldots \ldots \ldots \ldots \ldots \ldots \ldots$

5 Meta-Interpretadores $\quad \mathbf{4 2}$

5.1 Considerações Iniciais $\ldots \ldots \ldots \ldots \ldots \ldots \ldots \ldots \ldots$

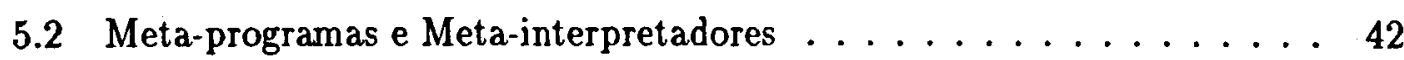

5.3 Meta-Interpretadores $\operatorname{Prolog} \ldots \ldots \ldots \ldots \ldots \ldots \ldots$

5.3.1 Um Meta-Interpretador Trivial $\ldots \ldots \ldots \ldots \ldots \ldots \ldots 43$

5.3.2 Um Meta-interpretador Básico . . . . . . . . . . . . 44

5.3.3 Um Meta-interpretador para Construir a Árvore de Prova . . . 46

5.3.4 Um Meta-interpretador para Rastrear a Execução de Programas 50

5.3.5 Árvore de Rastreamento . . . . . . . . . . . . . . . 51

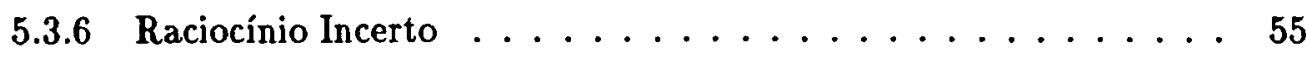

5.3 .7 Interação com o Usuário . . . . . . . . . . . . . . 57

5.3 .8 Relações do Sistema . . . . . . . . . . . . . . . 61

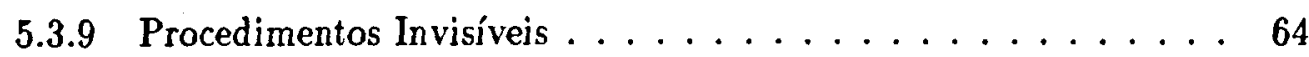


5.4 Classificação de Meta-interpretadores . . . . . . . . . . . . . 66

5.5 Consideraçōes Finais . . . . . . . . . . . . . . 67

6 Avaliação Parcial $\quad 68$

6.1 Considerações Iniciais $\ldots \ldots \ldots \ldots \ldots$

6.2 Avaliação Parcial em uma Máquina de Estados . . . . . . . . . . . 69

6.3 Avaliação Parcial em Programação Lógica . . . . . . . . . . . . . . . 71

6.3.1 Conceitos Básicos . . . . . . . . . . . . 72

6.3.2 Mecanismos de Avaliação Parcial . . . . . . . . . . . . 73

6.4 Avaliação Parcial de Programas Prolog . . . . . . . . . . . . . 75

6.5 Um Avaliador Parcial Básico para Prolog . . . . . . . . . . . . . 79

6.6 Decisões de Controle na Avaliação Parcial . . . . . . . . . . . . . . 82

6.7 Consideraçōes Finais . . . . . . . . . . . . . . 83

7 Uso de Avaliação Parcial na Construção de Sistemas Especialistas 84

7.1 Considerações Iniciais . . . . . . . . . . . . . . . 84

7.2 Meta-interpretadores na Construção de Sistemas Especialistas . . . . . 84

7.3 Avaliação Parcial de Meta-interpretadores . . . . . . . . . . . . 85

7.4 Avaliadores Parciais Gerais e Específicos . . . . . . . . . . . . . 86

7.50 Controle de Expansão na Avaliação Parcial . . . . . . . . . . . . . 87

7.5.1 Como Trabalha um Meta-Interpretador . . . . . . . . . 88

7.5.2 Critério de Expansão . . . . . . . . . . . . 88

7.5.3 Alguns Critérios para Remover o Nível Extra de Interpretação $\quad 89$

7.5.4 Pré-execuçāo de Símbolos Atômicos . . . . . . . . . . . . 89

7.5.5 Cláusulas Múltiplas $\ldots \ldots \ldots \ldots \ldots$

7.5.6 Como Garantir a Expansão Correta . . . . . . . . . . . . 90

7.6 Otimizaçōes Durante a Avaliação Parcial . . . . . . . . . . . . . 91

7.7 Exemplo de Especificação para o Avaliador Parcial . . . . . . . . . . 93

7.8 Eliminação do Meta-Interpretador . . . . . . . . . . . . . 94

7.9 Exemplo de Utilização . . . . . . . . . . . . . . . 95

7.10 Considerações Finais . . . . . . . . . . . . . . . . 99 
8 Conclusões 100

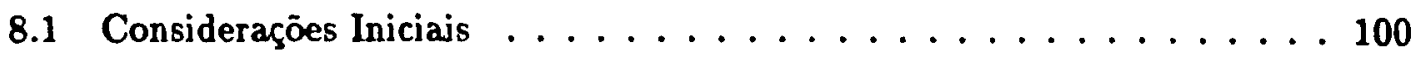

8.2 Análise do Avaliador Parcial . . . . . . . . . . . . . . 100

8.3 A valiação do Sistema GEN ESE . . . . . . . . . . . . . 101

8.4 Trabalhos Futuros ......................... 103

8.4 .1 Avaliação Parcial . . . . . . . . . . . . . . 103

8.4.2 Especialização de Programas . . . . . . . . . . . . 103

8.5 Considerações Finais . . . . . . . . . . . . . . . . . . . 104

$\begin{array}{ll}\text { Bibliografia } & 105\end{array}$ 


\section{Lista de Figuras}

2.1 Estrutura Básica de um Sistema Especialista . . . . . . . . . . . 11

2.2 Ambiente para Auxiliar a Construção de Núcleos Específicos . . . . . 12

3.1 Gerador de Núcleos Específicos . . . . . . . . . . . . . . . . 14

3.2 Exemplo de uma Árvore de Relacionamento entre Cláusulas . . . . . . . 17

4.1 Tela de Apresentação . . . . . . . . . . . . . . 25

4.2 Escolha de Módulo . . . . . . . . . . . . . . 25

4.3 Interface com o Implementador da Base de Conhecimento . . . . . . 26

4.4 Interface com o Implementador do Núcleo Geral . . . . . . . . . . 27

4.5 Manipulação de Árvores . . . . . . . . . . . . . . . . 28

4.6 Inserir Dados . . . . . . . . . . . . . . . . . . . . 29

4.7 Árvore Após a Inserção . . . . . . . . . . . . . . . . 29

4.8 Retirar um Elemento . . . . . . . . . . . . . . . 30

4.9 Árvore após Retirada de um Elemento . . . . . . . . . . . . . 30

4.10 Trocar Árvore Corrente . . . . . . . . . . . . . . . 31

4.11 Nova Árvore Corrente . . . . . . . . . . . . . . . 31

4.12 Criar uma Nova Árvore . . . . . . . . . . . . . . . 32

4.13 Árvore Recém-criada . . . . . . . . . . . . . . . . . 32

4.14 Manipulação de Sub-regras . . . . . . . . . . . . 33

4.15 Inserir uma Sub-regra . . . . . . . . . . . . . . . . 34

4.16 Lista de Sub-regras após Inserção . . . . . . . . . . . . . 34

4.17 Lista de Sub-regras após a Retirada de um Elemento . . . . . . . . . 35

4.18 Trocar Regra Corrente . . . . . . . . . . . . . . 36 
4.19 Nova Regra Corrente . . . . . . . . . . . . . . . . 36

4.20 Criar Nova Lista de Sub-regras . . . . . . . . . . . . . . 37

4.21 Inserção da Primeira Sub-regra . . . . . . . . . . . . . 38

4.22 Nova Lista de Sub-regras . . . . . . . . . . . . . . 38

4.23 Manipulação de Perguntas . . . . . . . . . . . . . . . . 39

4.24 Tela durante Digitação do Texto . . . . . . . . . . . . . . 40

4.25 Tela após a Digitação do Texto . . . . . . . . . . . . 40

6.1 Mecanismo de Avaliação Parcial . . . . . . . . . . . . 72

6.2 Sistema de Avaliação Parcial .................. 73 


\section{Capítulo 1}

\section{Introdução}

\subsection{O Projeto Computador de Quinta Geração}

Uma das metas do Projeto "Computador de Quinta Geração" é aumentar a capacidade de desenvolver eficientemente programas que processam conhecimento de grande complexidade, ou, como segunda alternativa, fornecer os meios necessários para tal desenvolvimento.

Para isto, é necessário o desenvolvimento de uma metodologia que facilite escrever tais programas. Essa metodologia visa atingir dois pontos essenciais:

1. aumentar o poder de expressão das linguagens de programação que são utilizadas no desenvolvimento dos programas

2. melhorar a eficiência dos programas escritos nessas linguagens

A linguagem de programação lógica Prolog - adotada para o desenvolvimento de programas no Projeto "Computador de Quinta Geração" - tem por si própria um grande poder de expressão. Devido a ela, progressos consideráveis foram feitos no desenvolvimento de programas que processam conhecimento, linguagem natural e outros processamentos complexos.

Não bastasse seu poder de expressão por si só, a linguagem Prolog também apresenta facilidades para a utilização de meta-programação, que pode ser utilizada para aumentar ainda mais a expressividade da linguagem. No entanto, a expressividade de uma linguagem nem sempre está aliada à eficiência. Aliás, em geral, acontece justamente o contrário, isto é, quanto maior o poder de expressão - que facilita a construção de programas mais claros e modulares - menos satisfatória é a eficiência da execução.

O mesmo problema pode ser encontrado quando discute-se generalização versus especialização. A construção de programas gerais pode torná-los ineficientes, enquanto o desenvolvimento de programas específicos pode tornar-se muito dispen dioso. 
Neste trabalho supõe-se algum conhecimento de programação lógica [Casanova 87] e da linguagem Prolog [Clocksin 87]. Em seu conteúdo serāo discutidas duas técnicas que, embora relativamente distintas, seguem o mesmo princípio básico: facilitar o desenvolvimento de programas - aumentando o poder de expressão das linguagens com meta-programação e permitindo construção de programas gerais - sem comprometer a eficiência da execução desses programas.

\subsection{Geração Automática de Programas Específicos}

Um programa Prolog é constituído por um conjunto de cláusulas que, durante a execução, são analisadas até que uma delas possa ser "executada". Deste modo, uma das características que afetam a eficiência dos programas é o número de cláusulas: quanto mais cláusulas existirem, menos eficiente ele será.

Uma das técnicas apresentadas neste trabalho trabalha justamente em cima dessa característica para construir programas específicos a partir de programas gerais. Isto é feito retirando as cláusulas do programa geral que são desnecessárias à execução de um determinado programa específico.

\subsection{Avaliação Parcial}

Uma das características que tornam a linguagem Prolog muito poderosa é a representação de programas e dados de forma idêntica, o que facilita a meta-programação. A metaprogramação é uma característica muito poderosa, pois aumenta a expressividade da linguagem e permite a construção de programas mais gerais. Porém, a metaprogramação introduz um nível extra de interpretação que compromete a eficiência de execução dos programas.

A segunda técnica utilizada para aumentar eficiência de programas apresentada neste trabalho, a Avaliação Parcial, pode ser utilizada para retirar esse nível extra de interpretação, o que torna viável o uso de meta-programação sem o risco de comprometer a eficiência de execução do programa.

Avaliação Parcial é uma técnica de transformação de programa que trabalha da seguinte forma: considerando a execução de um programa como se fosse um cálculo, a Avaliação Parcial efetua parte da execução deste cálculo, que pode ser feita antes ou durante a compilação de um programa.

Basicamente, a Avaliação Parcial é feita da seguinte forma: os dados de entrada são divididos em dados conhecidos e dados desconhecidos. Na Avaliação Parcial, o programa é executado à medida que os dados conhecidos estão presentes. Os dados desconhecidos são deixados como variáveis que serão instanciadas durante a execução do programa.

Por mejo da Avaliação Parcial, é possível suavizar grande parte do processamento, otimizando um programa na proporção em que os dados são conhecidos. 


\subsection{Motivação do Trabalho}

Os Sistemas Especialistas - uma das áreas mais difundidas da Inteligência Artificial - constituem uma das áreas de pesquisa do grupo de Inteligência Artificial do Departamento de Computação do ICMSC - USP. Porém, devido à política de informática existente no Brasil ao longo dos últimos anos - que tem dificultado a importação de software - e à falta de flexibilidade apresentada pelos poucos shells aos quais se tem acesso, surgiu a necessidade do desenvolvimento de um Núcleo de Sistemas Especialistas próprio, com o objetivo de melhor se adequar às necessidades do grupo de pesquisa [Rodrigues 90a]. Esse Núcleo foi desenvolvido não simplesmente como um Núcleo, mas como um ambiente para auxiliar a construção de Núcleos de Sistemas Especialistas. Esse ambiente consiste de um Núcleo geral, de onde podem ser derivados Núcleos Específicos de acordo com as necessidades da aplicação a que ele se destina. Porém, este processo é manual, exigindo, para a confecção de um núcleo específico, um certo conhecimento sobre os detalhes de implementação do ambiente. Deste modo, surgiu a necessidade da construção de um sistema para automatizar o processo de construção de Núcleos específicos a partir do Núcleo geral.

Outra deficiência apresentada pelo ambiente diz respeito à eficiência da execução, pois o ambiente foi construído utilizando meta-programação - mais especificamente, metainterpretação - que introduz um nível extra de interpretação durante a execução, comprometendo a sua eficiência. Essa característica motivou um aprofundamento nas técnicas de Avaliação Parcial e o desenvolvimento de um sistema de Avaliação Parcial de meta-interpretadores, para que se possa realizar um estudo acerca da viabilidade da utilização deste recurso no ambiente citado.

\subsection{Organização do Trabalho}

O trabalho está organizado da seguinte forma:

No Capítulo 2 é apresentada uma pequena introdução sobre Sistemas Especialistas, mostrando uma visão geral da estrutura e característica básica de um Sistema Especialista, bem como os passos envolvidos na construção de um Sistema Especialista. Descreve-se também o ambiente para construção de Sistemas Especialistas citado na seção 1.4, considerando os objetivos que motivaram seu desenvolvimento, as características do ambiente e o processo de construçâo de núcleos específicos a partir do núcleo geral implementado nesse ambiente.

No Capítulo 3 descreve-se a implementação de um sistema para automatizar a construção de Núcleos específicos a partir do Núcleo geral descrito no Capítulo 2. Este sistema visa permitir que o implementador da Base de Conhecimento de um determinado Sistema Especialista possa gerar seu núcleo específico sem conhecer os detalhes de implementação do núcleo geral.

No Capítulo 4 são apresentadas algumas telas para mostrar como é feita a interação do sistema descrito no Capítulo 3 com o usuário. Deste modo, é possível ter uma 
visão mais geral do sistema.

No Capítulo 5 são apresentados, de forma detalhada, os conceitos de meta-programação e mostra-se como meta-interpretadores podem scr usados na construção de Sistemas Especialistas.

No Capítulo 6 são descritos os princípios básicos da Avaliação Parcial, mostrando como um avaliador parcial pode ser utilizado para melhorar a eficiência de execução de programas. Neste capítulo são mostradas as principais vantagens e as maiores dificuldades na implementação de um Avaliador Parcial.

No Capitulo 7 são mostradas algumas técnicas para a utilização de Avaliação Parcial em sistemas implementados com meta-interpretadores. Apresenta-se também um avaliador parcial para um meta-interpretador específico - que é um subconjunto do meta-interpretador utilizado na implementação do ambiente descrito no Capítulo 2.

No Capítulo 8 encontram-se as conclusões do trabalho e são apresentadas propostas para trabalhos futuros. 


\section{Capítulo 2}

\section{Um Ambiente para Auxiliar a Construção de Núcleos de Sistemas Especialistas}

\subsection{Considerações Iniciais}

Inteligência Artificial é a parte da Ciência da Computação que se preocupa em elaborar "sistemas inteligentes", isto é, sistemas que exibem características que normalmente são associadas com inteligência no comportamento humano [Nilsson 82] [Winston 84]. Assim, as pesquisas na área de Inteligência Artificial concentram-se na elaboração de programas para resolver os problemas nos quais, até o momento, o ser humano supera a máquina [Ford 87].

Um dos segmentos mais explorados das pesquisas de Inteligência Artificial são os Sistemas Especialistas [Carnota 88], [Alty 84], [Hayes-Roth 83], [Michie 82], [Jackson 86], [Waterman 86]. Os Sistemas Especialistas são programas destinados a solucionar problemas em um campo específico do conhecimento, utilizando conhecimentos e procedimentos de inferência na solução de tais problemas. Estes programas possuem um desempenho comparável ao dos especialistas humanos neste campo.

Neste capítulo são introduzidos os princípios básicos de Sistemas Especialistas, indicando suas principais características e sua estrutura básica. Em seguida, descreve-se um ambiente desenvolvido para auxiliar a construção de Núcleos de Sistemas Especialistas [Rodrigues 90a] [Monard 91]. Este ambiente será utilizado no desenvolvimento deste trabalho.

\subsection{Sistemas Especialistas e Sistemas de Conhecimento}

Os Sistemas Baseados em Conhecimento, ou simplesmente Sistemas de Conhecimento, são programas de computador que resolvem - ou ajudam a resolver - problemas que 
requerem inteligência humana.

Diferenciando-se dos sistemas tradicionais de processamento de dados, que processam grandes volumes de informação algoritmicamente, os Sistemas de Conhecimento geralmente examinam um grande número de possibilidades e, em muitos casos, podem construir uma solução dinamicamente.

Outras diferenças entre sistemas convencionajs e Sistemas de Conhecimento que podem ser destacadas são:

- a maneira como estão organizados;

- o modo como incorporam o conhecimento;

- a forma de execução;

- a impressão que causam aos usuários, pois transmitem uma sensação de raciocínio.

Os Sistemas Especialistas constituem uma classe dos Sistemas de Conhecimento que resolvem problemas muito complexos. Suas principais características são:

1. contemplam múltiplas hipóteses simultaneamente;

2. interagem com o usuário para buscar informações que estão além do conhecimento do sistema;

3. justificam suas conclusões, bem como o motivo pelo qual solicitou alguma informação adicional durante o processamento;

4. trabalham com dados incertos e regras imprecisas;

5. o procedimento de resolução do problema deve ser de fácil compreensão para o usuário do sistema;

6. deve ser flexivel o suficiente para que seu conhecimento possa ser aplicado a novos tipos de problemas.

Existem algumas características que diferenciam um Sistema Especialista de um Sistema de Conhecimento [Jackson 86], mas basicamente um Sistema Especialista é um Sistema de Conhecimento que apresenta um desempenho comparável ao de um especialista humano.

O termo Sistema Baseado em Conhecimento foi introduzido como alternativa para o termo Sistema Especialista, que ganhou uma certa conotação negativa, dado que esse termo é muito pretencioso. Porém, na maioria dos trabalhos nesta área, estes termos continuam sendo usados indistintamente, critério que também é adotado neste trabalho. 


\subsection{Estrutura Básica de um Sistema Especialista}

Um Sistema Especialista pode ser composto por diversos subsistemas. Basicamente, ele consiste de uma Base de Conhecimento, uma Base de Dados e um Núcleo, descritos a seguir:

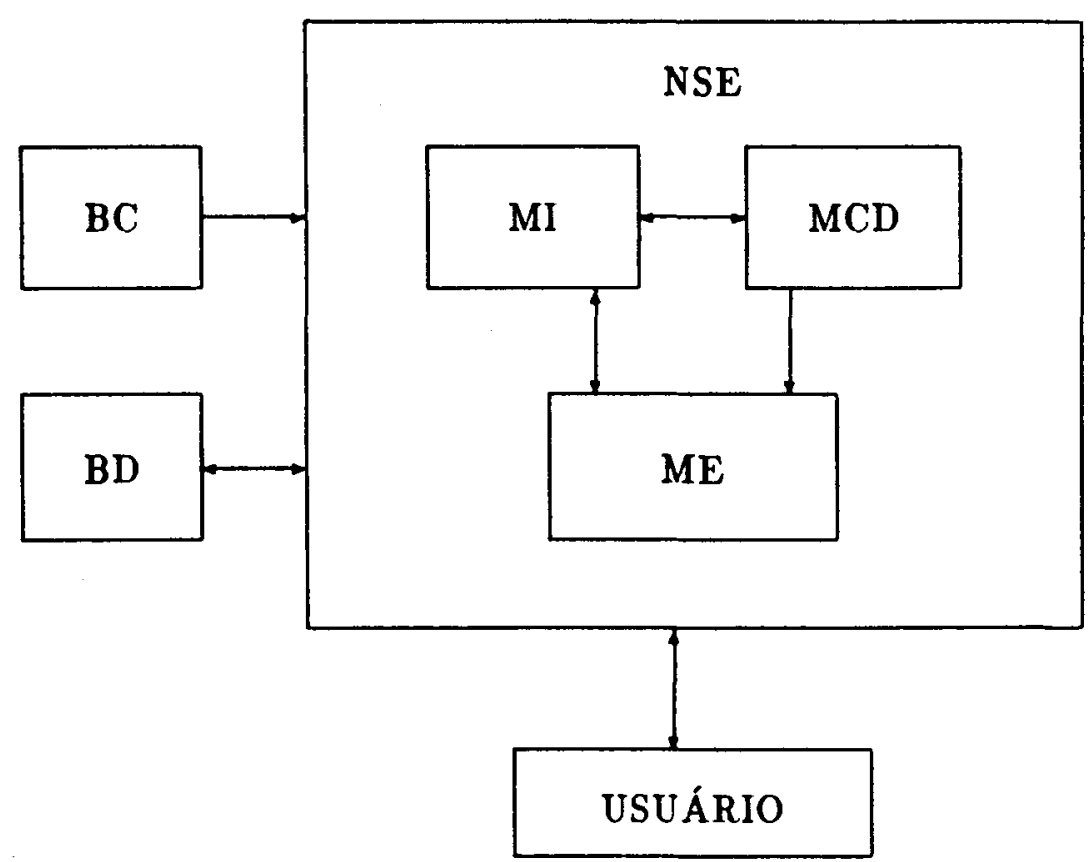

BC: Base de Conhecimento

BD: Base de Dados

NSE: Núcleo do Sistema Especialista

MCD: Módulo Coletor de Dados

MI: Motor de Inferência

ME: Módulo de Explicação

Figura 2.1: Estrutura Básica de um Sistema Especialista

Base de Conhecimento: contém a modelagem do conhecimento, isto é, as informaçōes necessárias para solucionar os problemas para o qual o sistema é projetado.

Base de Dados: contém os dados relativos ao problema específico que está sendo resolvido, ou seja, é a área de trabalho do sistema.

Núcleo do Sistema Especialista: é responsável pelo processamento do conhecimento, utilizando-se, para isto, de alguma linha de raciocínio. O Núcleo do Sistema Especialista também é responsável pela interação com o usuário e por explicar ou justificar as novas conclusōes obtidas durante o processamento da Base de 
Conhecimento. O Núcleo do Sistema Especialista pode ser subdividido em três módulos:

1. Motor de Inferência: é o módulo que processa a Base de Conhecimento, utilizando as informaçóes contidas na Base de Dados, a partir de uma determinada linha de raciocínio. Sua tarefa é propor alguma solução ao problema que está sendo analisado. As estratégias de raciocínio utilizadas pelo Motor de Inferência são Encadeamento Progressivo - Forward Chaining - e Encadeamento Regressivo - Backward Chaining. Estas estratégias encontram-se detalhadas a seguir.

- No Encadeamento Progressivo, o Motor de Inferência parte dos fatos dados ou asserções - existentes e, a seguir, baseando-se nas regras de conhecimento, deduz outras asserçōes até chegar à solução do problema.

- O Encadeamento Regressivo trabalha de forma contrária, isto é, parte de uma meta e busca os fatos que a tornem válida, a partir das informações existentes na Base de Conhecimento.

Em decorrência disto, pode-se associar uma determinada pergunta a cada estratégia de raciocínio.

O Encadeamento Regressivo pode ser associado à seguinte pergunta:

É possivel provar as metas a partir dos dados que temos?

O Encadeamento Progressivo, por sua vez, corresponde a perguntar:

O que é possivel concluir a partir dos dados que temos?

2. Módulo Coletor de Dados: é responsável pela comunicação com o meio externo - usuário, outros sistemas. Ele é ativado pelo Motor de Inferência quando há a necessidade de se obter alguma informação não existente na Base de Conhecimento.

3. Mecanismo de Explicação: é responsável pela explicação de como o Motor de Inferência chega a determinadas conclusões e porque faz certas perguntas.

A Figura 2.1 mostra a estrutura básica, bem como a interação entre os módulos de um Sistema Especialista.

\subsection{Desenvolvimento de um Sistema Especialista}

Resumidamente, o desenvolvimento de um Sistema Especialista consiste em extrair o conhecimento de um especialista humano e colocá-lo na Base de Conhecimento, na forma exigida pelo Motor de Inferência utilizado.

Isto é feito em duas etapas. Primeiramente, o conhecimento é extraído do especialista e modelado, utilizando alguma técnica de representação de conhecimento. Para isto, utiliza-se de um especialista em modelagem de conhecimento, que é chamado de Engenheiro de Conhecimento. 
Em seguida, o implementador da Base de Conhecimento, utilizando a modelagem feita pelo Engenheiro de Conhecimento, adiciona o conhecimento na forma exigida pelo Motor de Inferência utilizado pelo sistema.

O processo de aquisição de conhecimento é lento, sendo considerado o ponto crítico na construção de Sistemas Especialistas [Sawaki 91]. Isto ocorre porque, geralmente, os especialistas humanos são peritos em sua área de atuação, mas apresentam certa dificuldade em descrever seus próprios processos de raciocínio, o que dificulta o trabalho do Engenheiro de Conhecimento.

Neste trabalho, os problemas referentes à aquisição de conhecimento não serão abordados, pois o objetivo principal é melhorar a eficiência de execução de Sistemas Especialistas, e não agilizar o processo de construção da Base de Conhecimento.

\subsection{Considerações sobre Núcleos de Sistemas Especialis- tas}

É difícil encontrar um Núcleo de Sistemas Especialistas que se adeque perfeitamente às necessidades de uma aplicação específica. Normalmente, os Núcleos disponíveis no mercado, aos quais temos acesso, são restritos, ou seja, não apresentam muitas das características importantes na implementação de tais sistemas.

Por outro lado, um Núcleo que apresentasse todas essas características poderia tornar o sistema lento desnecessariamente, caso a aplicação envolvida não utilize algumas facilidades existentes nesse Núcleo. Isto ocorre porque, em um Núcleo fechado, as características desnecessárias não podem ser eliminadas, o que pode deixar o sistema lento, devido à quantidade excessiva de código.

Em alguns casos, pode ocorrer também a existência de procedimentos inerentes ao núcleo que não se adequam à implementação de um determinado sistema. Por exemplo, o método usado para calcular o fator de certeza feito pelo núcleo pode ser diferente do desejado para uma determinada aplicação.

Por tais motivos, pode-se afirmar que, para o projetista de um Sistema Especialista, seria interessante que o Núcleo fosse maleável o bastante para melhor se adequar à tarefa na qual é utilizado. Uma possível solução, para dotar um Núcleo de Sistemas Especialistas com tais características, é montá-lo como um conjunto de subsistemas que possam ser alterados, retirados e, inclusive, trocados por outros subsistemas.

A seguir, será apresentado um ambiente desenvolvido para auxiliar a construção de Núcleos de Sistemas Especialistas que possui a estrutura e a maleabilidade acima mencionadas.

Este ambiente está implementado na linguagem Prolog para micros compatíveis com o IBM-PC, e engloba as principais características que podem ser utilizadas na implementação de um Sistema Especialista. Ele é dirigido a projetistas de Sistemas Especialistas com algum conhecimento da linguagem Prolog. 


\subsection{Descrição do Ambiente}

O ambiente desenvolvido para auxiliar a construção de Núcleos de Sistemas Especialistas possui as seguintes características [Rodrigues 90a]:

- É implementado no sistema Arity Prolog versão 5.1 [Arity 88], que utiliza a sintaxe do Prolog de Edinburgh [Clocksin 87][Bratko 90];

- As regras de conhecimento interpretadas pelo núcleo também devem ser escritas em Prolog de Edinburgh;

- O ambiente é modular, facilitando a inserção, retirada e alteração dos subsistemas que o compõem;

- As principais características utilizadas por Sistemas Especialistas estão implementadas no ambiente, na forma de um meta-interpretador. Estas características são as mostradas no Capítulo 5, implementadas de forma independente - cada característica é implementada em um meta-interpretador distinto;

- A estrutura básica na qual o ambiente está apoiado compõe-se de Motor de Inferência, Módulo Coletor de Dados e Mecanismo de Explicação, como pode ser visto na Figura 2.1;

- O Motor de Inferência utiliza encadeamento regressivo. Sua implementação encontra-se detalhada em [Monard 89b];

- Interage com o meio externo - usuário, equipamentos, outros sistemas - através do Módulo Coletor de Dados [Rodrigues 90b];

- Pode explicar seus processos dedutivos, via Módulo de Explicação.

O processo de construção de núcleos específicos a partir do núcleo geral implementado encontra-se a seguir. Este processo pode ser visualizado na Figura 2.2.

No Nível superior encontram-se todos os subsistemas que compõem o ambiente. Ou seja, é a implementação completa do núcleo, contendo todas as características nele definidas. A seguir, o projetista do Sistema Especialista considera quais as características que são realmente utilizadas pela Base de Conhecimento a ser processada, eliminando os subsistemas desnecessários. Deste modo, obtém-se um núcleo mais restrito, com um código mais eficiente que o anterior, já que o mesmo foi reduzido. Este núcleo restrito corresponde ao nível 1 da Figura 2.2.

Neste ponto, o projetista pode adequar o núcleo à Base de Conhecimento específica, alterando o código de alguns subsistemas do núcleo restrito, tais como a forma de acesso à Base de Dados ou à Base de Conhecimento. Este núcleo, agora especifico para uma determinada tarefa, corresponde ao nível 2 da Figura 2.2. 


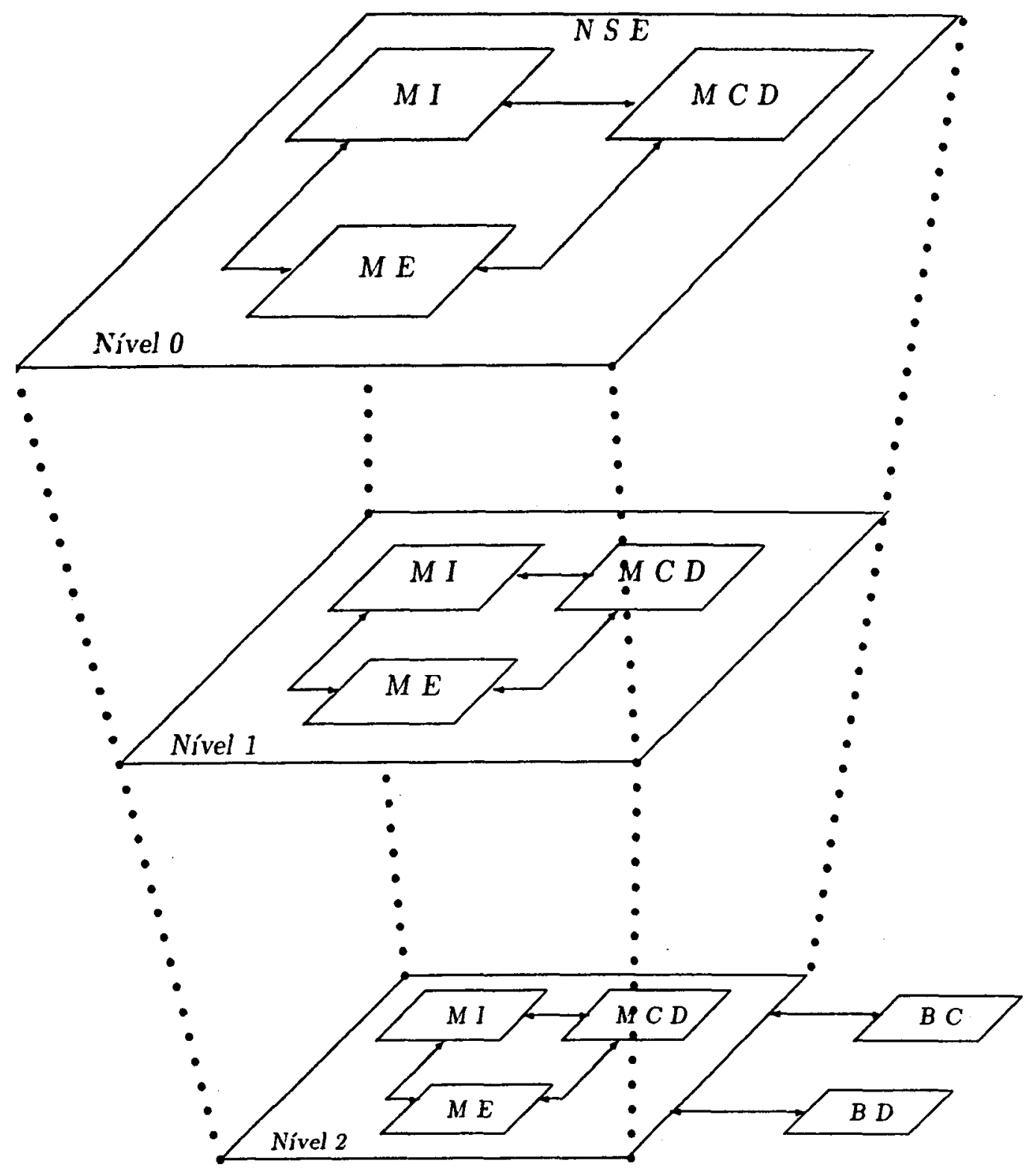

Figura 2.2: Ambiente para Auxiliar a Construção de Núcleos Específicos 


\subsection{Considerações Finais}

Uma característica que pode ser observada em Sistemas Especialistas é sua modularidade. Como mostrado neste capitulo, os principais módulos de um Sistema Especialista são a Base de Dados, a Base de Conhecimento e o Núcleo do Sistema Especialista.

Neste capítulo foi descrito um ambiente para desenvolvimento de Núcleos de Sistemas Especialistas, desenvolvido no ICMSC-USP. 0 ambiente é implementado em forma de meta-interpretadores, visando manter a Base de Conhecimento independente do Núcleo do Sistema Especialista.

O ambiente visa permitir ao projetista construir um núcleo que seja o mais adequado para a aplicação em que ele será utilizado. Para isto, o ambiente é composto de subsistemas, de onde o projetista pode retirar o código irrelevante para sua aplicação, inserir novos subsistemas e, inclusive, redefinir partes do código.

Este ambiente será utilizado no desenvolvimento deste trabalho, já que uma das propostas é automatizar o processo de construção do nível 1 - Figura 2.2. 


\section{Capítulo 3}

\section{GENESE - Um Gerador de Núcleos Específicos de Sistemas Especialistas}

\subsection{Considerações Iniciais}

O Núcleo de Sistemas Especialistas Geral descrito no capítulo anterior, desenvolvido para auxiliar projetistas de Sistemas Especialistas, pode ser utilizado por um implementador de Base de Conhecimento sem grandes dificuldades, desde que este possua bom conhecimento da linguagem Prolog. Porém, o processo de enxugar esse Núcleo Geral, elaborando - por razões de eficiência - um núcleo mais restrito, exige um conhecimento sobre os detalhes da implementação desse Núcleo Geral. No entanto, seria mais interessante que o próprio implementador da Base de Conhecimento seja capaz de construir seu núcleo específico, tornando-se independente de um "especialista em construção de núcleos específicos". Isto conduz à necessidade de um sistema para automatizar a construção de núcleos específicos. A implementação desse sistema - que deve ser uma interface entre o Núcleo Geral e o implementador da Base de Conhecimento - é discutida neste capítulo.

\subsection{Objetivos Gerais}

O gerador de núcleos específicos considera o núcleo geral e, a partir de informações fornecidas pelo usuário, constrói um núcleo específico adequado para a aplicação. Este processo pode ser observado na figura 3.1. 


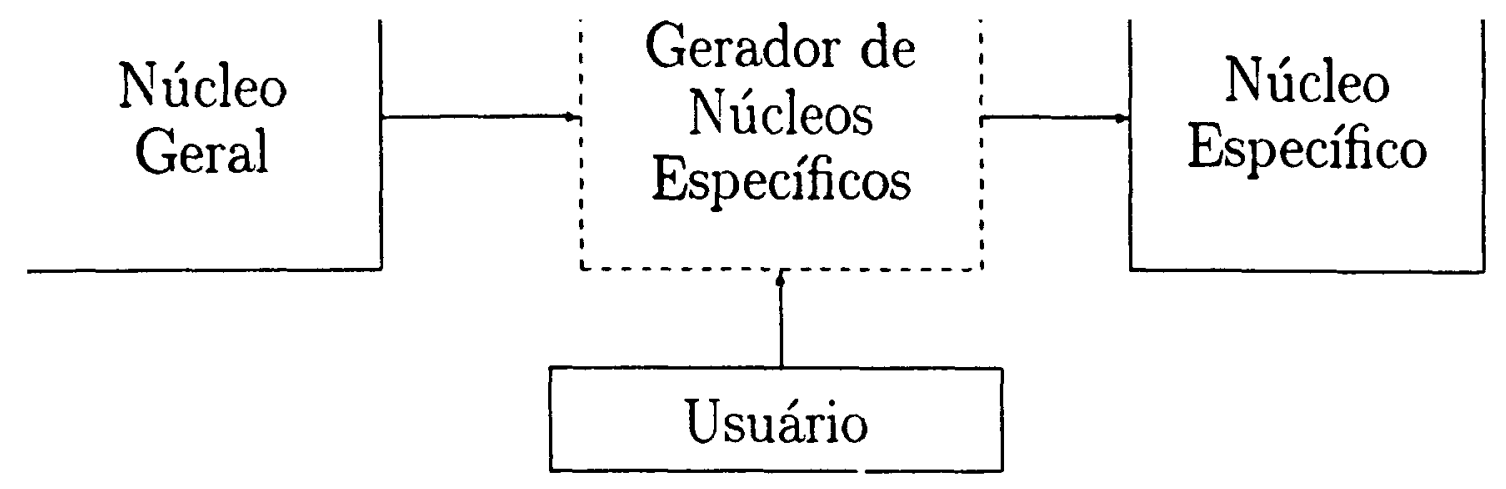

Figura 3.1: Gerador de Núcleos Específicos

A construção desse gerador de núcleos específicos deve considerar os seguintes aspectos:

\section{Interface simples}

A interação do sistema com o usuário - implementador da Base de Conhecimento - deve ocorrer de forma fácil e clara, evitando perguntas que possam parecer ambíguas. De preferência, as perguntas devem ser diretas, de modo que o usuário do sistema responda simplesmente sim ou não.

\section{Segurança}

O processo de apagar o código Prolog do Núcleo Geral que é desnecessário ao processamento de uma Base de Conhecimento específica deve ser muito cuidadoso, pois deve-se ter a certeza da não utilização de uma determinada cláusula antes de apagá-la da base. Por exemplo, considerando as cláusulas abaixo:

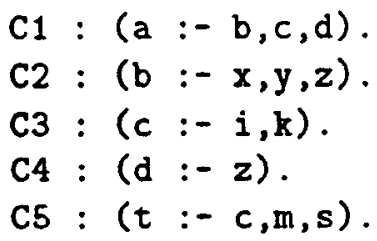

Se o sistema é informado que a cláusula C1 não será utilizada, ela deveria ser apagada da base, bem como as cláusulas que compōem seu corpo, neste caso as cláusulas $\mathrm{C} 2$, C3 e C4. Porém, isto nem sempre pode ser fejto, pois pode haver uma outra cláusula que necessite de uma destas cláusulas. Neste exemplo, a cláusula C5 também utiliza a cláusula C3, que, portanto, não poderia ser apagada.

\section{Alterabilidade}

O Núcleo de Sistemas Especialistas Geral é um sistema aberto, ou seja, sujeito a alterações. Portanto, o sistema para automatizar a construção de núcleos específicos deve fornecer facilidades para sua readaptação ao núcleo quando ele for alterado, sem que isto exija do responsável pela al teração do núcleo geral conhecer internamente o gerador de núcleos específicos. 


\subsection{Proposta de Implementação}

Como citado anteriormente, a construção de núcleos específicos a partir do núcleo geral exige um conhecimento profundo sobre a implementação deste. Este conhecimento envolve quais as cláusulas do meta-interpretador que estão relacionadas a cada característica do núcleo, bem como todos os predicados associados a estas cláusulas. Considerando as características da linguagem Prolog, este processo manual pode ser feito da seguinte forma:

1. Monta-se uma árvore onde cada nó é uma cláusula e seus filhos são os predicados que compõem o corpo desta cláusula.

2. De acordo com as características que serão utilizadas no Sistema Especialista para o qual o núcleo será utilizado, os ramos desnecessários são podados.

3. Elimina-se da árvore resultante as cláusulas que se repetem.

4. O núcleo específico é montado tomando-se cada uma das cláusulas existentes na árvore final.

Após um estudo cuidadoso do método mostrado acima, surgiu a idéia de construir o gerador de núcleos específicos baseado nesse mesmo procedimento. 0 sistema $G E \mathcal{N} E S E$ é dividido em dois módulos:

- Módulo de interface com o implementador do núcleo geral

Este módulo permite ao implementador do núcleo geral colocar no sistema a árvore contendo o relacionamento entre as cláusulas do núcleo geral e as características implementadas por elas.

- Módulo de interface com o implementador da Base de Conhecimento

Este módulo interage com o usuário a partir das informações contidas na árvore implementada pelo módulo anterior, automatizando os passos 2, 3 e 4 da construção do núcleo específico.

\subsection{A Árvore de Relacionamento entre as Cláusulas}

Para facilitar a construção da Árvore de Relacionamento entre Cláusulas, o implementador do núcleo geral atribui a cada cláusula deste núcleo um código e um número, de modo que cada par (Codigo, Numero) define uma única cláusula do núcleo geral. $\mathbf{O}$ implementador tem a liberdade de utilizar qualquer informação como código, de modo a facilitar a identificação da cláusula correspondente, isto é, o código atribuído é utilizado como uma forma de documentação do sistema. Por exemplo, se há um conjunto de 10 cláusulas que são utilizadas para calcular o fator de certeza de uma regra, essas cláusulas poderiam ter um código fc, e seriam diferenciadas pelo seu número. Deve 
haver um certo cuidado na atribuição dos números, pois a ordem em que as cláusulas aparecerão no núcleo específico seguem essa ordem numérica.

Na construção da Árvore de Relacionamento entre Cláusulas, podem ser utilizados 3 tipos de nós:

átomos: são representados por um par (Codigo,Numero), isto é, cada átomo representa uma cláusula do núcleo geral.

de decisão: são nós ligados a uma pergunta, cuja resposta informará se esse ramo da árvore deve ser podado.

árvore: são nós que representam uma outra árvore.

A construção da Árvore de Relacionamento entre Cláusulas segue as seguintes regras:

- A raiz é um nó árvore.

- Um nó árvore pode ter um número ilimitado de filhos, que podem ser átomos ou nós de decisão.

- Os nós filhos de um átomo só podem ser átomos.

- Um nó de decisão pode ter um único filho, que pode ser um átomo ou um nó arvore.

A figura 3.2 é um exemplo de uma Árvore de Relacionamento entre Cláusulas. Essa árvore possui quatro filhos, sendo dois átomos (mi 3 e mi 14) e dois nós de decisão (sys e perg). O átomo mi 14 possuj dois filhos (ak 6 e mm 4) que também são átomos. 0 nó de decisão sys possui um átomo como filho (mi 6). Já o nó de decisão perg tem como filho um nó árvore.

Os nós de decisão do exemplo tem as seguintes perguntas associadas:

- perg $\rightarrow$ O sistema deve interagir com o usuário?

- sys --> A Base de Conhecimento utiliza relaçōes do sistema?

- desc --> O usuário pode responder não sei? 


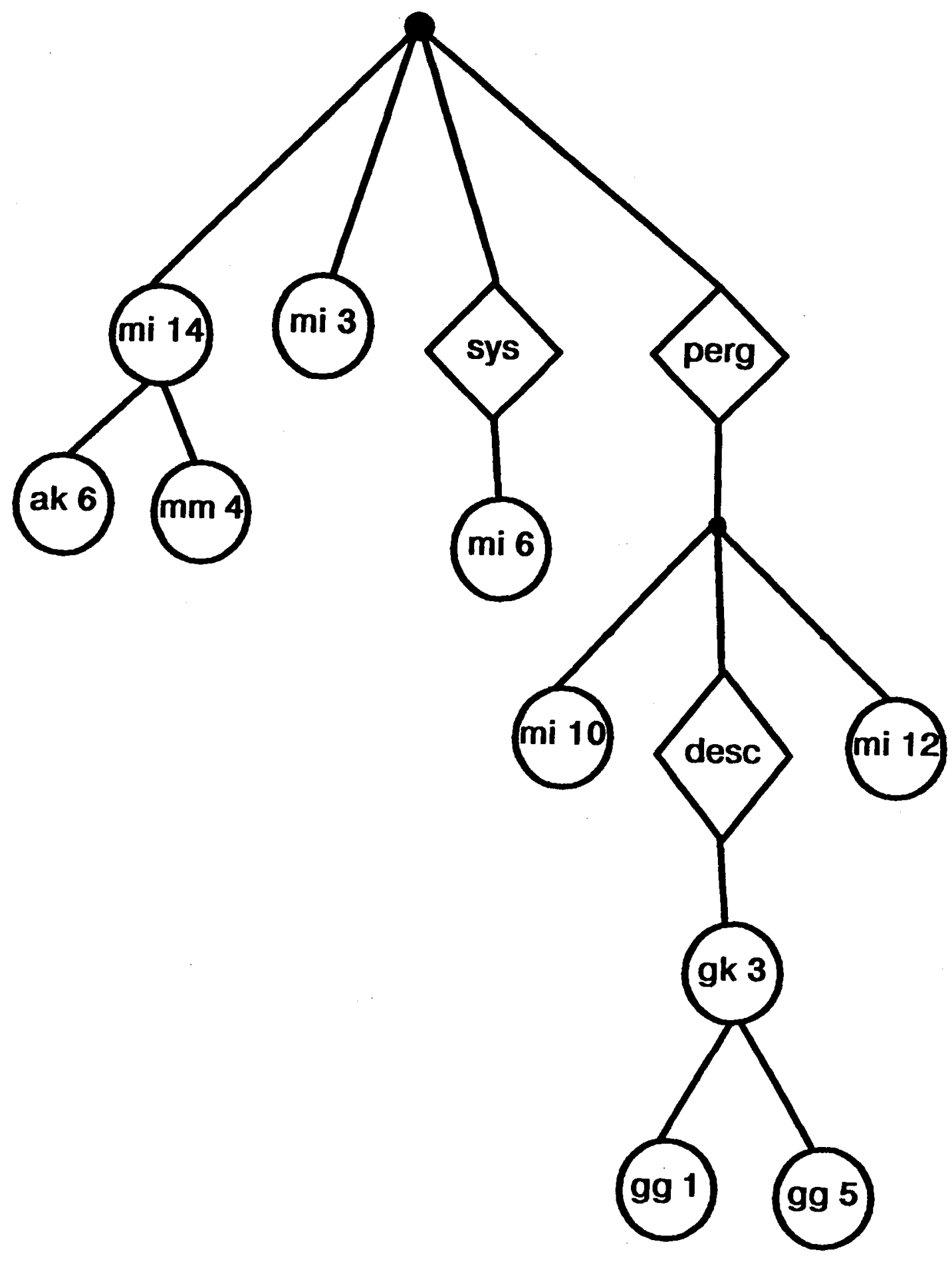

Figura 3.2: Exemplo de uma Árvore de Relacionamento entre Cláusulas 


\subsection{O Módulo de Interface com o Implementador do Núcleo Geral}

Este módulo permite ao implementador do Núcleo Geral colocar no sistema uma Árvore de Relacionamento entre Cláusulas. Ele é composto de 3 partes:

1. Manipulação de Árvores

Permite ao usuário definir uma árvore contendo a raiz, os nós ligados diretamente à raiz e cada um dos nós ligadosdiretamente aos nós de decisão, ou seja, cada árvore contém basicamente a raiz e o primeiro nivel da árvore. Os níveis restantes são implementados da seguinte forma: se for um nó árvore, será definida uma nova árvore utilizando o mesmo módulo. Se for um átomo contendo filhos, o segundo módulo deve ser ativado.

2. Manipulação de Sub-cláusulas

Este módulo é utilizado para definir que predicados estão ligados diretamente a uma cláusula, isto é, os predicados que fazem parte do corpo de uma determinada cláusula. Isto significa que, se o nó-pai for selecionado, todos os nós filhos devem ser selecionados, independente de qualquer informação fornecida pelo implementador da Base de Conhecimento.

3. Manipulação de Perguntas

Este módulo é utilizado para definir que pergunta deve ser feita ao usuário quando um nó de decisão é encontrado. Cada nó de decisão deverá ter sua pergunta associada.

\section{Interação entre os Módulos}

As árvores, regras e perguntas estão intimamente ligadas dentro do sistema, mas há certos relacionamentos que são invisíveis em um determinado módulo. Por exemplo, no módulo de manipulação de árvores, as regras que estão diretamente ligadas a uma outra regra não podem ser vistas. Porém, o sistema tem um modo de fornecer algumas informações ${ }^{1}$ importantes ao usuário, como mostrado a seguir:

1. As regras $\operatorname{rg}$ (Cod,Nro), que representam uma cláusula do núcleo geral, aparecem no vídeo em vermelho, tanto no módulo de manipulação de árvores quanto no módulo de manipulação de regras. Porém, quando uma regra possuir subregras diretamente ligadas a ela, esta regra aparecerá em azul.

2. No módulo de manipulação de árvore, o terceiro valor de cada nó representa uma regra ou outra árvore. Neste último caso, o nome dessa sub-árvore aparecerá em branco com fundo azul.

\footnotetext{
${ }^{1}$ As características mencionadas a seguir só podem ser observadas utilizando-se monitor colorido
} 
3. 0 módulo de manipulação de perguntas permite apenas que o usuário altere o texto da pergunta relacionado a um determinado código, isto é, não permite ao usuário inserir ou retirar um código da lista existente. Este controle é feito automaticamente pelo sistema na execução do módulo de manipulação de árvores. Quando é inserido um código que deve ter uma pergunta associada, este código é inserido na lista de perguntas com um texto vazio. Quando um nó é eliminado da árvore, o texto associado a seu código é eliminado também, caso ele exista. Quando um código não possui ainda um texto para sua pergunta, ele aparece piscando na tela, tanto no módulo de manipulação de árvores como na manipulação de perguntas.

\subsection{Representação Interna}

A seguir são mostradas as diversas formas como são representadas internamente árvores, cláusulas e perguntas associadas aos nós de decisão. Deve-se observar que nem o implementador do núcleo geral nem o implementador da Base de Conhecimento precisam conhecer esta representação para utilizar o sistema.

Cada árvore é representada por um a estrutura Prolog da seguinte forma:

arvore(Nome,Lista_de_Nos)

- Nome é o nome associado a uma árvore

- Lista_de_Nos é uma lista contendo os nós ligados diretamente à raiz.

Cada nó é representado pela seguinte estrutura:

$$
\text { no(Identificacao, Resposta, Filho) }
$$

- Identificacao é um nome associado ao nó, seja ele átomo ou de decisão.

- Resposta pode conter um dos três valores: *** sim nao

Se o valor é diferente de ***, significa que é um nó de decisão, associado a uma pergunta pelo predicado

$$
\text { pega_pergunta(Identificacao, Texto_da_pergunta). }
$$

- Filho pode ser um átomo ou uma outra árvore.

Os átomos representados na árvore como filhos de um outro átomo são representados pela seguinte estrutura:

sub_regras (Atomo, Lista_de_atomos_filhos). 


\subsection{Módulo de Interface com o Implementador da Base de Conhecimento}

Este módulo é quem vaj gerar o núcleo específico, a partir das especificações fornecidas pelo usuário, que provavelmente é o implementador da Base de Conhecimento. Sua execução é direcionada pela instanciação das estruturas mostradas acima, que representam a Árvore de Relacionamento entre Cláusulas do núcleo geral.

De posse destas estruturas, o gerador trabalha da seguinte forma:

1. Os átomos ligados diretamente à raiz são selecionados automaticamente.

2. As perguntas ligadas aos nós de decisão são feitas ao usuário. Se a resposta for igual à esperada, o próximo passo depende do tipo do nó ligado a esse nó de decisão.

- átomo: é selecionado para o núcleo específico.

- árvore: o gerador passa a processar a árvore cuja raiz possui o mesmo nome desse nó.

3. Sempre que um átomo é selecionado, todos os átomos ligados a ele são também selecionados.

Ao final do processamento, tem-se um conjunto de átomos selecionados, cada um deles representando uma cláusula do núcleo geral. Assim, depois de eliminar os átomos repetidos, basta montar o núcleo específico com cada uma das cláusulas por eles representados.

Considerando o exemplo mostrado na figura 3.2 , o sistema trabalharia da seguinte forma:

1. Seleciona mi 14

- Seleciona ak 6

- Seleciona mm 4

2. Seleciona mi 3

3. Pergunta se a Base de Conhecimento utiliza relações do sistema. Em caso afirmativo:

- Seleciona mi 6

4. Pergunta se o sistema interage com o usuário. Em caso afirmativo:

- Seleciona mi 10 
- Pergunta se o sistema aceita náo sei como resposta. Em caso afirmativo:

- Seleciona gk 3

(a) Seleciona $\mathrm{gg} 1$

(b) Seleciona $g g 5$

- Seleciona mi 12

\subsection{Interface com o Usuário}

\subsubsection{Definição de Menus}

A interação com o usuário é feita através de menus de diversos tipos. A linguagem Arity Prolog [Arity 88] utilizada na implentação fornece as rotinas de interação através de menus chamadas caixas de diálogos. No entanto, sua utilização torna-se complexa quando as listas de opções que são apresentadas ao usuário podem ser alteradas dinamicamente durante a execução, além de exigirem rotinas específicas para trabalhar a resposta do usuário em cada uma das caixas de diálogo utilizadas.

Visando tornar os programas mais claros - pois a utilização das caixas de diálogo envolve rotinas essencialmente procedimentais - e mais eficientes - pois a alteração dinâmica das opções exigiria alterações na base de dados - foram desenvolvidas três rotinas de interação através de menus que oferecem maior facilidade em sua utilização. Essas rotinas são descritas a seguir:

\section{1. menu(Posicao,Msg, Lista, Resp)}

É um menu que apresenta uma lista de itens permitindo ao usuário escolher um deles.

Posicao indica em que posição o menu deve aparecer na tela. Pode assumir os seguintes valores:

- centro : posiciona o menu no centro da tela

- esquerda : posiciona o menu na parte esquerda superior

- direita : posiciona o menu na parte direita superior

- rodape : posiciona o menu na parte inferior da tela

- atual : posiciona o menu na posicao atual do cursor

- retirar : posiciona o menu na posicao $(5,35)$, sendo utilizado no módulo de retirar subregras.

Msg é o texto que é mostrado na parte superior da borda da janela.

Lista contém os elementos dentre os quais o usuário fará sua escolha.

Resp unifica com o elemento escolhido pelo usuário.

2. menu_sim_nao(Perg, Resp)

Este menu apresenta ao usuário uma pergunta e permite que ele responda apenas sim ou não. 
Perg contém a pergunta a ser feita

Resp unifica com a resposta do usuário.

3. multmenu (Nome, Msg, Lista, Posicao)

Este menu apresenta ao usuário uma lista de operações executadas por um determinado módulo do sistema.

Nome é o nome que define o conjunto de operações apresentado

Msg é o texto que é mostrado na parte superior da borda da janela.

Lista contém as operações dentre as quais o usuário fará sua escolha.

Posicao indica em que posição o menu deve aparecer na tela. Como em menu/4, pode assumir os valores centro, esquerda, direita, rodape, atual, retirar.

Neste tipo de menu, deve existir uma cláusula que indica que rotina deve ser executada para cada escolha feita pelo usuário. Isto é feito pelo predicado

$$
\text { pega_rotina(Nome, Valor, Rotina). }
$$

Nome é o nome que indica a qual menu está se referindo

Valor indica uma das opções desse menu

Rotina indica a rotina que deve ser executada se essa foi a opção escolhida.

Exemplo:

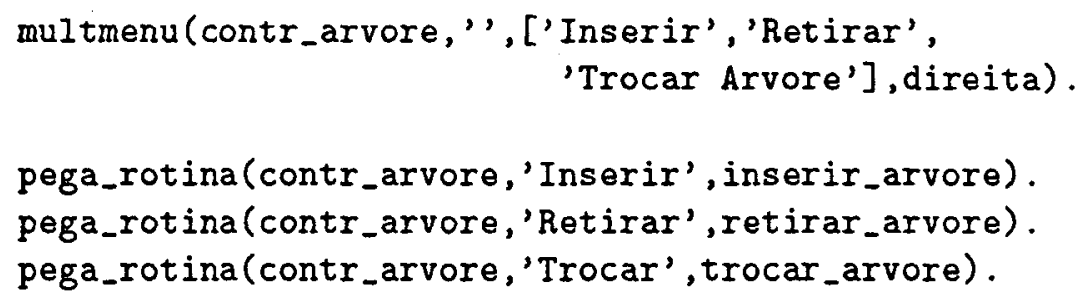

Quando a rotina que realiza a operação escolhida pelo usuário se encerra, o controle de execução volta para o menu, permitindo ao usuário escolher uma outra operação ou sair do menu, escolhendo a opção 'Terminar' - que é inserida automaticamente na lista de opções do menu.

\subsubsection{Manipulação de Perguntas}

$\mathrm{Na}$ manipulação de perguntas é utilizado um tipo de menu diferente dos mostrados na seção anterior, embora sigam o mesmo espírito. Neste caso, os elementos contidos na lista do menu que é apresentado ao usuário são os códigos utilizados em nós de decisão. Além do menu, é apresentado ao usuário uma outra janela na parte inferior do vídeo. Essa janela contém o texto da pergunta que está relacionada ao código do menu apontado pelo cursor. Assim, quando o usuário movimenta o cursor de um código para outro, a pergunta apresentada na janela inferior muda simultaneamente. Quando o usuário escolhe uma opção do menu, o cursor passa para a janela inferior, permitindo ao usuário modificar o texto da pergunta, voltando ao menu ao final dessa operação. 


\subsubsection{Inserção e Retirada de Elementos na Lista de Opções}

O módulo de interface com o implementador do Núcleo Geral apresenta uma lista de elementos, permitindo acrescentar ou retirar elementos dessa lista. A interface com o usuário nesse caso é feita através de dois métodos distintos. Na manipulação de árvores, o usuário fornece, tanto na inserção como na retirada, a posição em que o elemento deve ser inserido ou da qual deve ser retirado. No caso da manipulação de subregras, a regra (código + número) é a única informação a ser fornecida, pois os elementos são mantidos ordenados. No caso da retirada, a escolha é feita apresentando-se os elementos em forma de menu, de modo que o elemento selecionado pelo usuário é o que deve ser retirado da lista de opções.

\subsection{Considerações Finais}

Neste capítulo descreveu-se a implementação do sistema GENESE - sistema para automatizar a construção de núcleos específicos de Sistemas Especialiștas a partir de um núcleo geral.

Há alguns pontos que merecem destaque:

- torna transparente ao implementador do Núcleo Geral os detalhes de implementação do GENESE

- torna transparente ao implementador da Base de Conhecimento:

- detalhes de implementação do GENESE

- detalhes de implementação do núcleo geral

- o código do núcleo específico gerado pelo sistema

- possui interface amigável que tenta facilitar ao máximo a tarefa do usuário do sistema

Apesar do sistema ter sido construído para uma aplicação de certo modo um tanto específica, pode-se observar que o mesmo pode ser utilizado para aplicações mais gerais que envolvam especializações de programas.

Isto pode ser feito porque todo programa Prolog pode ser descrito em forma de árvore. Deste modo, pode-se construir um sistema geral que pode ser utilizado para uma diversidade de aplicações específicas e, em seguida, o relacionamento entre as cláusulas do sistema e suas aplicações específicas podem ser codificadas pelo GENESE através do módulo de interface com o implementador do núcleo geral. Deste modo, o módulo de interface com o implementador da Base de Conhecimento pode ser utilizado para gerar programas específicos para uma determinada aplicação eliminando o código desnecessário. 


\section{Capítulo 4}

\section{Exemplos de Funcionamento do Sistema GENESE}

\subsection{Considerações Iniciais}

Neste capítulo são apresentados alguns exemplos que mostram como é feita a interação do sistema $G E N E S E$ com o usuário. Isto é feito para que se possa ter uma visão mais geral do funcionamento do sistema.

Pode-se observar que o módulo de interação com o implementador da base de conhecimento é muito simples. Ele compõe-se de um conjunto de perguntas, apresentadas uma a uma, às quais o implementador da base de conhecimento responde simplesmente sim ou não, dependendo das necessidades da base de conhecimento que irá interagir com o núcleo que está sendo especificado.

Já o módulo de interface com o implementador do núcleo geral é mais complexo, pois ele deve apresentar ao usuário todas as cláusulas do sistema e o relacionamento existente entre elas, além de permitir alterações sobre essas estruturas.

\subsection{Apresentação}

A execução do sistema começa apresentando ao usuário a tela mostrada na Figura 4.1. Após o usuário apertar qualquer tecla, aparecerá a tela mostrada na Figura 4.2, onde o sistema permite ao usuário escolher o módulo que deseja trabalhar. 


$$
\begin{aligned}
& 6 \text { I I I I } \\
& \text { Gerador de Mucleos Ispecificos } \\
& \text { de Sistemas Ispecialistas } \\
& \text { Autos - -) Jo20 Luiz Iranco } \\
& \text { Orientaca - - > Maria Carolima Monasd }
\end{aligned}
$$

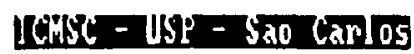

Para continuar aperte rualquer tecla

Figura 4.1: Tela de Apresentação

Qual modulo sera utilizado?

1- Interface con o Implementador da Base de Conhecimento

2- Interface con o Implementador do Nucleo Geral

$$
\text { Opcao ---> }
$$

Figura 4.2: Escolha de Módulo 


\subsection{O Módulo de Interface com o Implementador da Base de Conhecimento}

Este módulo trabalha a partir das informaçōes fornecidas pelo módulo de interface com o implementador do núcleo geral, ou seja, a Árvore de Relacionamento entre Cláusulas descrita na seção 3.4. A interação com o usuário é mostrada na Figura 4.3.

Utiliza relacoes do sistena? Sim

n20

Figura 4.3: Interface com o Implementador da Base de Conhecimento 


\subsection{O Módulo de Interface com o Implementador do Núcleo Geral}

Conforme explicado na seção 3.5, este módulo é composto por três partes:

- manipulação de árvores

- manipulação de sub-regras

- manipulação de perguntas.

Deste modo, o usuário deve indicar com qual dessas estruturas ele pretende trabalhar, conforme mostrado na Figura 4.4.

Indique o tipo de elemento a ser manipulado:

Gruores

Sub Kegras

Perguntas

Iin

Figura 4.4: Interface com o Implementador do Núcleo Geral 


\subsubsection{Manipulação de Árvores}

Se o usuário escolhe a opção de manipulação de árvores, o sistema apresenta os elementos ligados à raiz da Árvore de Relacionamento entre Cláusulas, denominada árvore principal, como pode ser observado na Figura 4.5. O usuário pode escolher uma das opçōes apresentadas no menu que fica no canto direito da tela.

\begin{tabular}{|c|c|c|}
\hline $\begin{array}{l}\text { criterio parada } \\
\text { ja provado } \\
\text { conjuncao } \\
\text { disjuncao } \\
\text { negacao } \\
\text { sistema } \\
\text { grinitiva } \\
\text { deterwinistica } \\
\text { fatorcestera } \\
\text { verifican } \\
\text { perguntavel }\end{array}$ & 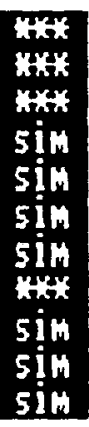 & 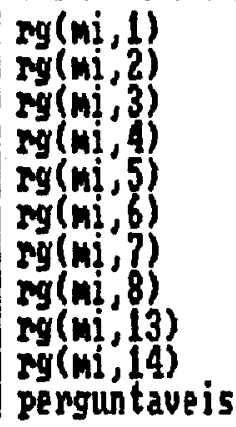 \\
\hline
\end{tabular}

losenis
Retiras
Irocar Arvore
Criar Arvore
Ieminar

* Nanipular Aruores*

Figura 4.5: Manipulação de Árvores

- Inserir um elemento

Se porventura o usário optar por inserir um nó na árvore, o sistema lhe solicitará o nome que identifica esse nó, a posição onde ele deve ser inserido, o valor de aceitação e a regra associada a ele, como pode ser observado na figura 4.6

A Figura 4.7 mostra como fica a árvore após a inserção do nó na sexta posição. Deve-se observar que, na tela, o código teste_arv aparece piscando, indicando que é um código que está relacionado a uma pergunta mas ainda não possui o texto para essa pergunta.

- Retirar um elemento

Se o usuário escolhe a opção de retirar um nó da árvore, ele deve somente especificar a posição, como pode ser verificado na Figura 4.8.

Considerando que a primeira posição foi escolhida, a remoção do nó pode ser constatada observando-se atentamente a Figura 4.9 .

Se existe um único nó na árvore, a retirada do mesmo elimina a árvore correspondente. 


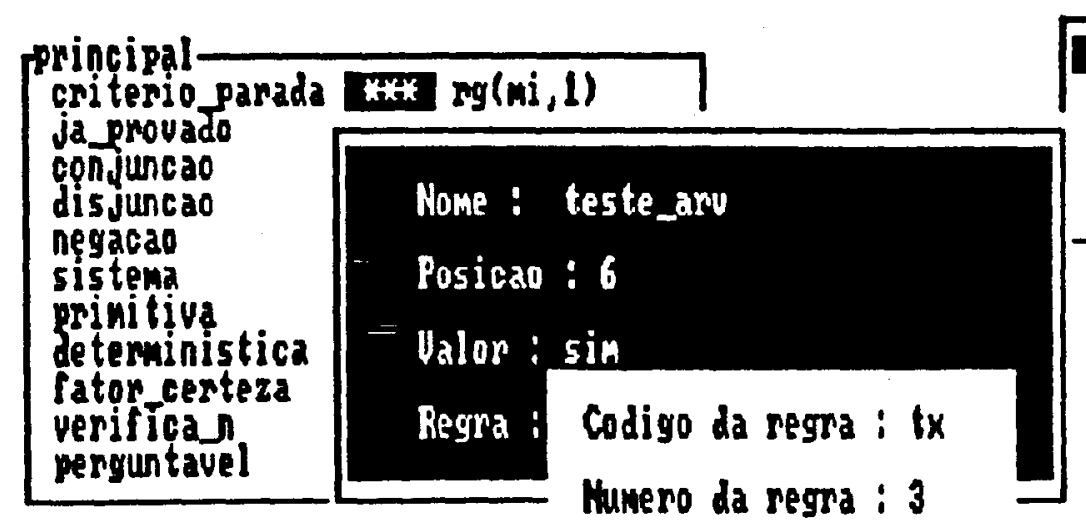

loseris

Retiras

Irocar Arvore

Criar Arvore

lerminar

* Nanipular aruores*

Figura 4.6: Inserir Dados

* Nanigular Aruores*

Figura 4.7: Árvore Após a Inserção 


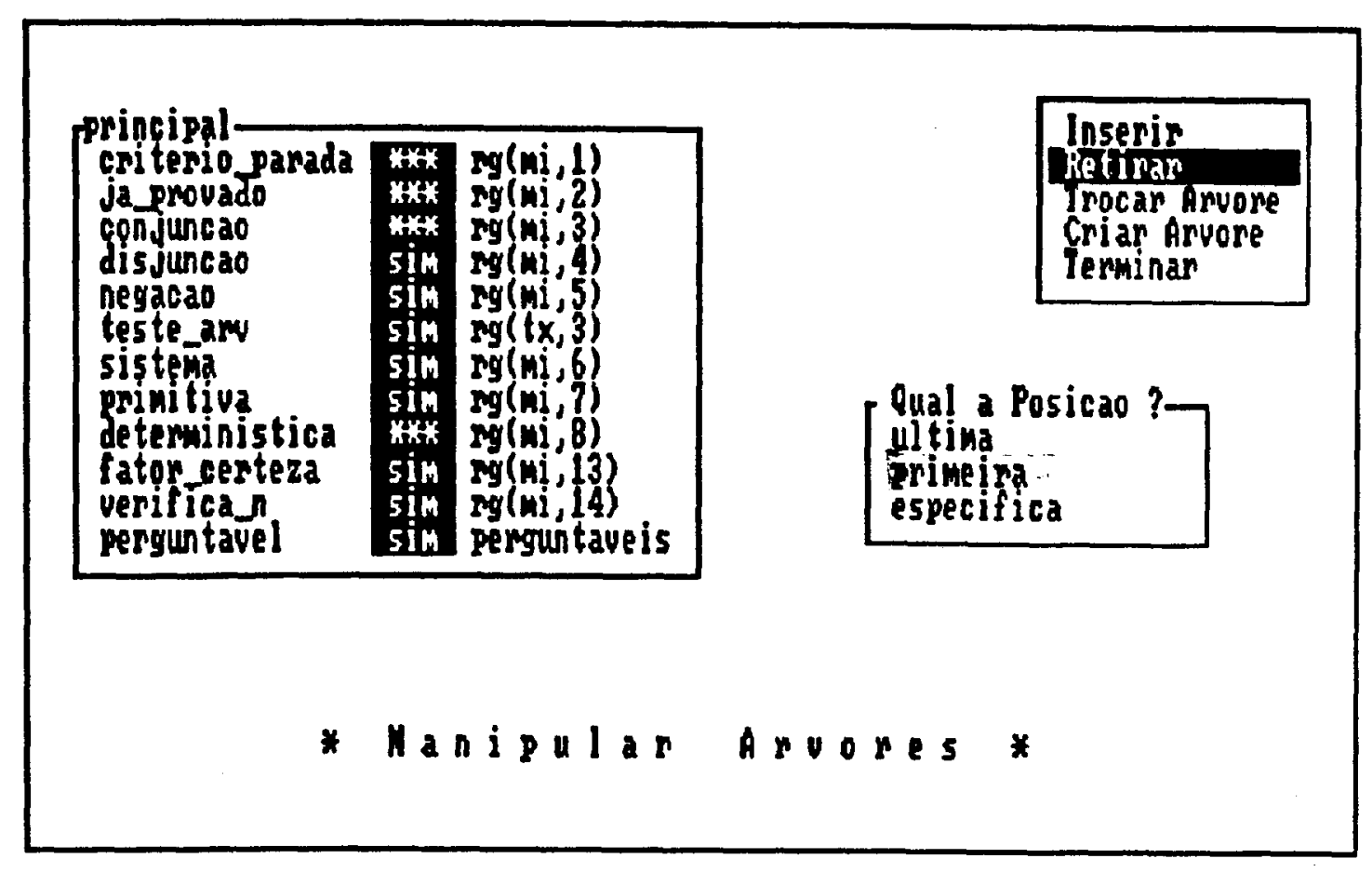

Figura 4.8: Retirar um Elemento

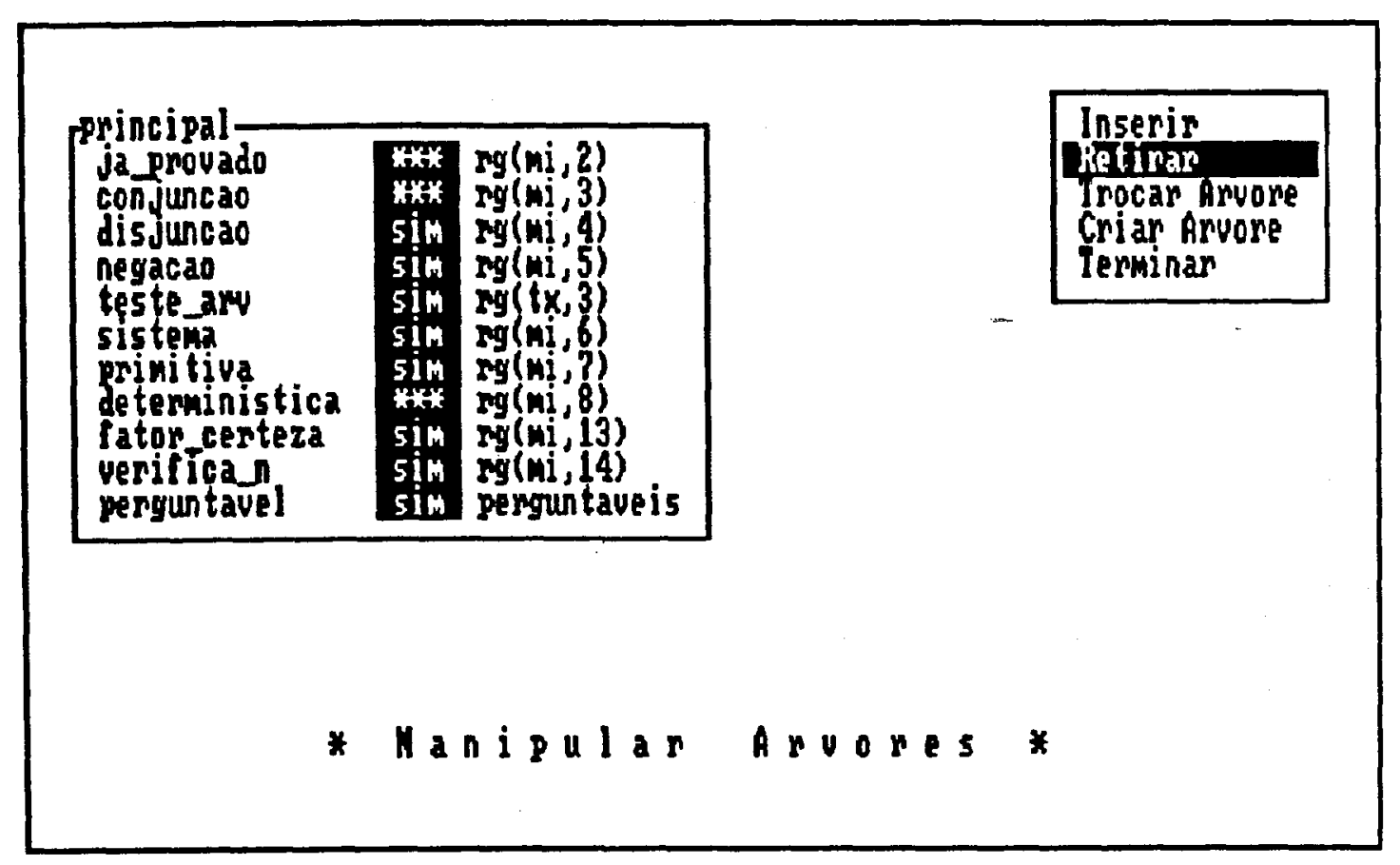

Figura 4.9: Árvore após a Retirada do Elemento 
- Trocar de árvore

$\mathrm{Na}$ opçāo Trocar Arvore, apresenta-se ao usuário um menu para que ele escolha uma entre as árvores existentes - Figura 4.10. Supondo que a escolha foi perguntaveis, será apresentada a tela mostrada na Figura 4.11.

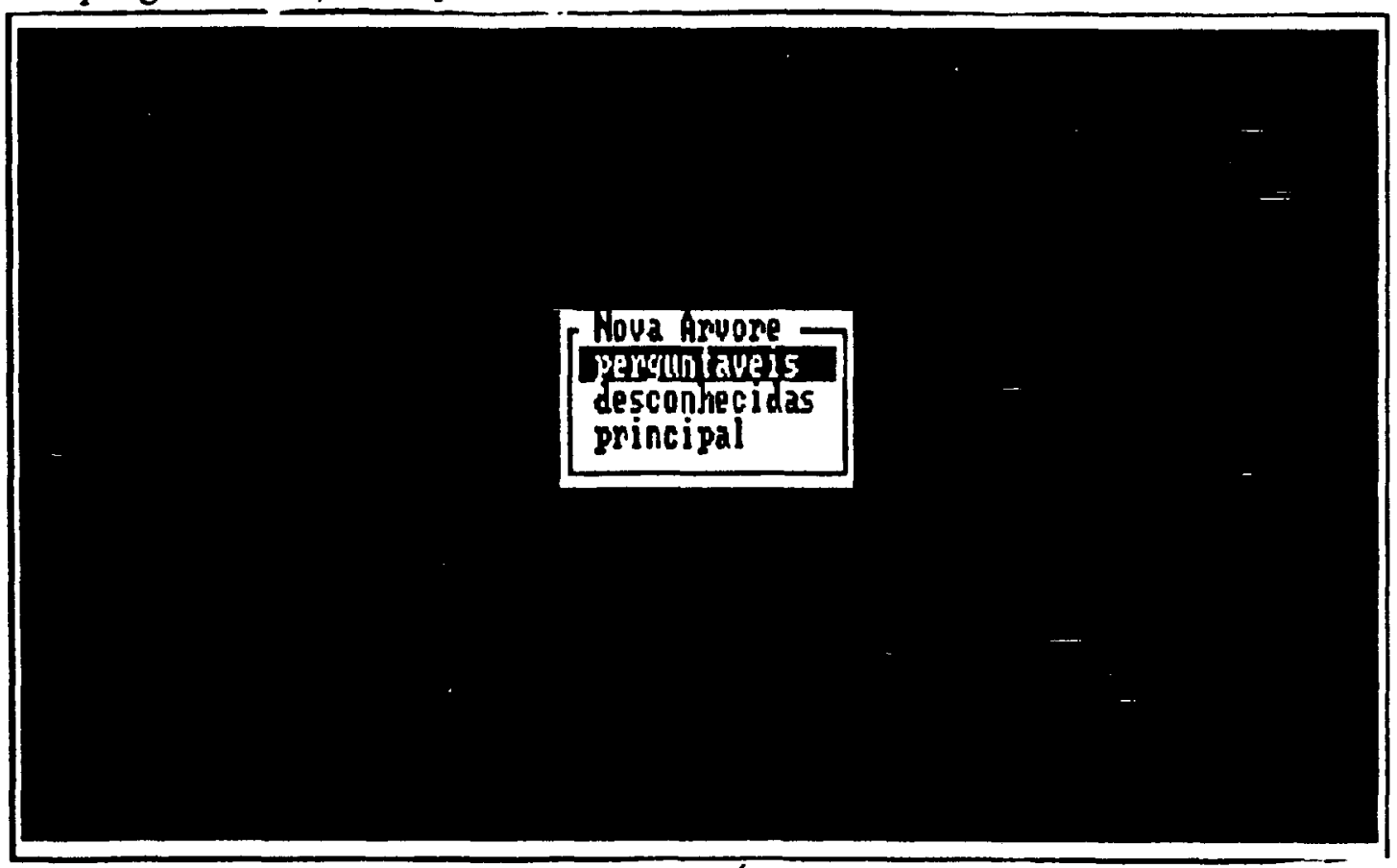

Figura 4.10: Trocar Árvore Corrente

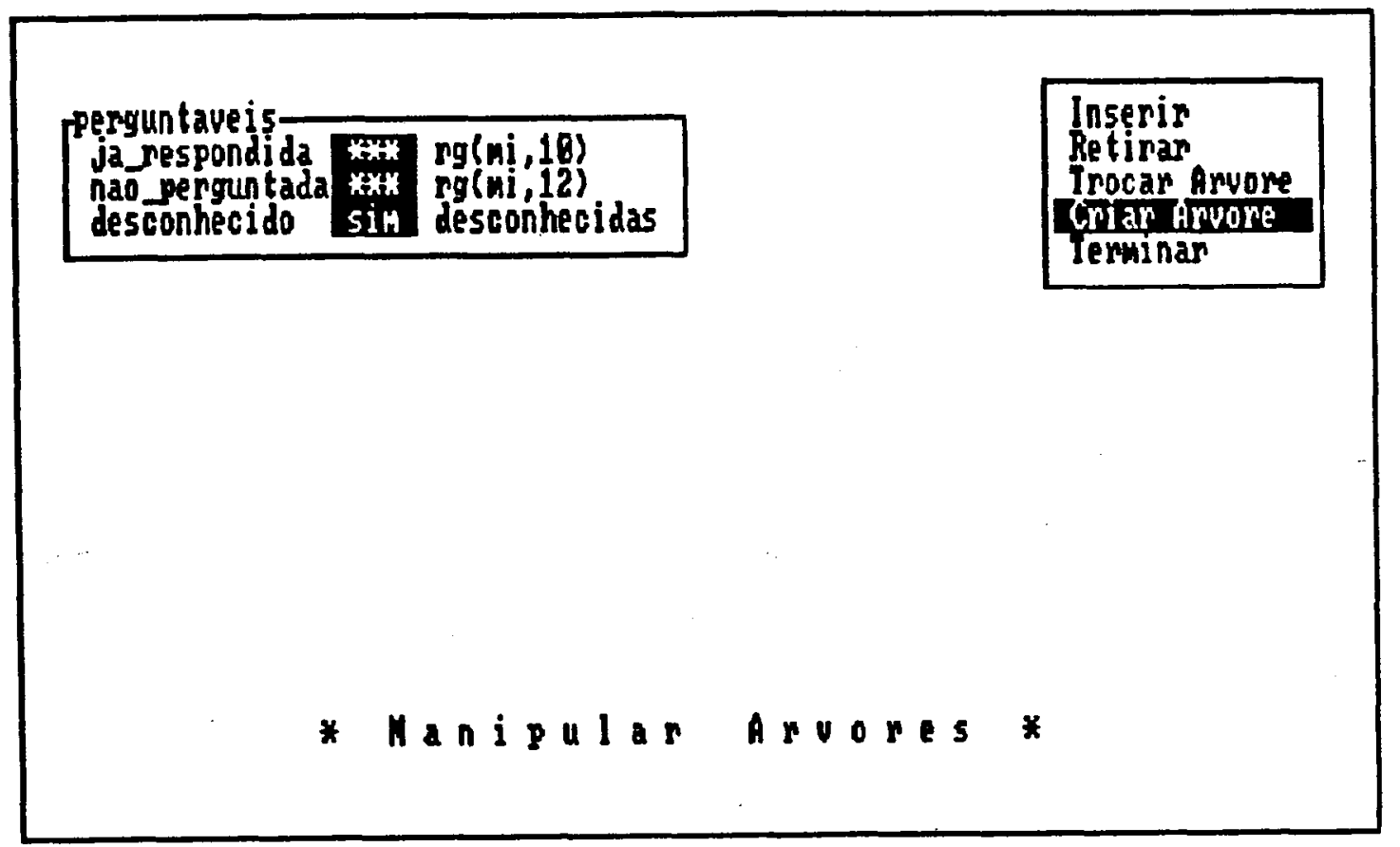

Figura 4.11: Nova Árvore Corrente 
- Criar uma nova árvore

No processo de criação de uma nova árvore, o sistema solicita inicialmente ao usuário o nome da árvore e, em seguida, solicita a inserção de um nó - Figura 4.12. A árvore recém-criada passa a ser a nova árvore corrente - Figura 4.13.

None da Arvore : tree

Introduza o primeim no

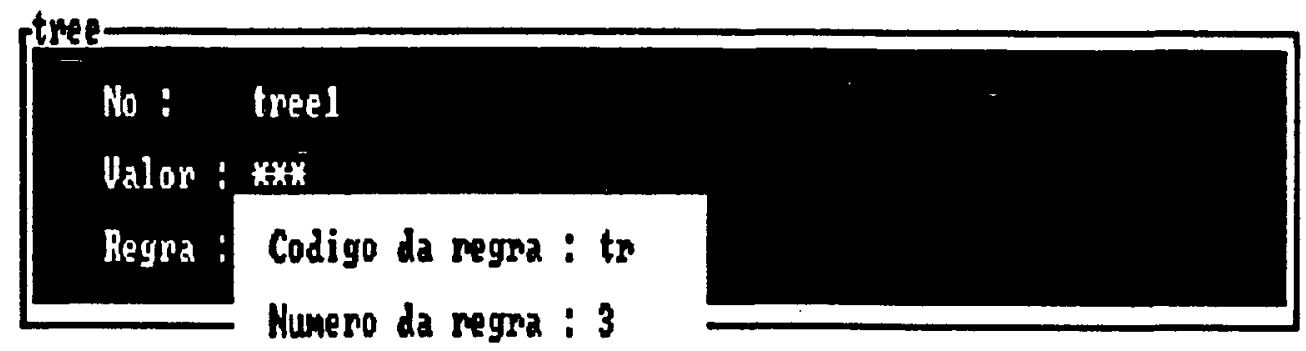

Figura 4.12: Criar uma Nova Árvore

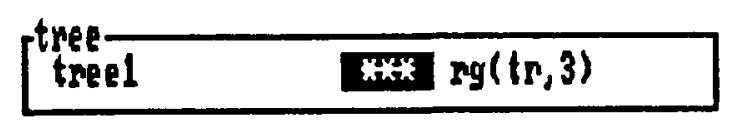

Figura 4.13: Árvore Recém-criada 


\subsubsection{Manipulação de Sub-regras}

O módulo de manipulação de sub-regras permite ao usuário indicar as cláusulas que estão diretamente ligadas a uma outra cláusula

Para efeito de execução do GENESE, quando uma cláusula é selecionada para ser parte do núcleo específico, todas as cláusulas diretamente ligadas a ela são também selecionadas.

Na Figura 4.14 pode-se ver um exemplo da tela que é apresentada ao usuário na escolha da opção de manipulação de sub-regras.

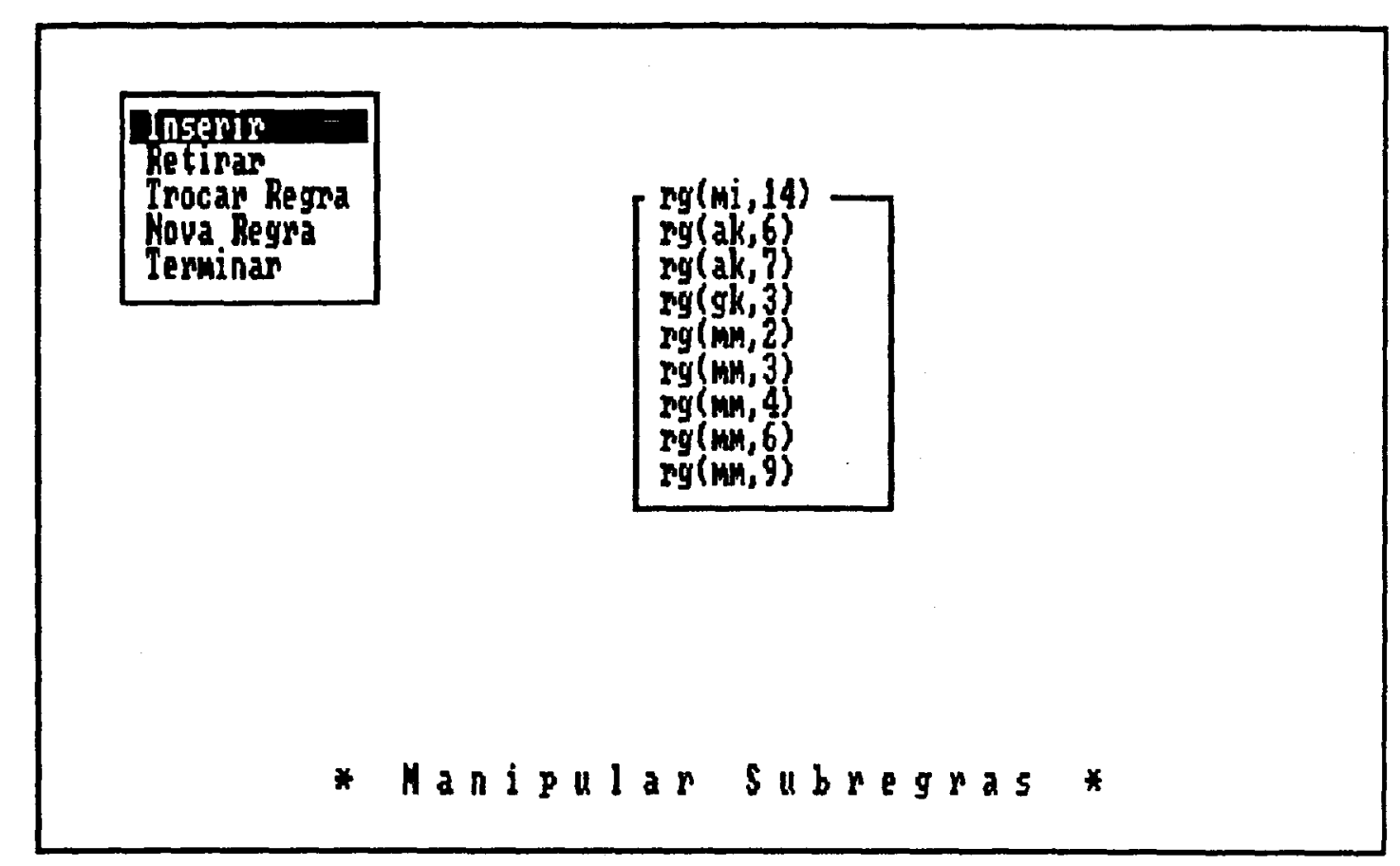

Figura 4.14: Manipulação de Sub-regras

O menu no canto esquerdo da tela permite ao usuário escolher uma das opções para alterar a estrutura existente.

- Inserir uma sub-regra

Se o usuário deseja inserir uma nova sub-regra na lista apresentada na tela, é necessário somente informar o código e o número da regra - ver Figura 4.15. Não é necessário especificar a posição do elemento, pois os elementos da lista de sub-regras são armazenados de forma ordenada.

A Figura 4.16 mostra a lista de sub-regras após a inserção da regra rg (mm,5). 


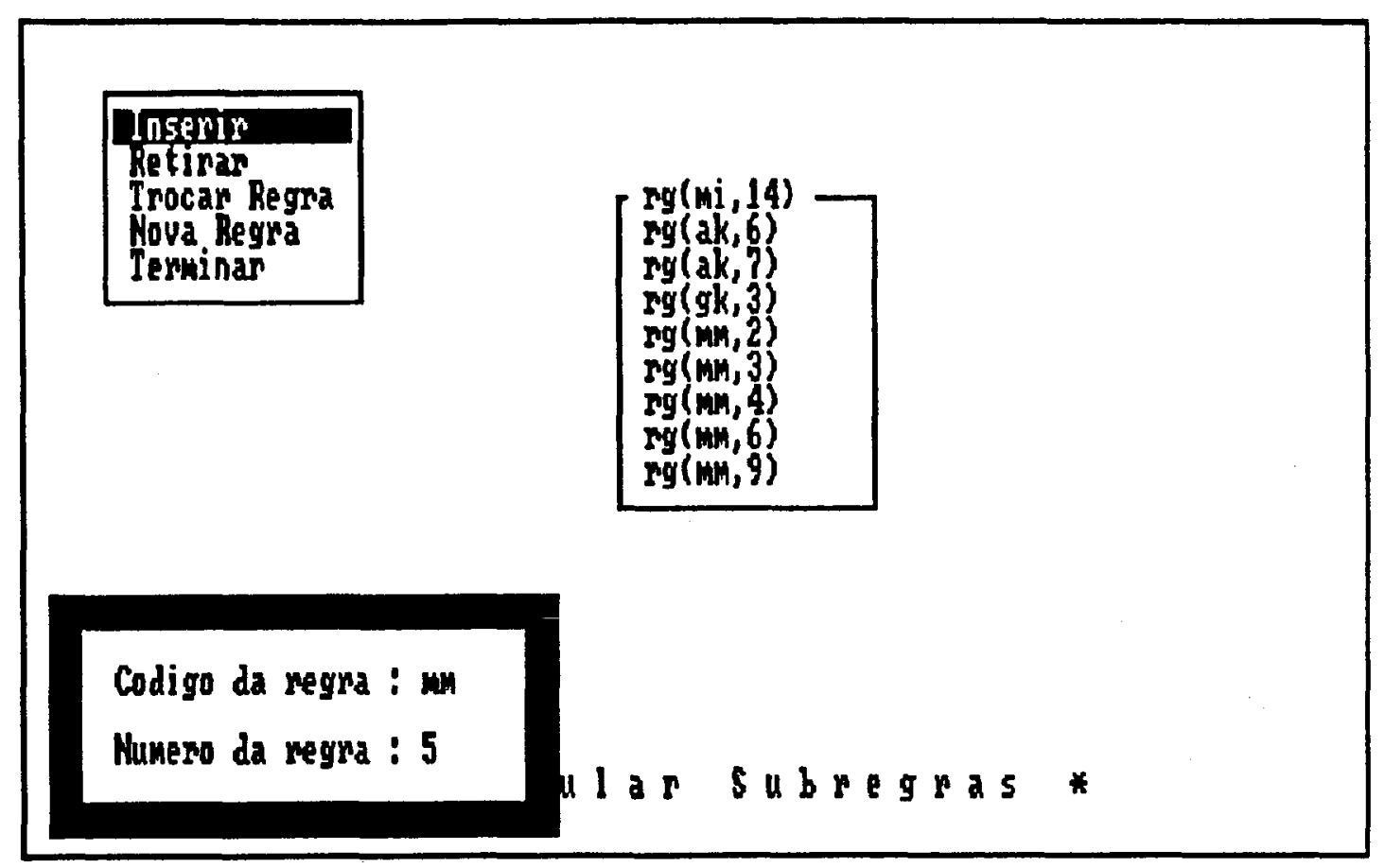

Figura 4.15: Inserir uma Sub-regra
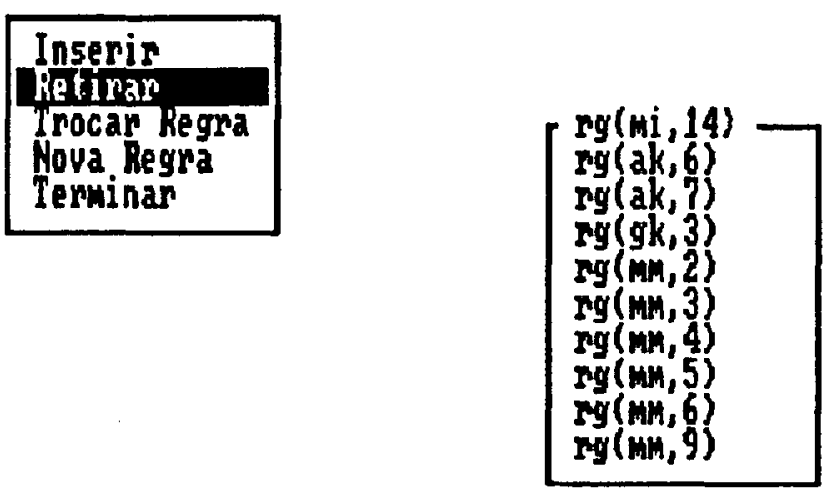

* Hágular subregras*

Figura 4.16: Lista de Sub-regras após Inserção 
- Retirar uma sub-regra

Na opção de retirar uma sub-regra, a janela com a lista de sub-regras transformase em um menu, onde a sub-regra selecionada é retirada da lista. A Figura 4.17 mostra a lista de sub-regras após a retirada da regra $\mathrm{rg}(\mathrm{mm}, 4)$. Se a lista contém uma única sub-regra, a regra é eliminada do módulo de manipulação de sub-regras, que assume uma outra regra como regra corrente.

\begin{tabular}{|l|}
\hline Inseris \\
Retinas \\
Irocar hegma \\
houa kegra \\
Terminar \\
\hline
\end{tabular}

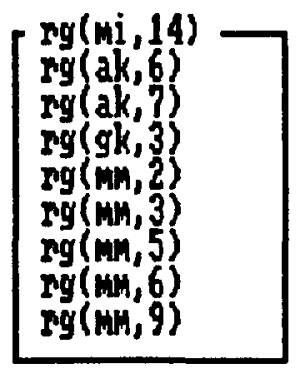

* Hanipular subregras*

Figura 4.17: Lista de Sub-regras após a Retirada de $\mathrm{rg}(\mathrm{mm}, 4)$

- Trocar a regra corrente

Se o usuário decidir manipular uma outra regra, ele deve escolher a opção Trocar Regra. Neste caso, o sistema apresenta ao usuário uma lista das regras que possuem uma lista de sub-regras - Figura 4.18. Supondo que a opção escolhida foi $\mathrm{rg}(\mathrm{gk}, 3)$, ela passa a ser a nova regra corrente - Figura 4.19. 


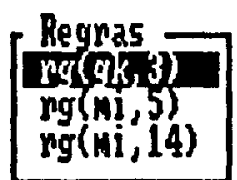

* Hanipular subregras*

Figura 4.18: Trocar Regra Corrente

\begin{tabular}{l}
\hline Inseris \\
Re tiras \\
Trocar Regra \\
houa hecra \\
\hline leminar \\
\hline
\end{tabular}

$$
\begin{aligned}
& \operatorname{rg}(g k, 3) \\
& \operatorname{rg}(g g, 1) \\
& \operatorname{rg}(g g, 5) \\
& \operatorname{sg}(g g, 6) \\
& \operatorname{rg}(g g, 7) \\
& \operatorname{rg}(h h, 6)
\end{aligned}
$$

* Hanipular subregras*

Figura 4.19: Nova Regra Corrente 
- Criar uma nova lista de sub-regras

Se o usuário decidir criar uma nova lista de sub-regras associadas a uma dada regra, o sistema inicialmente pede o nome da regra cujas sub-regras estarão associadas - Figura 4.20.

\section{DIGITE A REGRA \\ Codigo da regra : wh \\ Numero da regra : 3}

\section{* Nanipular subregras*}

Figura 4.20: Criar Nova Lista de Sub-regras

Em seguida o sistema solicita uma sub-regra para inicializar a lista de sub-regras - Figura 4.21. A nova regra passa a ser a regra corrente do sistema, conforme pode ser comprovado pela Figura 4.22. 


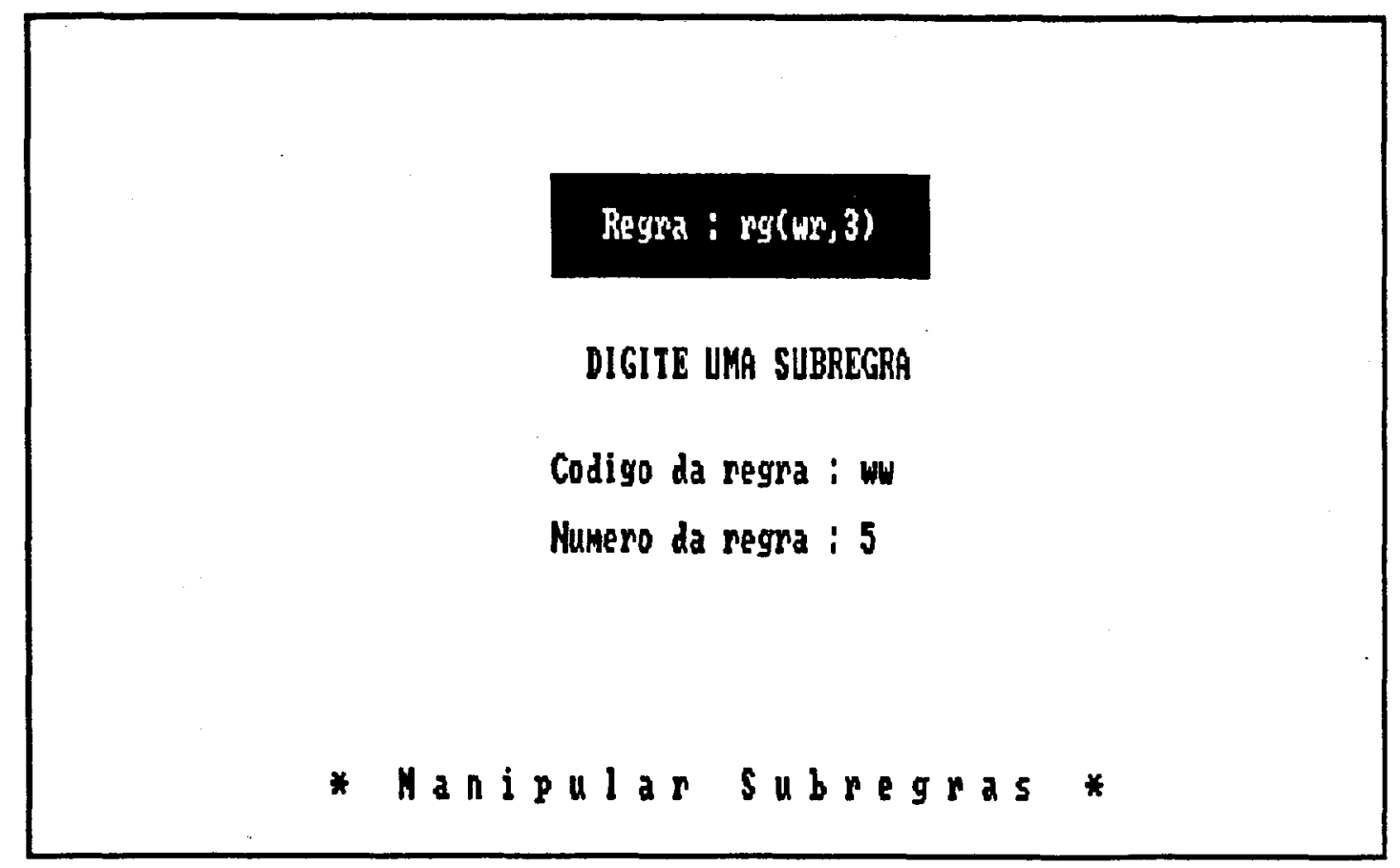

Figura 4.21: Inserção da Primeira Sub-regra

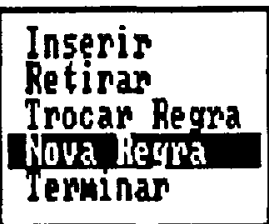

$\mathbf{N g}(w r, 3)$

$x g(w w, 5)$

* Nanipularsubregas *

Figura 4.22: Nova Lista de Sub-regras 


\subsubsection{Manipulação de Perguntas}

Se o usuário optar pela Manipulação de Perguntas, o sistema apresenta a tela mostrada na Figura 4.23.

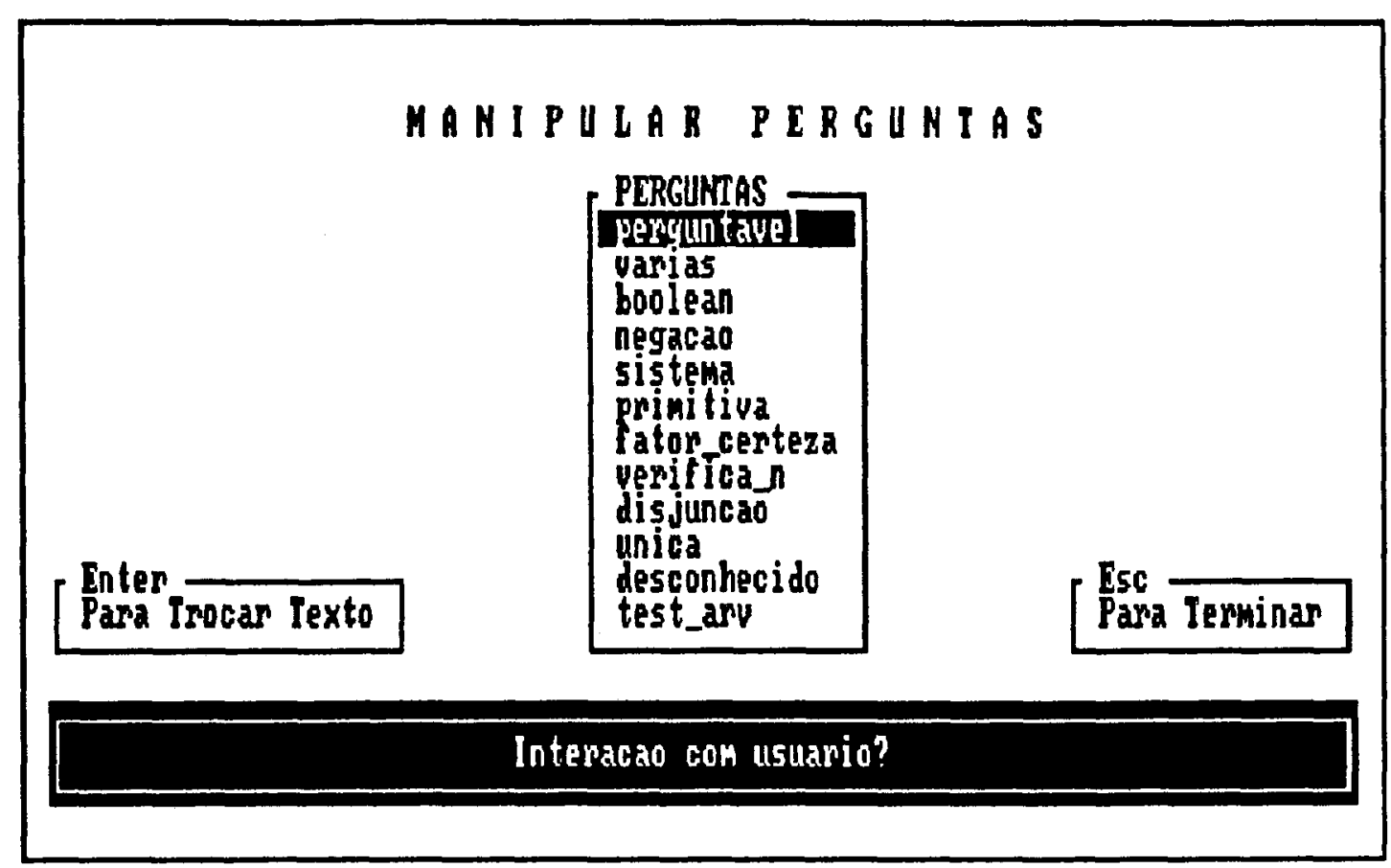

Figura 4.23: Manipulação de Perguntas

No menu, existem os códigos dos nós que devem ter perguntas relacionadas. $\mathrm{Na}$ janela inferior aparece a pergunta relacionada ao código mostrado pelo cursor no menu. Se o usuário move o cursor de um código para o outro, o sistema modifica a pergunta da janela inferior. Se um código não tem ainda uma pergunta associada, o código fica piscando no menu. No exemplo mostrado, o código test_arv está nessa condição. Se o usuário seleciona um determinado código, o cursor passa para a janela inferior, permitindo ao usuário alterar o texto da pergunta. Isto pode ser verificado observandose a Figura 4.24, que mostra a tela durante a digitação do texto, e a Figura 4.25, que mostra a tela após a digitação do texto. 


\section{MAHIPULAR PERGUNIAS}

PERCUNTAS perguntavel

varias

boolean

negacao

sistema

prinitiva

fatorcerteza

verifican

disjuncao

unica

desconhecido

test any

\section{Teste de Manipular Per}

Figura 4.24: Digitando um Novo Texto

\section{NANIPULAR PERGUNTAS}

PERGUNTAS

perguntavel

varias

boolean

negacao

sistema

prinitiva

fator certeza

verifican

disjuncao

unica

desconhecido

test ary

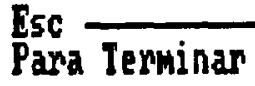

\section{Teste de Vanipular Perguntas}

Figura 4.25: Tela após a Digitação do Texto 


\subsection{Considerações Finais}

Neste capítulo foram vistos alguns exemplos mostrando a interação do sistema GENESE com o usuário. Com isto, espera-se tornar mais fácil entender como funciona o sistema. Pode-se verificar que o trabalho maior é do implementador do núcleo geral, responsável por reestruturar o relacionamento entre as regras, enquanto o implementador da Base de Conhecimento precisa somente especificar quais são suas necessidades. No entanto, deve-se observar que o módulo de interface com o núcleo geral só será utilizado quando for necessário realizar uma alteração no núcleo geral, o que deve acontecer apenas esporadicamente. Esta particularidade é que torna GENESE um sistema viável para uma real utilização. 


\section{Capítulo 5}

\section{Meta-Interpretadores}

\subsection{Considerações Iniciais}

A linguagem de programação Prolog vem se mostrando uma linguagem apropriada para prototipagem rápida, onde há interesse na implementação imediata de novas idéias [Amble 87]. Isto é importante no desenvolvimento de novas linguagens ou novos paradigmas de programação, pois as novas idéias podem ser rapidamente implementadas e testadas. Em prototipagem, a ênfase é implementar novas idéias com rapidez e a um custo pequeno, não importando muito a eficiência da implementação. Após desenvolvido um primeiro protótipo, o sistema pode ser implementado em uma outra linguagem de programação, caso seja necessário.

A linguagem Prolog é também apropriada para implementar outras linguagens, devido à facilidade de se escrever meta-programas nesta linguagem [Sterling 84] [Bowen 82].

Neste capítulo, o objetivo maior é apresentar o conceito de meta-programação e mostrar o uso de meta-programação na construção de Sistemas Baseados em Conhecimento.

\subsection{Meta-programas e Meta-interpretadores}

Meta-programas são programas que tratam outros programas como dados. Eles analisam, transformam e simulam outros programas. Interpretadores e compiladores são exemplos de meta-programas [Monard 90].

A meta-programação em Prolog é muito simples [Furukawa 89], e essa facilidade devese, principalmente, a dois fatores. O primeiro deles é a equivalência entre programas e dados: ambos são termos Prolog. A capacidade de manipulação simbólica é outra característica que torna Prolog uma linguagem poderosa para meta-programação [Gallaire 82].

Meta-interpretadores são uma classe particular de meta-programas. Um meta-interpretador para uma linguagem é um interpretador para a linguagem escrito na própria 
linguagem [Sterling 87]. Portanto, um meta-interpretador Prolog é um interpretador para a linguagem Prolog escrito em Prolog. A facilidade para escrever meta-interpretadores é uma poderosa característica de uma linguagem de programação, pois possibilita a construção de um ambiente de programação integrado e dá acesso ao processo computacional da linguagem [Sterling 86].

\subsection{Meta-Interpretadores Prolog}

Um meta-interpretador Prolog toma um programa Prolog juntamente com uma meta Prolog e executa a meta com respeito ao programa, isto é, o meta-interpretador tenta provar que a meta segue-se logicamente do programa. Porém, para ter real interesse, um meta-interpretador Prolog não deve comportar-se exatamente como o interpretador Prolog original, e sim oferecer alguma funcionalidade adicional, tal como gerar uma árvore de prova ou rastrear a execução de programas Prolog [Bratko 90].

A Base de Conhecimento a seguir - denominada Korez e que não apresenta nenhuma informação contextual em suas regras - será utilizada para mostrar a execução dos diversos meta-interpretadores apresentados nas próximas seções.

Programa 5.1 Base de Conhecimento Korez

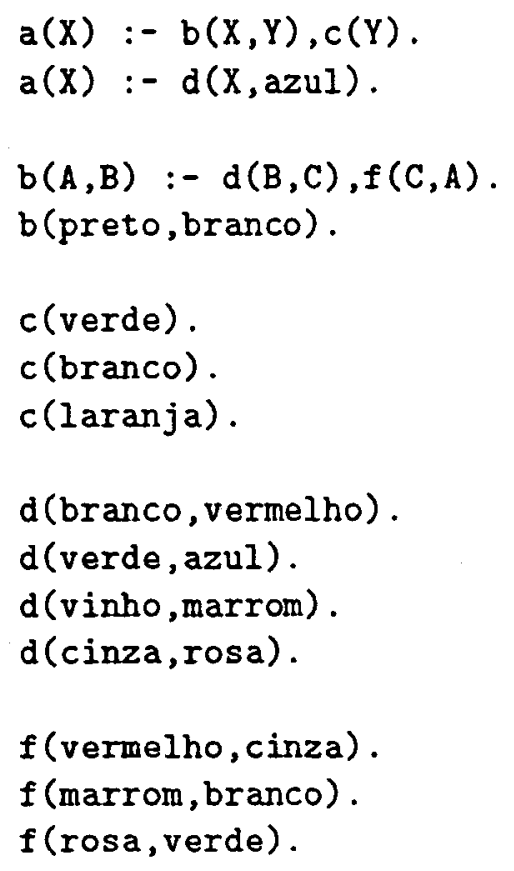

\subsubsection{Un Meta-Interpretador Trivial}

A relação prove/1 será utilizada para implementar um meta-interpretador em Prolog. O meta-interpretador mais simples que pode ser escrito em Prolog, apresentado a seguir, 
usa uma meta-variável:

\section{Programa 5.2 Meta-Interpretador Trivial}

prove(Meta) :- Meta.

Neste caso, todo o trabalho é deixado para o interpretador de Prolog, e o meta-interpretador Trivial comporta-se exatamente como o interpretador Prolog original. A seguir é mostrado um exemplo de execução utilizando a Base de Conhecimento Korez apresentada anteriormente.

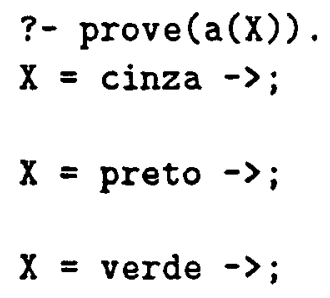

no

Com certeza, este meta-interpretador não tem valor prático, pois não fornece nenhuma característica adicional àquelas fornecidas pelo interpretador Prolog. Para que este objetivo possa ser atingido, é necessário um meta-interpretador mais refinado.

\subsubsection{Um Meta-interpretador Básico}

As diferenças entre meta-interpretadores podem ser caracterizadas em termos de sua granularidade, que é a quantidade de detalhes computacionais que são acessíveis ao programador. A granularidade do meta-interpretador Trivial - programa 5.2 - é muito grossa. Consequentemente, há pouco espaço para sua aplicação. Por outro lado, um meta-interpretador de granularidade muito fina nem sempre é realmente útil, pois o refinamento também sacrifica a eficiência e, na maioria dos casos, a perda de eficiência exigida por meta-interpretadores de niveis muito finos não se justifica.

Utilizando-se o predicado interno clause/2 - fornecido na maioria das implementações de Prolog - é possível refinar o meta-interpretador Trivial. Este predicado recupera uma cláusula do programa consultado realizando uma busca em profundidade. Por exemplo, se a interrogação

$$
\text { ?- clause(Cab,Corpo) }
$$

é bem sucedida, Cab é a cabeça da cláusula recuperada e Corpo unifica com o corpo da cláusula. No caso de um fato, Corpo unifica com o átomo true. No caso de regras, 
o corpo pode conter uma ou mais sub-metas. Se contiver uma única sub-meta, Corpo unificará com ela. Se contiver diversas sub-metas, Corpo unificará com a seguinte estrutura:

\section{(Meta1, OutrasMetas)}

Neste caso, OutrasMetas também pode ser tanto uma única sub-meta como diversas sub-metas, estruturadas da mesma maneira. Por exemplo, a execução de clause/2, considerando como exemplo a BC Korez, é:

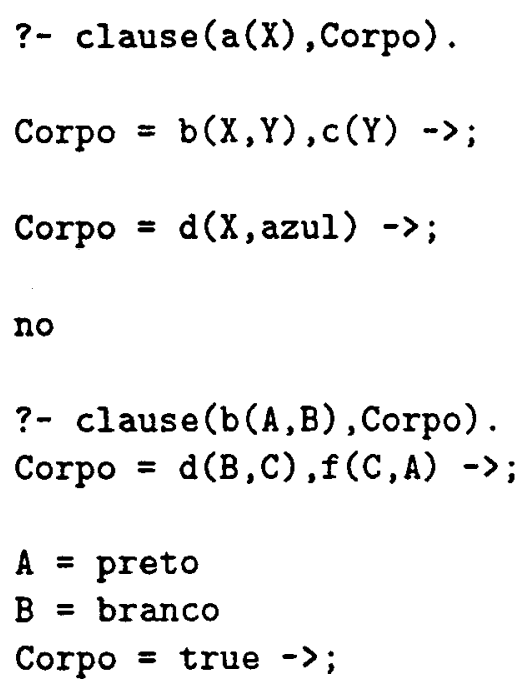

A seguir, é apresentado um meta-interpretador mais interessante que aquele mostrado no programa 5.2. Este meta-interpretador - que será denominado meta-interpretador Básico - simula o modelo computacional de programas lógicos. Ele é descrito pelas três cláusulas abaixo:

Programa 5.3 Meta-Interpretador Básico

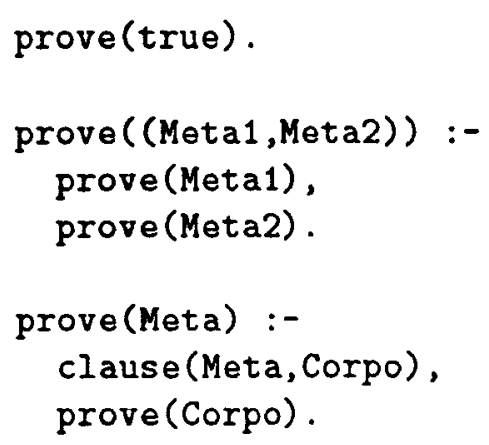


Estc meta-interpretador possui granularidade mais fina que o meta-interpretador Trivial - programa 5.2. Ele apresenta nível de redução de cláusulas, possuindo granularidade suficiente para um grande número de aplicações.

Declarativamente, o programa pode ser descrito da seguinte forma:

- a constante true é verdadeira;

- a conjunção (Meta1,Meta2) é verdadeira se Meta1 é verdadeira e Meta2 é verdadeira;

- a meta Meta é verdadeira se há uma cláusula Meta :- Corpo tal que Corpo é verdadeira.

$\mathrm{O}$ aspecto procedimental do programa pode ser descrito da seguinte forma:

- O fato prove(true), indicando meta vazia - representado em Prolog pelo átomo true) -, é resolvido;

- Para resolver uma conjunção de cláusulas (Meta1,Meta2), resolva Meta1 e resolva Meta2;

- No caso geral, para resolver uma meta, escolha uma cláusula do programa cuja cabeça unifica com a meta e recursivamente resolva o corpo da cláusula.

O resultado da execução - com relação à base de conhecimento que está sendo utilizada - é o mesmo do meta-interpretador Trivial. No entanto, este meta-interpretador pode ser facilmente expandido para incorporar algumas outras características, das quais serão apresentadas as de maior in teresse.

\subsubsection{Un Meta-interpretador para Construir a Árvore de Prova}

A técnica utilizada para construir a árvore de prova é similar àquela utilizada na construção de árvores de prova em analisadores de sentenças, através da adição de argumentos extras [Marcus 86].

A relação básica é:

$$
\text { prove (Meta,Arv) }
$$

onde Arv é a árvore de prova para resolver a meta Meta. As árvores de prova são representadas pela estrutura (Meta $<==$ Prova), onde Prova é a conjunçào dos ramos que provam a meta Meta.

O programa 5.4, que implementa prove/2, é uma extensão direta do programa 5.3. As quatro cláusulas correspondem exatamente às quatro cláusulas do meta-interpretador Básico para Prolog puro, acrescidas somente da variável que deve unificar com a árvore de prova da meta. 
Programa 5.4 Meta-Interpretador Arv-Prova

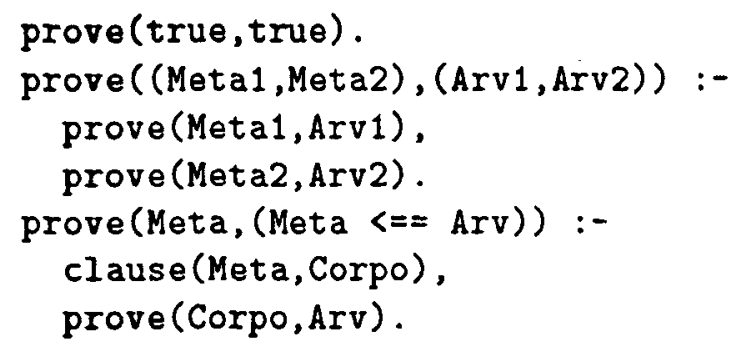

O exemplo a seguir mostra passo a passo como o meta-interpretador atua sobre a BC Korez.

?- $\operatorname{prove}(\mathrm{a}(\mathrm{X}), \mathrm{Arv})$.

Neste caso, apenas a terceira cláusula de prove/2 unifica com a meta acima:

\#1 prove $(\mathrm{a}(\mathrm{X}),(\mathrm{a}(\mathrm{X})<==\operatorname{Arv} 0))$ :-

clause (a $(X)$, Corpo),

\#2 prove (Corpo, ArvO).

$\mathrm{Na}$ ativação de clause $(\mathrm{a}(X)$, Corpo), ocorre a seguinte unificação:

Corpo $=(b(X, Y), c(Y))$

A seguir, há a chamada de prove $((b(X, Y), c(Y))$, que irá unificar com a segunda cláusula de prove/2:

\#2 prove $((b(X, Y), c(Y)),(\operatorname{Arv1}, \operatorname{Arv} 2))$ :-

\#3 prove $(b(X, Y), A r v 1)$,

\#4 prove $(c(Y), A r v 2)$.

Uma vez mais, prove $(b(X, Y), A r v 1)$ unifica com a terceira cláusula de prove/2.

\#3 prove $(b(X, Y),(b(X, Y)<==A r v 3))$ :-

clause $(b(X, Y)$, CorpoB $)$,

\#5 prove(CorpoB, Arv3).

$\mathrm{Na}$ ativação de clause $(b(X, Y)$, CorpoB $)$ tem-se:

CorpoB $=(d(Y, Z), f(Z, X))$

$\mathrm{Na}$ ativação de prove/2, a unificação será feita com a segunda cláusula:

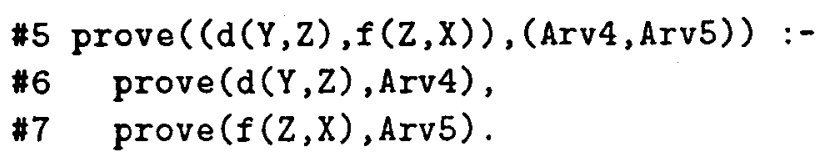


O próximo passo é ativar prove $(\mathrm{d}(Y, Z), A r v 4)$, que é feito utilizando-se a terceira cláusula de prove/2:

\#6 prove $(d(Y, Z),(d(Y, Z)<==A r v 6))$ :-

clause $(d(Y, Z)$, CorpoD),

\#8 prove(CorpoD,Arv6).

A ativação de clause/2 proporciona a seguinte unificação:

clause $(d(Y, Z)$, CorpoD)

$Y=$ branco

$Z=$ vermelho

CorpoD $=$ true

Desta vez, a ativação de prove/2 irá unificar com a primeira cláusula:

\#8 prove(true, Arv6).

Arv6 = true

Com isto, tem-se o final da execução do ramo \#6 da árvore de prova, com as seguintes unificações:

$\mathrm{Y}=\mathrm{branco}$

$Z$ = vermelho

Arv4 $=d$ (branco, vermelho) $s==$ true

O próximo passo é solucionar o ramo $\# 7$ da árvore de prova, que começa com a chamada de prove $(f(Z, X), A r v 5)$. Neste caso, o valor de $Z$ encontrado no ramo \#6 é passado para o ramo $\# 7$ na ativação de prove/2. A unificação será com a terceira cláusula:

\#7 prove( $f($ vermelho, $X),(f($ vermelho, $X)<==$ Arv7)) :clause ( $f$ (vermelho, $X)$, CorpoF),

\#9 prove(CorpoF, Arv7).

A ativação de clause/2 ocasiona a unificação abaixo:

$X=$ cinza

CorpoF $=$ true

A ativação de prove/2 no ramo \#9 utilizará a primeira cláusula:

\#9 prove(true, Arv7)

Arv7 = true 
Isto resolve o ramo \#7 da árvore de prova, envolvendo as seguintes unificações:

$X=$ cinza

Arv5 $=f($ vermelho, cinza $)<=$ true

Como os ramos \#6 e \#7 já estão resolvidos, o ramo \#5 também está, com as seguintes unificações:

CorpoB $=(d(b r a n c o$, vermelho $), f($ vermelho, cinza $))$

Arv3 $=(d(b r a n c o$, vermelho $)<==$ true, $f$ (vermelho, cinza $)<==$ true $)$

A resolução do ramo \#5 implica na resolução do ramo \#3, com as unificaçes abaixo:

$X=\operatorname{cinza}$

$Y=$ branco

Arv1 = b (cinza, branco) $<==$ (d(branco, vermelho) $<==$ true , $f$ (vermelho, cinza) $<==$ true)

O próximo passo é ativar o predicado prove(c(branco),Arv2), que utiliza a terceira cláusula de prove/2.

\#4 prove (c(branco), (c(branco) <== Arv8)) :-

clause (c(branco), Corpoc), prove (CorpoC, Arv8).

$\mathrm{Na}$ ativação de clause (c (branco), Corpoc) haverá uma unificação com a terceira cláusula do predicado $c / 1$, resultando CorpoC $=$ true. A chamada de prove (true, Arv8) utiliza-se da primeira cláusula para fazer Arv8 = true. Isto encerra o ramo \#4 da árvore com as seguintes unificações:

$\mathrm{Y}=$ branco

Arv2 $=c($ branco $)<==$ true

Isto conclui também o ramo de execução \#1 e \#2, com as seguintes unificaçōes:

$X=$ cinza

Corpo $=(b(c i n z a, b r a n c o), c(b r a n c o))$

Arvo $=(b(c$ cinza, branco $)<==(d$ (branco, vermelho $)<==$ true ,

$f($ vermelho, cinza $)<==$ true $), c($ branco $)<==$ true $)$

Finalmente, chegando à raiz da árvore, a solução para prove(a(X), Arv) é: 
$X=\operatorname{cinza}$

Arv $=a($ cinza $)<==(b($ cinza,branco $)<==(d(b r a n c o, v e r m e l h o)<==$

true, $f($ vermelho, cinza $)<==$ true $), c($ branco $)<==$ true $) \rightarrow$;

Seguindo o mesmo procedimento, o sistema pode apresentar outras duas soluções:

$X=$ preto

Arv $=a($ preto $)<==($ b (preto,branco $)<==$ true $), c($ branco $)<==$ true) $\rightarrow$;

$X=$ verde

Arv $=a($ verde $)\langle==(d($ verde, azul $)\langle==$ true $)->$;

no

\subsubsection{Un Meta-interpretador para Rastrear a Execução de Progra- mas}

Outra extensão que pode ser feita ao meta-interpretador Básico é rastrear a execução de um programa. Neste caso, um parâmetro extra é inserido para indicar a altura da árvore de prova. $\mathrm{O}$ valor inicial, que corresponde à altura da raiz na árvore de prova, é zero.

Programa 5.5 Meta-interpretador Trace

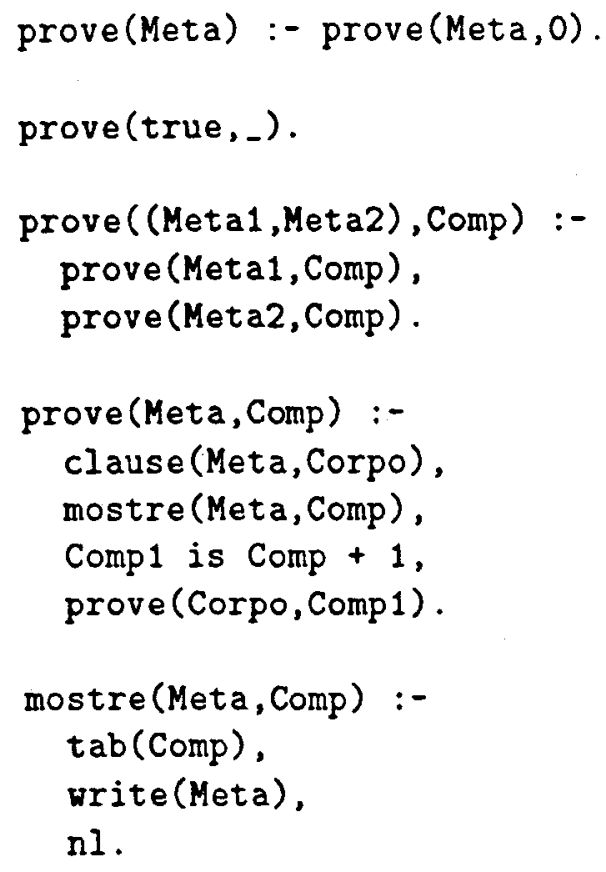


Um exemplo de execuşão, utilizando a Base de Conhecimento Korez é apresentado a seguir:

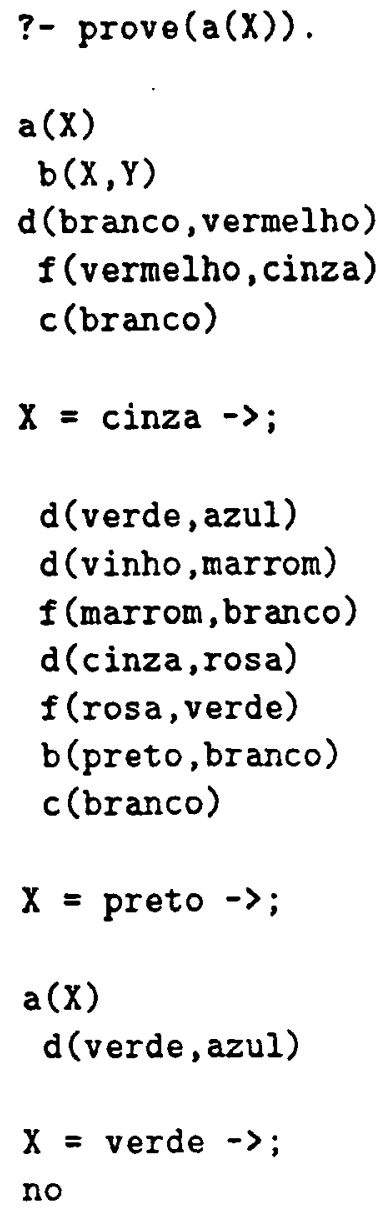

\subsection{5 Árvore de Rastreamento}

Outra característica muito interessante para ser incorporada a um meta-interpretador é manter uma árvore que carrega informações sobre como a meta está sendo resolvida. Neste caso, um parâmento extra é inserido tal que, sempre que o procedimento prove/ 2 é ativado, o segundo argumento contém as informações sobre os passos que foram executados até chegar ao estado corrente de prove/2. Essa árvore é de grande importância na implementação do Mecanismo de Explicação em Sistemas Especialistas, que é a parte do sistema responsável por mostrar ao usuário como se chegou a uma determinada conclusão, bem como explicar porque está a procura de uma determinada informação, quando o sistema solicita informações externas adicionais [Rodrigues 89] [Rodrigues $90 \mathrm{~b}]$. Segue-se o programa que implementa a árvore de rastreamento. 
Programa 5.6 Metu-interpretador Arv-Info

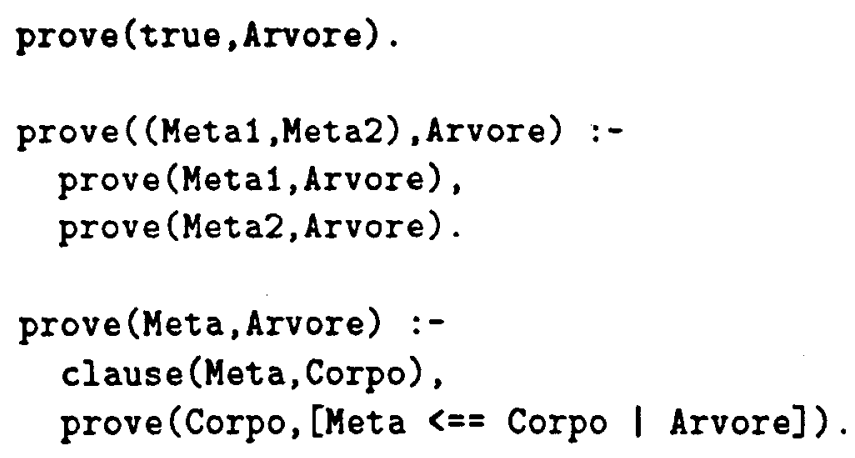

Neste caso, o processo de construção da árvore é o processo oposto ao utilizado pelo meta-interpretador Arv-Prova - programa $5.4-$, no qual as submetas recebem uma variável livre e devolvem-na unificada com os passos que foram percorridos para provar essa sub-meta. Já no caso do meta-interpretador Arv-Info, a meta envia para as submetas uma árvore contendo os passos utilizados até o momento.

Para mostrar a execuçào do meta-interpretador Arv-Info com relação à Base de Conhecimento Korez, será feita uma pequena alteração no meta-interpretador Arv-Info, acrescentando um comando de impressão à primeira e à terceira cláusula de prove/2:

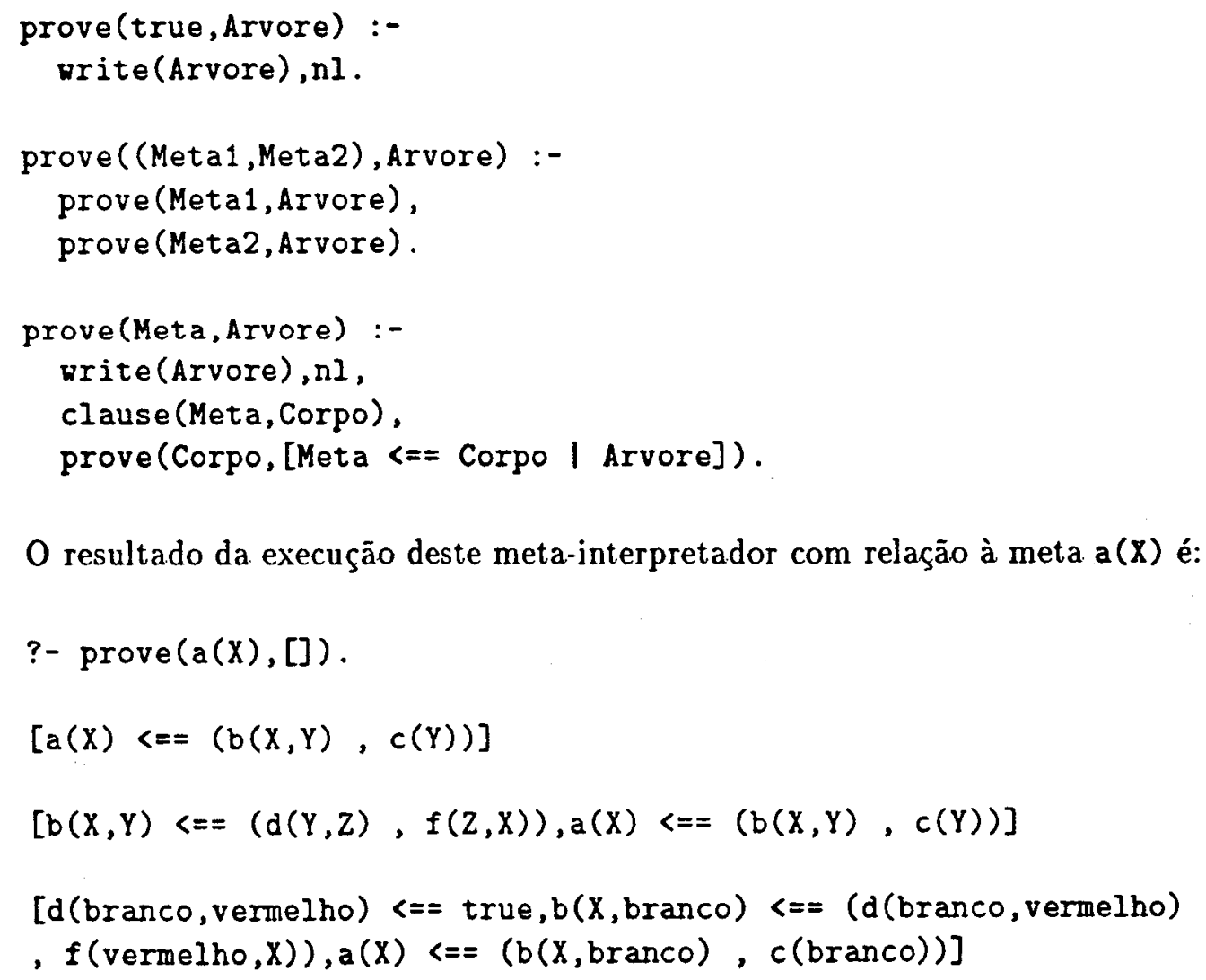

O resultado da execução deste meta-interpretador com relação à meta a (X) é:

?- $\operatorname{prove}(a(X),[])$.

$[a(X)<==(b(X, Y), c(Y))]$

$[b(X, Y)<==(d(Y, Z), f(Z, X)), a(X)<==(b(X, Y), c(Y))]$

[d(branco, vermelho) $<==$ true, $\mathrm{b}(X, \mathrm{branco})<==$ ( $\mathrm{d}$ (branco, vermelho)

- $f($ vermelho, $X)), a(X)<==(b(X, b r a n c o), c(b r a n c o))]$ 
$[b(X, b r a n c o)<==(d($ branco, vermelho $), f($ vermelho, $X)), a(X)<==$ $(b(X, b r a n c 0), c(b r a n c o))]$

[f(vermelho, cinza) $<==$ true,b(cinza, branco) $<==$ ( $d$ (branco, vermelho $), f($ vermelho, cinza $)), a(c$ inza $)<==(b($ cinza,branco), $c($ branco $))]$

$[a(c$ inza $)<==(b($ cinza, branco $), c(b r a n c o))]$

$[c($ branco $)<==$ true,$a($ cinza $)<==(b($ cinza, branco $), c($ branco $))]$

$X=\operatorname{cinza}->$;

$[c(b r a n c o)<==$ true,$a(c$ inza $)<==(b($ cinza, branco $), c(b r a n c o))]$

[f (vermelho, cinza) $<==$ true,b(cinza,branco) $<==$ (d(branco, vermelho), $f($ vermelho,cinza $)), a(c i n z a)<==(b(c i n z a, b r a n c o)$, $c($ branco $))]$

[d(branco, vermelho) $<==$ true, $b(x, b r a n c o)<==$ (d (branco, vermelho) - $f($ vermelho,$X)), a(X)<==(b(X, b r a n c o), c(b r a n c o))]$

[d(verde, azul) $<==$ true,$b(X, v e r d e)<==$ (d(verde, azul) , $f(a z u l, X)), a(X)<==(b(X$, verde $), c($ verde $))]$

$[b(X$, verde $)<==(d($ verde, azul $), f(a z u l, X)), a(X)<==(b(X$, verde $)$ , $c($ verde) $)]$

[d(verde, azul) $<==$ true, $b(X, v e r d e)<==$ ( $d$ (verde, azul) , $f(a z u l, X)), a(X)<==(b(X$, verde $), c($ verde $))]$

$[d$ (vinho, marrom) $s==$ true,$b(X, v i n h o)<==$ ( $d(v$ inho, marrom), $f($ marrom,$X)), a(X)<==(b(X, v$ inho $), c($ vinho $))]$

$[b(X, v i n h o)<==(d($ vinho, marrom $), f($ marrom,$X)), a(X)<==(b(X$, vinho), $c($ vinho $))]$

[f(marrom,branco) $<==$ true, $b(b r a n c o, v i n h o)<==$ (d (vinho, marrom), $f($ marrom, branco $)), a($ branco $)<==(b($ branco,vinho $), c($ vinho $))]$

$[a(b r a n c o)<==(b(b r a n c o, v i n h o), c($ vinho $))]$

[f(marrom,branco) $<==$ true, $\mathrm{b}$ (branco, vinho) $<==$ (d(vinho, marrom), $f$ (marrom, branco)), $a($ branco $)<==$ (b(branco,vinho), $c$ (vinho))]

[d(vinho, marrom) $<==$ true, $b(X, v i n h o)<==$ (d (vinho, marrom) , $f(\operatorname{marrom}, X)), a(X)<==(b(X, v$ inho $), c($ vinho $))]$ 


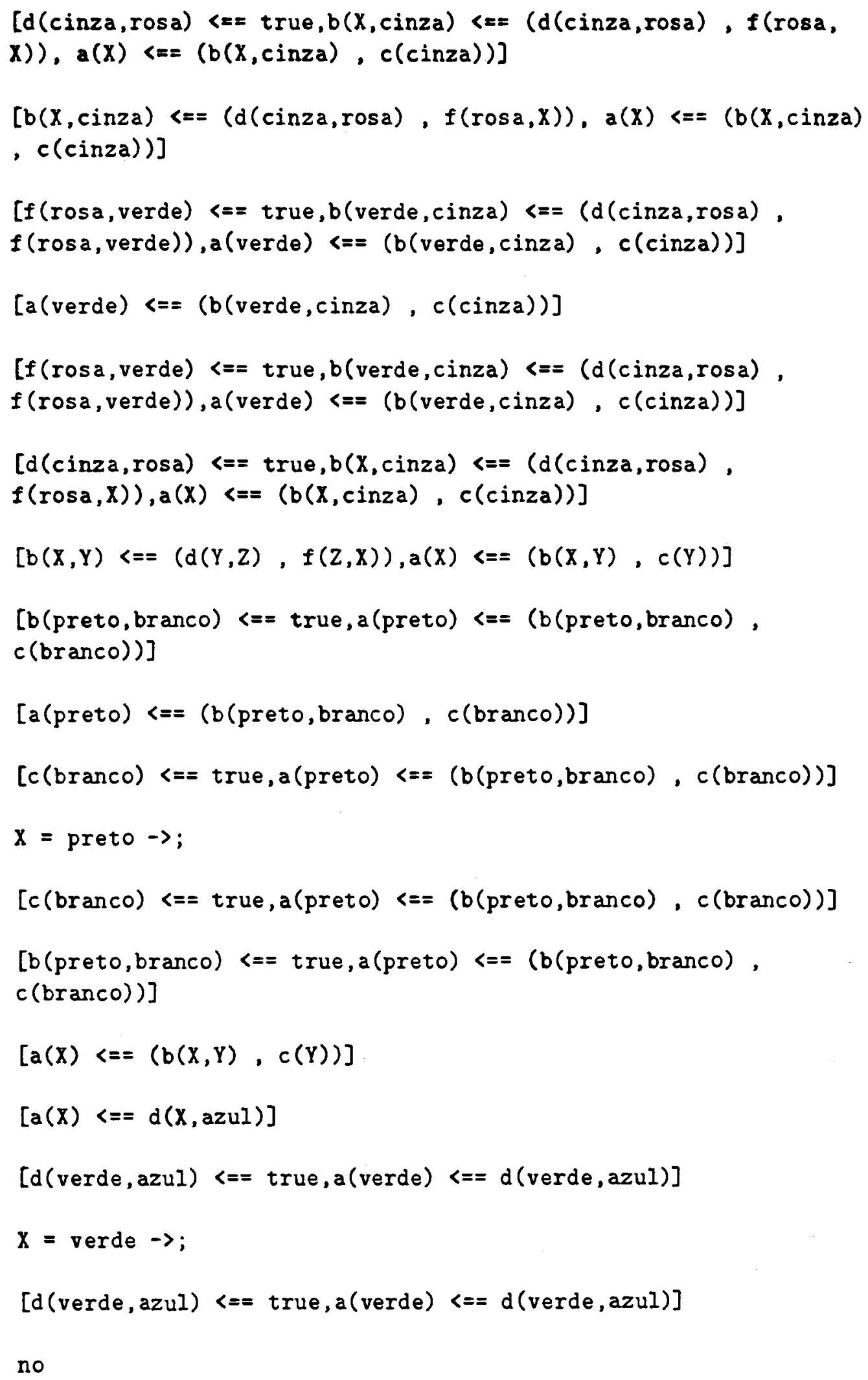




\subsubsection{Raciocínio Incerto}

É frequente, nos problemas que manipulam conhecimento, os casos em que a resposta final não é conhecida com certeza absoluta. Tanto as regras do especialista podem ser vagas como o usuário pode não ter certeza ao responder algumas questōes. Isto pode ser visto facilmente em sistemas de diagnóstico médico, onde os especialistas nem sempre são capazes de definir a relação entre sintomas e doenças com precisão absoluta. De fato, os médicos podem apontar muitos diagnósticos possíveis para um dado conjunto de sintomas.

Deste modo, torna-se muito importante na construção de Sistemas Especialistas a existência de um mecanismo de raciocínio incerto. Um método frequentemente utilizado para implementar raciocínio incerto é associar um fator de certeza a cada regra na Base de Conhecimento. 0 fator de certeza indica a certeza do especialista quanto à veracidade de uma determinada regra.

Há vários formalismos para tratar estes fatores de certeza [Monard 89a], mas todos eles têm sido questionados [Pearl 86], [White 85]. Portanto, qualquer método escolhido será aberto a críticas.

Este questionamento pode ser justificado por várias razōes. Em primeiro lugar, os Sistemas Baseados em Conhecimento necessitam de um modelo de raciocínjo; porém, não se sabe com absoluta certeza como o ser humano pensa e raciocina, pelo menos até o momento. Um segundo ponto que pode ser destacado são os métodos para tratamento de incerteza que vêm sendo utilizados, pois, embora estejam baseados em teorias supostamente corretas, algumas suposiçōes devem ser aceitas para que se possa realizar uma implementação do método que evite a explosão combinatória.

Entre as muitas propostas existentes, o mecanismo escol hido neste trabalho para representar raciocínio incerto é semelhante ao usado em MYCIN [Shortliffe 76], que associa a cada regra ou fato um fator de certeza entre 0 e 1 . Um programa lógico com incerteza é um conjunto de pares

$$
\langle\text { Clausula, Fator }\rangle \text {, }
$$

onde Fator é o fator de certeza da cláusula Clausula. Neste caso, a regra utilizada para o cálculo de incertezas encontra-se abaixo.

Considerando que uma cláusula do programa é $\langle(A:=B), F\rangle$, o grau de certeza é calculado da seguinte forma:

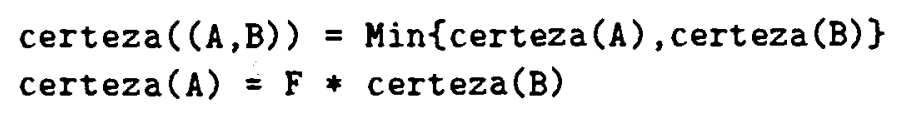

O meta-interpretador Fator-Certeza é uma extensão do meta-interpretador básico que incorpora um mecanismo para cálculo de incerteza utilizando a regra acima. 
Programa 5.7 Meta-interpretador Fator-Certeza

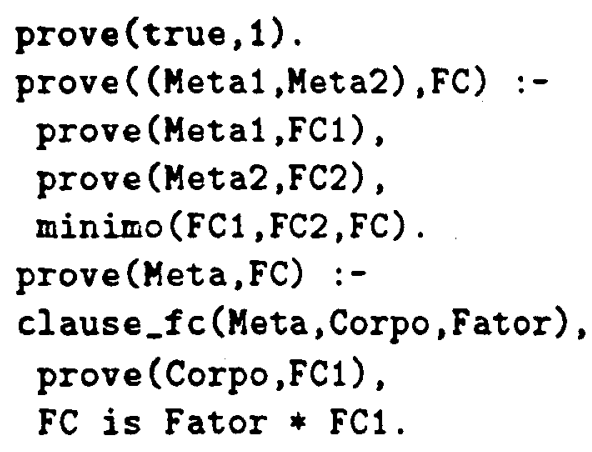

$O$ predicado minimo $(C 1, C 2, C)$ unifica $C$ com o menor valor entre $C 1$ e $C 2$ :

minimo $(\mathrm{C} 1, \mathrm{C} 2, \mathrm{C} 1):-\mathrm{C} 2>=\mathrm{C} 1$.

minimo $(\mathrm{C} 1, \mathrm{C} 2, \mathrm{C} 2):-\mathrm{C} 1>\mathrm{C} 2$.

0 procedimento clause_f $\mathrm{c} / 3$ tem função semelhante ao predicado pré-definido de Prolog clause/2, somente que, além de unificar com o corpo de uma meta, ele unifica também com o fator de certeza associado a essa regra. Não há grandes dificuldades para a implementação de clause _cf/3, pois ela depende apenas da maneira escolhida para representar o fator de certeza das regras. Como exemplo, será considerado o seguinte método:

A representação da regra

$r(R, S):-r 1(R), r 2(S)$.

com fator de certeza FC é

$r(R, S):-f c=F C, r 1(R), r 2(S)$.

A representação do fato

$f$ (estrela).

com fator de certeza $F$ é

$f(e s t r e l a):-f c=F$.

Neste caso, a implementação de clause_cf/3 seria:

clause_cf(Meta,Corpo,Fator) :- clause(Meta, (fc = Fator,Corpo)).

clause_cf(Meta,true,Fator) :- clause(Meta,fc = Fator).

Para mostrar como o meta-interpretador Fator-Certeza atua sobre um programa Prolog, a Base de Conhecimento Korez será modificada, acrescentando-se fatores de certeza às regras e aos fatos, como mostrado a seguir. 


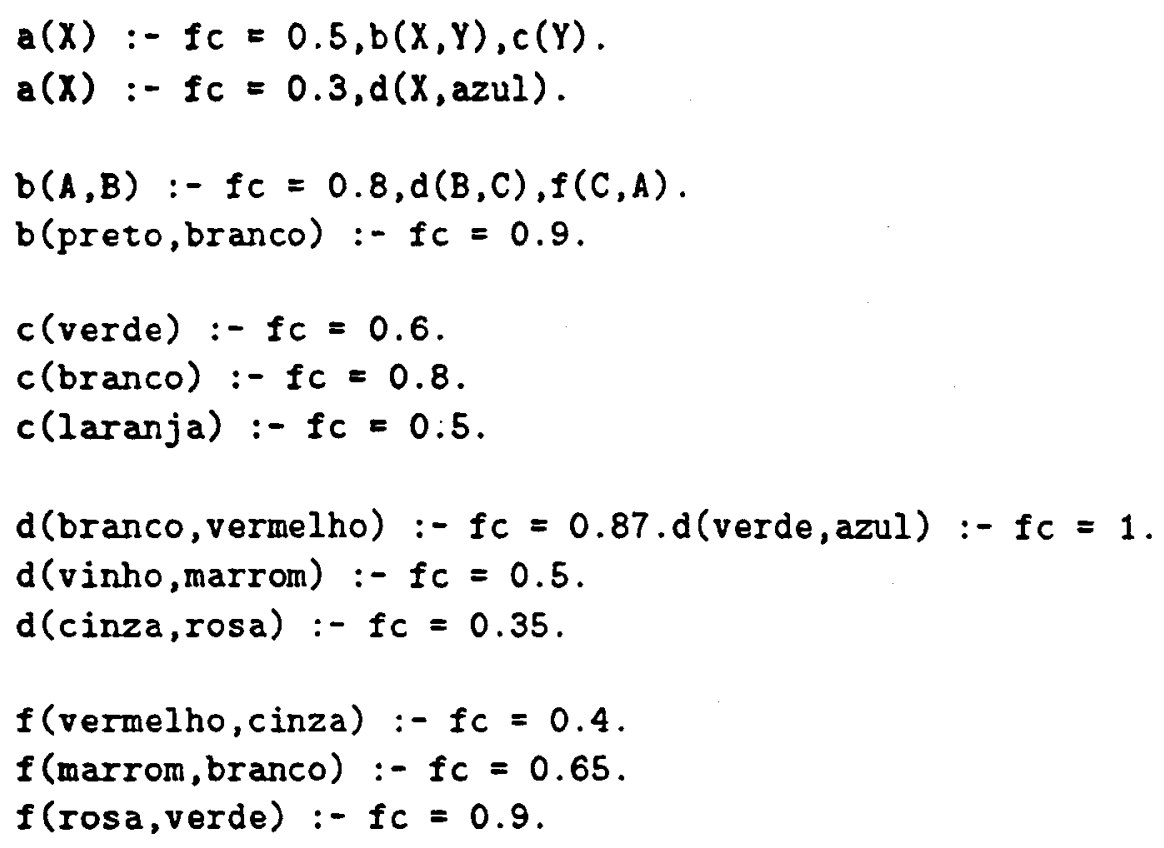

O resultado da execução do meta-interpretador Fator-Certeza com relação à Base de Conhecimento acima é:

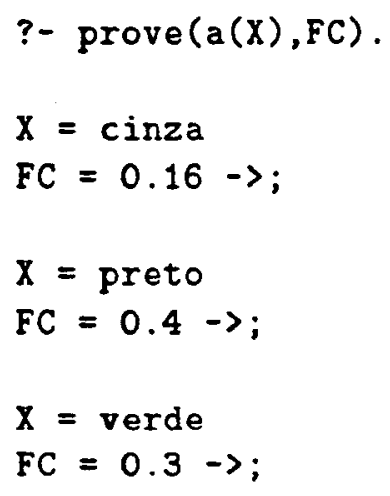

no

\subsubsection{Interação com o Usuário}

Muitos Sistemas Especialistas devem incorporar mecanismos de interação com o usuário durante o processo de prova de uma meta. Neste caso, quando uma meta não pode ser provada por nenhuma das cláusulas do meta-interpretador, uma solução é perguntar ao usuário a veracidade ou falsidade da meta. Na implementação mostrada a seguir, a meta será considerada provada se o usuário responder sim, falhando caso contrário. A cláusula prove/1 abaixo pode ser incorporada ao final do meta-interpretador Básico - programa 5.3 - para que possa ser realizada a interação com o usuário: 


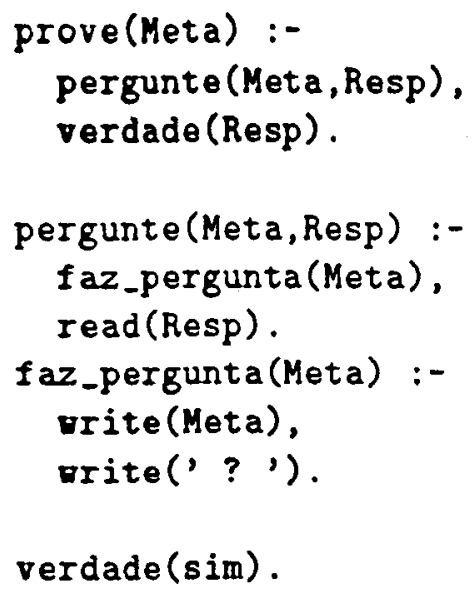

O mecanismo de interasào acima ainda apresenta algumas deficiências. A primeira delas é a repetição da pergunta ao usuário sempre que for necessário repetir a prova de uma meta. A solução para isso é guardar a resposta do usuário para que ela possa ser lembrada. Neste caso, o meta-interpretador deve verificar, antes de perguntar ao usuário, se a pergunta já foi feita anteriormente. Segue-se o meta-interpretador que implementa esta solução.

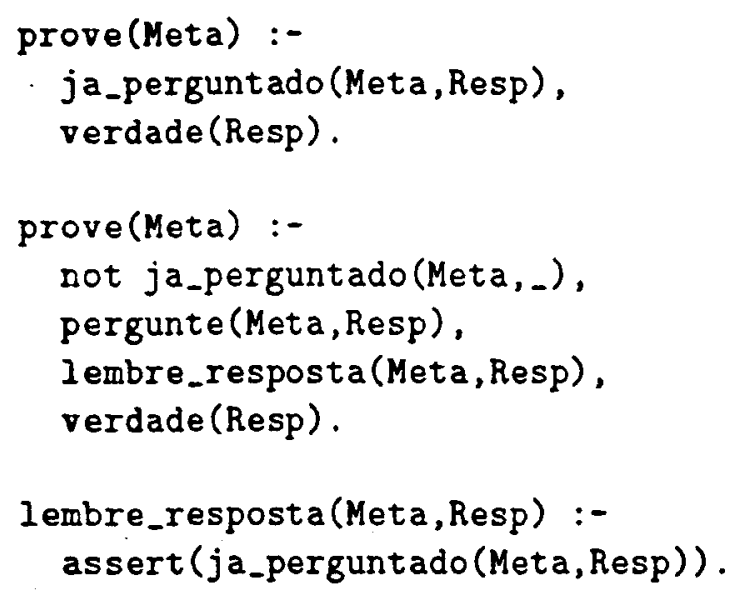

Uma outra falha apresentada pelo mecanismo de interação descrito acima é que nem sempre uma meta deve ser perguntada ao usuário, pois pode ser que algumas metas devam realmente falhar. Isto é facilmente sanado pela relação perguntavel/1, que indica se uma meta deve ou não ser perguntada ao usuário. O programa 5.8 contém as cláusulas que compōem o meta-interpretador Interativo. 


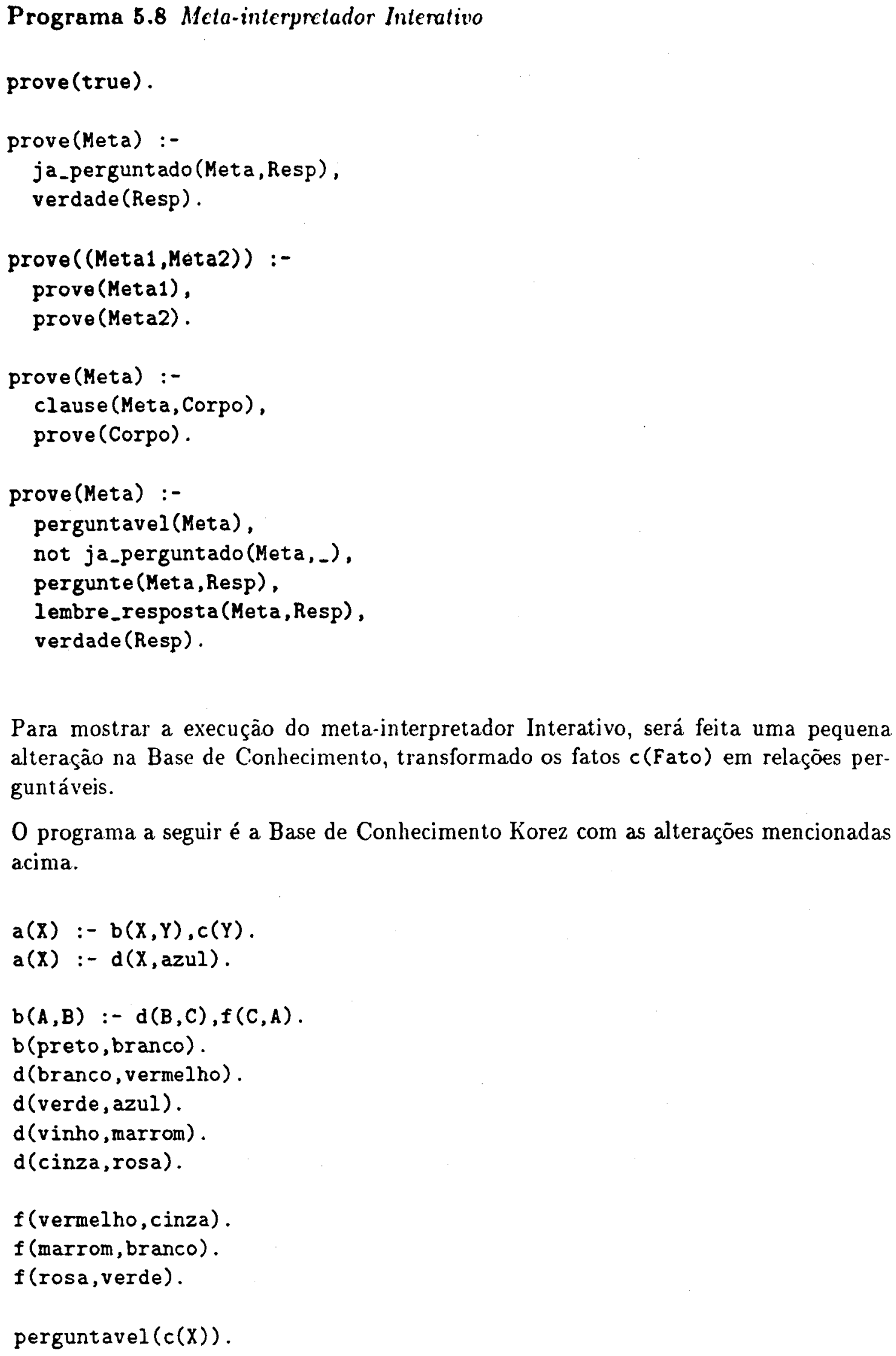

Para mostrar a execução do meta-interpretador Interativo, será feita uma pequena altera.̧ão na Base de Conhecimento, transformado os fatos c(Fato) em relações perguntáveis.

O programa a seguir é a Base de Conhecimento Korez com as alterações mencionadas acima. 
Abaixo são mostradas duas interrogaçōes utilizando este meta- interpretador, considerando as respostas dadas pelo usuário distintas em cada uma delas. Pode-se observar que, neste caso particular, a resposta do sistema é diferente em cada caso.

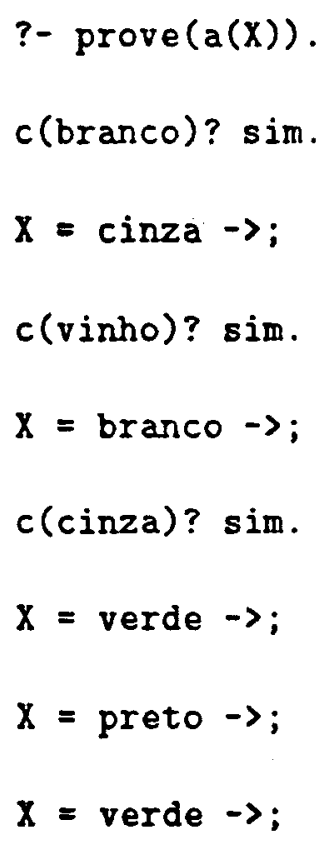

no

Para a obtenção de um resultado correto na segunda ativação de prove/1, é necessário eliminar da base todas as cláusulas ja_perguntado (Meta, Resp). O procedimento prédefinido abolish(Meta/Aridade) é utilizado para essa finalidade.

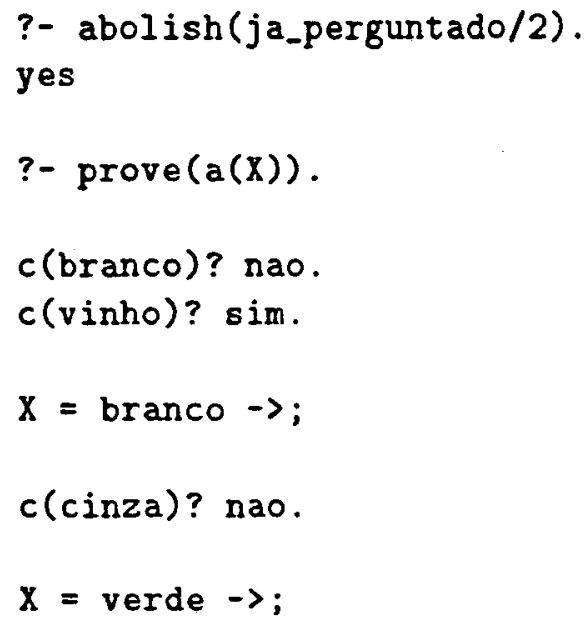




\subsubsection{Relações do Sistema}

Muitas vezes, é interessante que um meta-interpretador manipule certas características da linguagem que não pertencem ao Prolog puro, como, por exemplo, os vários predicados pré-definidos do sistema. Estes predicados não são definidos por cláusulas no programa e, portanto, precisam ser tratados de forma diferente. Em Prolog, há a função pré-definida system $(P / N)$, que determina se um predicado $P$ com $N$ argumentos é ou não um predicado pré-definido do sistema. O predicado sistema/1 abaixo indica se um predicado é um pré-definido do sistema.

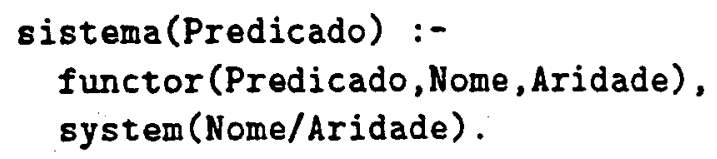

O predicado functor/3 utilizado acima é um predicado pré-definido de Prolog que quebra uma estrutura, retornando seu nome e aridade. Por exemplo:

?- functor(jogo(bola, sapato,mel), Nome, Aridade).

Nome $=$ jogo

Aridade $=3$

A seguinte cláusula prove/1 incorpora os predicados de sistema ao meta-interpretador Básico apresentado no programa 5.3

prove(Meta) :- sistema(Meta), Meta.

Esta cláusula extra faz com que os predicados do sistema sejam invisíveis ao meta-interpretador prove/1. Porém, há alguns predicados fornecidos pelo sistema que deveriam ser visiveis, como por exemplo o predicado not - negação por falha de Prolog. Para melhor manipular esses predicados, cada um deles deverá ter uma cláusula especial no meta-interpretador, tornando mais fina sua granularidade. No caso do predicado not, a implementação seria:

prove(not Meta) :- not prove(Meta).

A Base de Conhecimento Korez será alterada para que se possa mostrar a influência das características adicionais apresentadas acima.

Programa 5.9 Base de Conhecimento Korez-System

$a(X):-b(X, Y), c(Y), \operatorname{not} d(Y, X)$.

$a(X):-d(X, a z u l)$. 


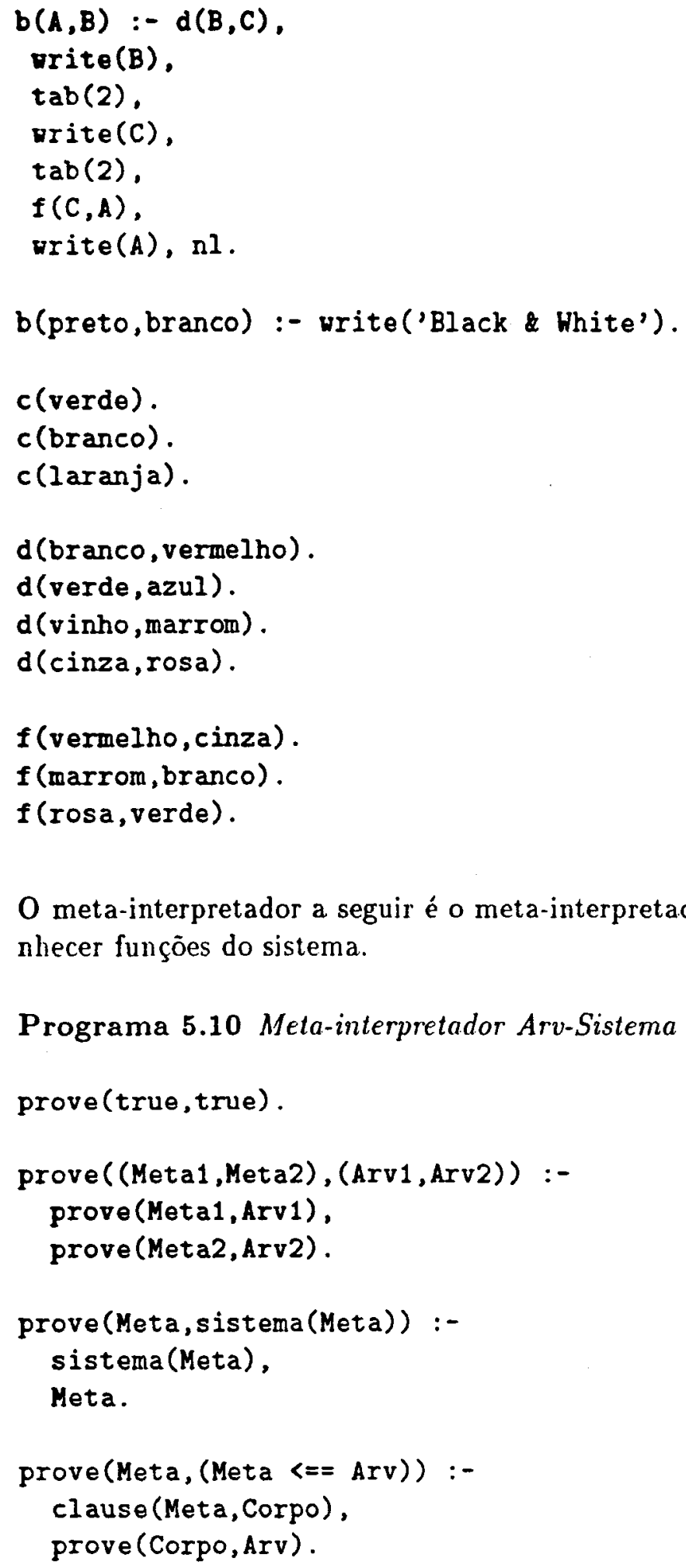
nhecer funçooes do sistema.

Programa 5.10 Meta-interpretador Arv-Sistema

O meta-interpretador a seguir é o meta-interpretador Arv-Prova extendido para reco-

Segue-se o resultado da execução do meta-interpretador acima com relação à Base de Conhecimento Korez-System - programa 5.9. 


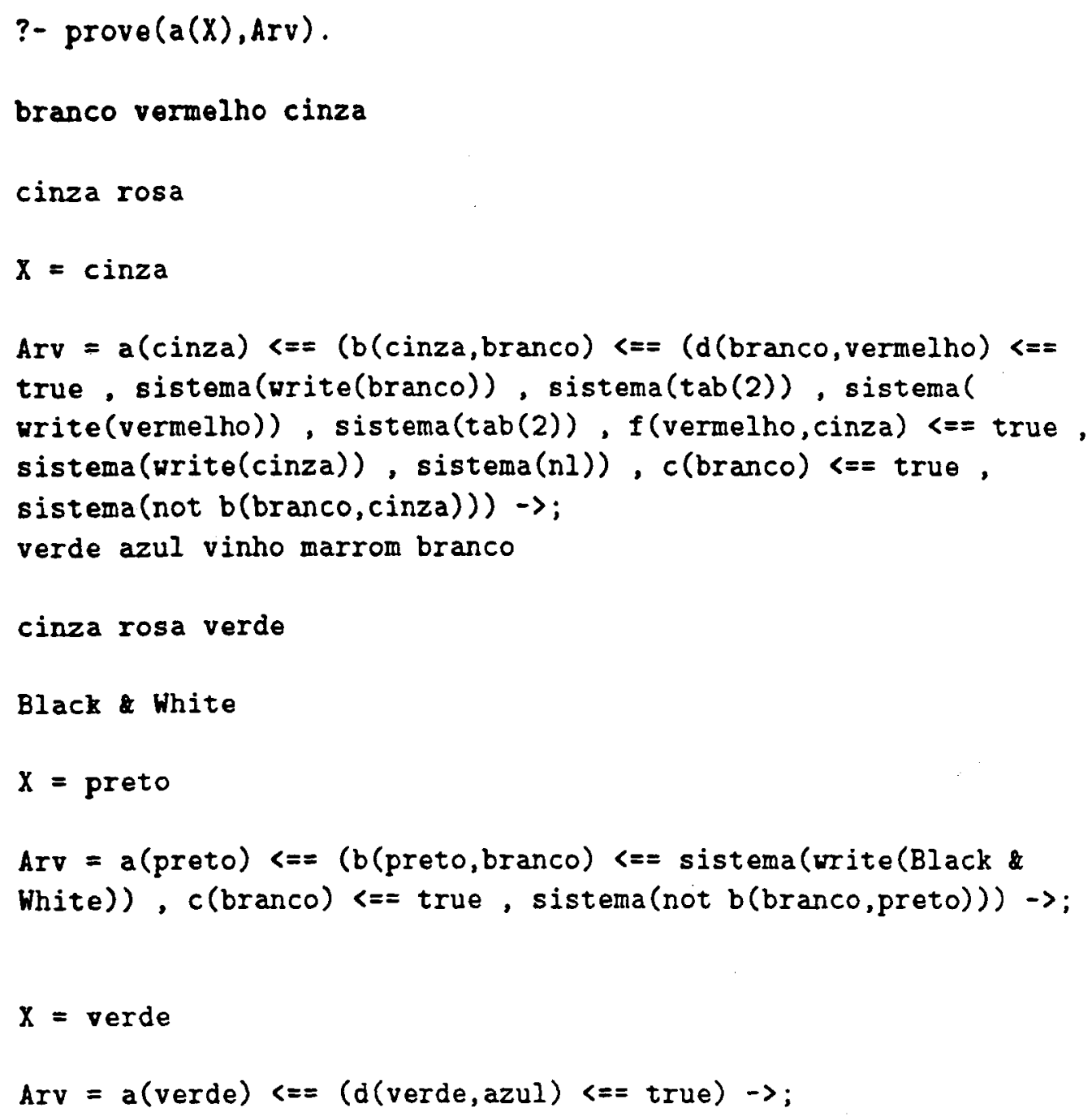

Como já foi mencionado anteriormente nesta seção, pode-se desejar que alguns predicados do sistema nào sejam invisíveis ao meta-interpretador. Para que isto possa ser exemplificado, a cláusula abaixo é adicionada como terceira cláusula no meta-interpretador Arv-Sistema. Neste caso, a árvore de prova será diferente da anterior.

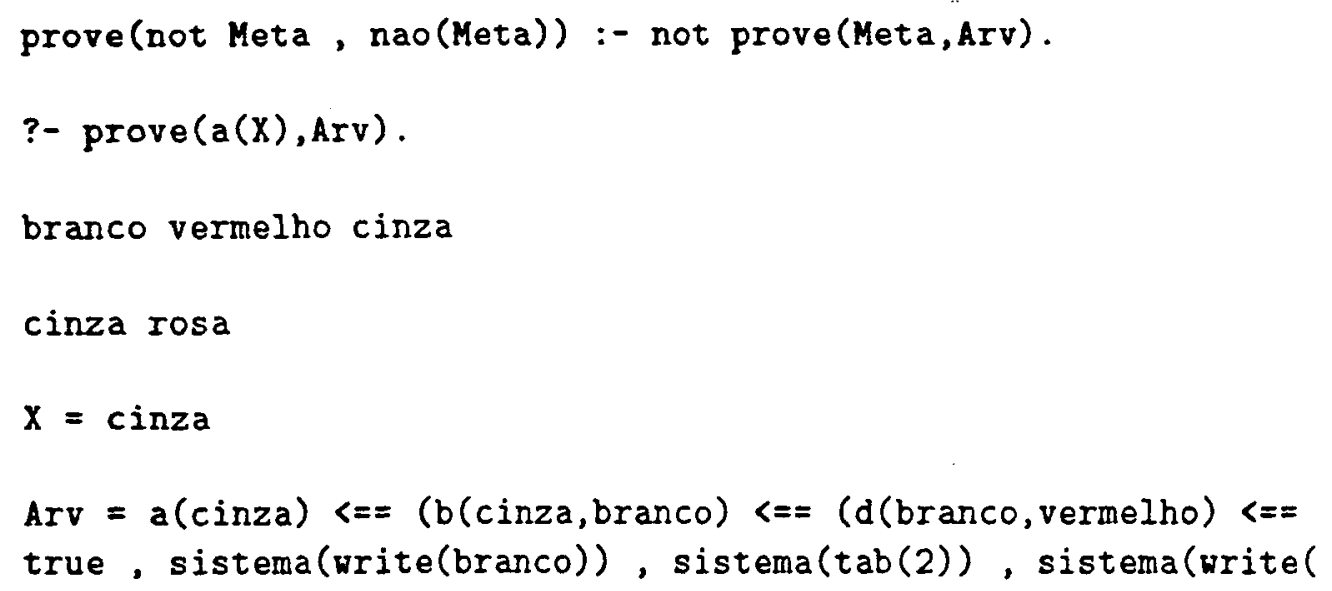




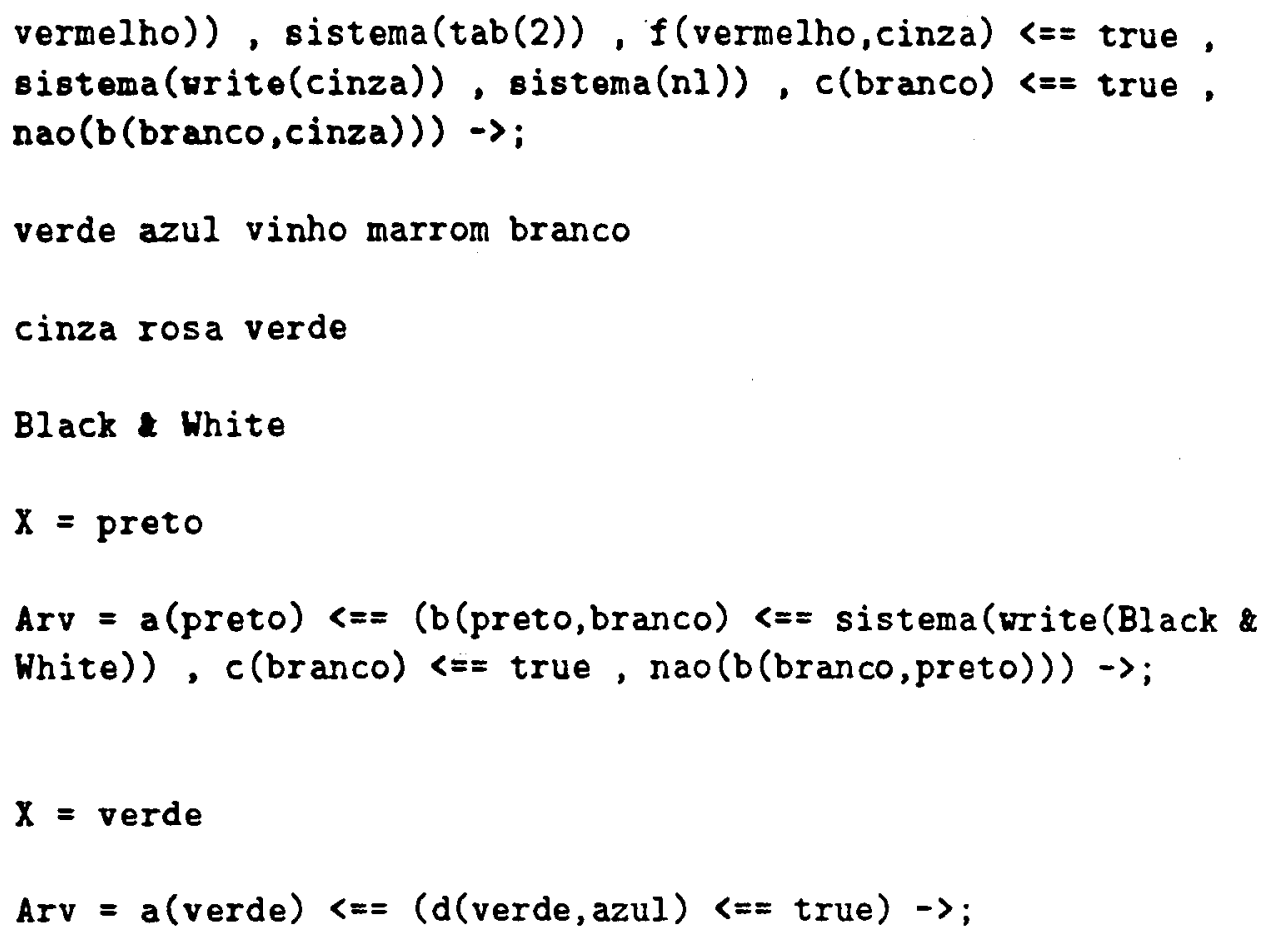

\subsubsection{Procedimentos Invisiveis}

Da mesma maneira em que há interesse em tornar alguns predicados do sistema visíveis ao meta-interpretador, pode ser também necessário tornar invisíveis alguns predicados, mesmo que estes não sejam predicados do sistema. Neste caso, pode ser utilizado um procedimento análogo ao utilizado na definição de relações do sistema. Isto pode ser feito definindo-se um predicado para indicar todas as relações que serão invisíveis ao meta-interpretador. No exemplo a seguir, primitiva(Meta) define Meta como uma. relação invisível ao meta-interpretador.

prove(Meta) :- primitiva(Meta), Meta.

As relaçòes invisiveis ao meta-interpretador são executadas diretamente pelo motor de inferência de Prolog.

O meta-interpretador Cristalino abaixo é uma extensão do meta-interpretador ArvProva com as seguintes características adicionais: relações do sistema, negação de metas e relações primitivas - invisiveis ao meta-interpretador.

Programa 5.11 Meta-interpretador Cristalino

prove(true,true).

prove((Meta1, Meta2), (Arv1, Arv2)) :prove(Meta1, Arv1), 


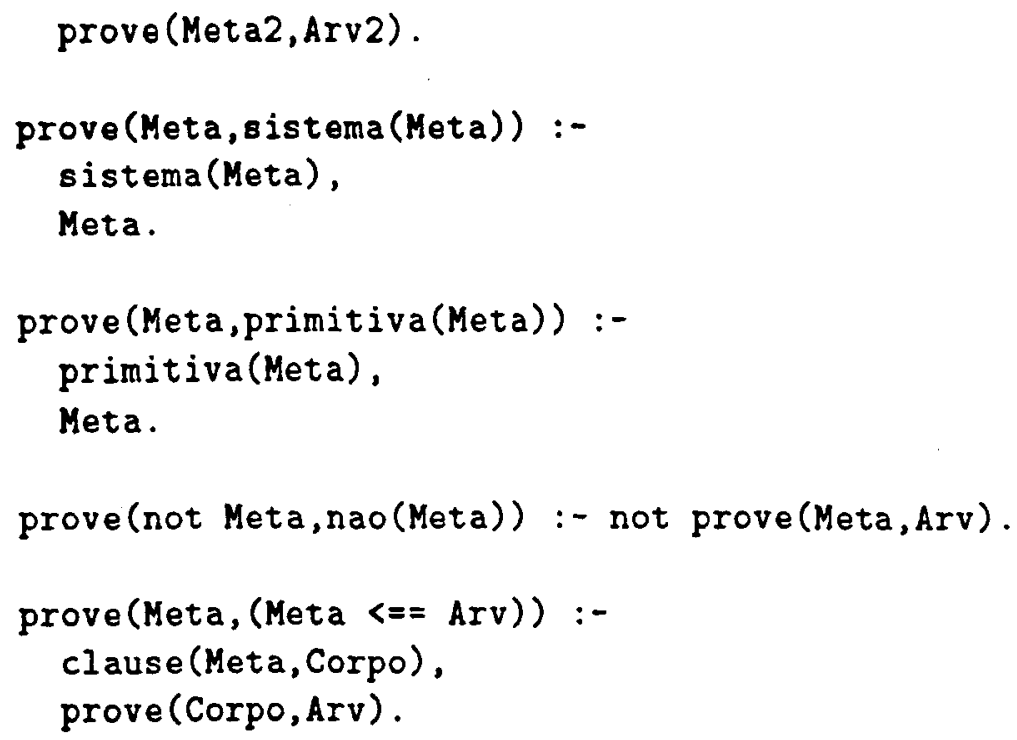

Se a relação

primitiva(b(Arg1, Arg2))

for adicionada à Base de Conhecimento Korez-System - programa 5.9 - e o meta-interpretador Cristalino for interrogado com relação a essa base, a resposta é:

?- prove(a(X),Arv).

branco vermelho cinza

cinza rosa

$X=\operatorname{cinza}$

$\operatorname{Arv}=a($ cinza $)<==($ primitiva $(b($ cinza,branco $)), c($ branco $)<=a$ true, nao(b(branco,cinza $))) \rightarrow$;

verde azul vinho marrom branco

cinza rosa verde

Black White.

$X=$ preto

Arv $=a($ preto $)<==($ primitiva $(b($ preto,branco $)), c($ branco $)<==$ true, nao(b(branco,preto))) $\rightarrow$; 
Arv $=a(v e r d e)<==(d(v e r d \theta, a z u I)<==$ true $) \rightarrow$;

Pode-se observar que os detalhes da execução de $b(X, Y)$ foram omitidos na árvore de prova, ou seja, os detalhes da prova de $b(X, Y)$ tornaram-se invisiveis ao meta-interpretador.

\subsection{Classificação de Meta-interpretadores}

Os meta-interpretadores podem ser classificados de acordo com a influência que eles exercem sobre a Base de Conhecimento que manjpulam. Alguns meta-interpretadores alteram a resolução de uma dada meta, isto é, a resolução de uma meta via execução direta da Base de Conhecimento escrita em Prolog fornecerá uma solução, enquanto a resolução da meta utilizando o meta-interpretador pode fornecer outra.

Na maioria dos casos, estes meta-interpretadores alteram a Base de Conhecimento durante a execução. Um meta-interpretador com essas características é classsificado como meta-interpretador com aumento procedimental. Os meta-interpretadores que não alteram a resolução de uma dada meta classificam-se em meta-interpretadores com aumento estrutural e meta-interpretadores com aumento contextual. Segue-se uma classificação mais detalhada para meta-interpretadores:

Meta-Interpretadores com aumento procedimental: são aqueles que podem alterar o resultado da execução de uma dada meta. Os meta-interpretadores interativos - semelhantes a.o meta-interpretador Interativo (programa 5.8) - possuem tal característica e, portanto, são classificados como meta-interpretadores com aumento procedimental.

Meta-Interpretador com aumento estrutural: são aqueles que realizam operações que indicam como a meta está sendo resolvida. Por exemplo, o meta-interpretador Arv-Prova - programa 5.4 - possui aumento estrutural, e o argumento extra introduzido unifica com a árvore de prova, que indica os passos utilizados para provar a meta.

Meta-Interpretador com aumento contextual: são aqueles que carregam informações sobre o contexto no qual a meta está sendo resolvida. Por exemplo, o meta-interpretador Arv-Info - programa 5.6 - possui aumento contextual, e o argumento extra introduzido contém, a cada ponto da execução, a informação sobre todos os passos necessários para se chegar até aquele ponto. 


\subsection{Considerações Finais}

Neste capítulo foi mostrada a importância de meta-programação e de meta-interpretação, principalmente na construção de Sistemas Especialistas.

Diversos meta-interpretadores - implementados na linguagem Prolog - foram apresentados, cada um deles apresentando uma característica importante na implementação de um Sistema Baseado em Conhecimento. Estas características podem ser combinadas de modo a obter-se o meta-interpretador que seja mais adequado para a implementação de um sistema específico.

Uma Base de Conhecimento simples foi utilizada para mostrar os efeitos de cada metainterpretador.

Finalmente, mostrou-se como os meta-interpretadores podem ser classificados, conforme sua influência sobre a Base de Conhecimento com a qual se relacionam. Essa classificação é importante para a avaliação parcial de meta-interpretadores - capítulo 6. 


\section{Capítulo 6}

\section{Avaliação Parcial}

\subsection{Considerações Iniciais}

Inicialmente, a Avaliação Parcial não foi uma idéia levada muito a sério, sendo utilizada somente em algumas pequenas subrotinas utilizadas em pesquisas de programação incremental. Porém, Beckman mostrou que, quando bem desenvolvida e bem utilizada, Avaliasão Parcial pode ser útil como uma ferramenta de trabalho para auxiliar os programadores a aumentar a eficiência dos programas [Beckman 76].

Atualmente, a Avaliação Parcial é usada em diversas aplicações, entre as quais destacam-se:

- especialização de programas gerais para uso restrito, a fim de torná-los mais eficientes [Jones 88a] [Fujita 87b];

- compilação incremental [Fujita 87a] [Bulyonkov 90];

- geração automática de compiladores [Fujita 88];

- programação automática [Jones $88 \mathrm{~b}$ ];

- transposição do fosso semântico [Yamaki 90].

Neste capítulo são vistos os conceitos básicos de Avaliação Parcial e sua importância para aumentar a eficiência de programas.

São abordados os mecanismos utilizados na implementação de sistemas de Avaliação Parcial de programas Prolog, bem como os principais problemas causados pelos predicados extra-lógicos da linguagem. 


\subsection{Avaliação Parcial em uma Máquina de Estados}

As idéias desenvolvidas nesta seção provém dos trabalhos de Ershov, a quem se devem os primeiros estudos teóricos de impacto sobre computação parcial [Ershov 77] [Ershov 82]. Ershov considera que a computaşão é realizada em uma máquina de estados, na qual cada estado pode ser representado por um conjunto de variáveis com valores especificados.

Considerando-se este ponto de vista, um programa é executado utilizando um estado de memória inicial. Estes dois elementos causam uma computação que leva a outro estado de memória.

A fim de facilitar a compreensão dos elementos envolvidos no processo de transformação de estados, será considerada uma linguagem de programação estruturada semelhante à linguagem Pascal, na qual são escritos os programas para a máquina de estados mencionada acima. O procedimento Potencia, descrito a seguir, é um exemplo de programa utilizado para calcular o resultado de elevar um número a uma determinada potência.

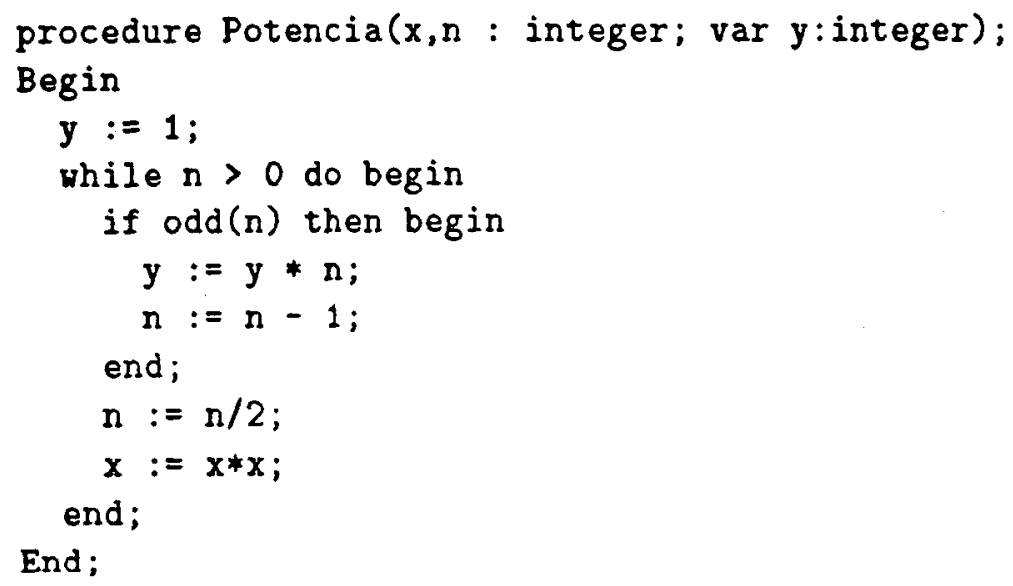

A computação resultante de um programa junto a um estado de memória pode ser dividido em uma sequência de operações, composta por operações de decisão e operações de atribuição. No caso do programa acima, as operações de atribuição são:

- $\mathbf{y}:=1$

- $\mathrm{y}:=\mathrm{y} * \mathrm{n}$;

- $\mathrm{n}:=\mathrm{n}-1$

- $\mathrm{n}:=\mathrm{n} / 2$;

- $x:=x * x$.

e as operações de decisão são: 
- $n>0$;

- $\operatorname{odd}(n)$.

A sequência de operações que caracteriza a computação é denominada história. A história é um programa linear contendo somente operações de atribuição e operações de decisão.

A fim de exemplificar, é considerado o programa acima e o seguinte estado de memória inicial:

- $x=3$;

- $\mathrm{n}=5$.

A história referente à computação causada pelos elementos descritos acima é mostrada a seguir. Na notação utilizada neste trabalho, o símbolo + indica que a Avaliação é bem sucedida, enquanto o símbolo - indica que a expressão é falsa.

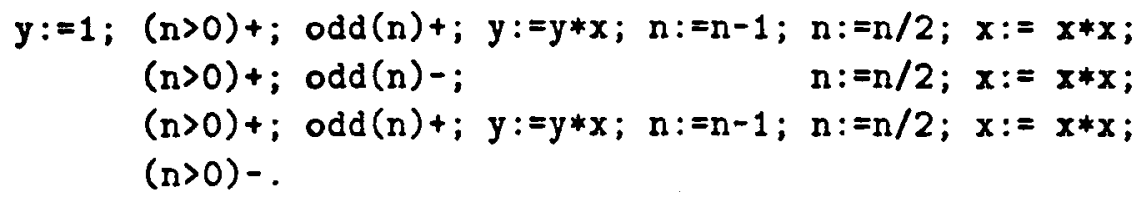

No caso de uma máquina de estados, a Avaliação Parcial pode ser imaginada como uma divisão das operaçōes que compōem a história em duas sequências de operaçôes: as operaçōes que podem ser executadas a partir de um conjunto parcial dos dados de entrada - sequéncia superior - e as operaçōes que ainda não podem ser executadas - sequência inferior. As operaçōes da sequência superior alteram o estado de memória inicial, produzindo um estado que será denominado estado transiente.

O programa composto pelas operaçōes da sequência inferior é denominado programa residual, e a sequência de elementos que compōem a sequência superior é chamada história parcial.

Para que possa ser feita a Avaliação Parcial, é necessário que parte dos dados de entrada. do programa sejam conhecidos. Tomando como exemplo o seguinte estado inicial:

- $\mathrm{n}=5$

- $x$ desconhecido;

- y desconhecido.

Neste caso, a Avaliação Parcial sobre o programa Potencia produz o seguinte resultado: 


\section{História Parcial}

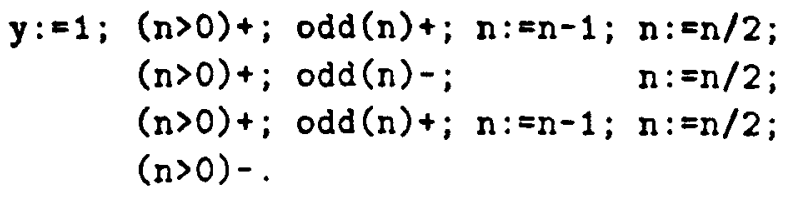

\section{Estado de Memória Transiente}

- $\mathrm{n}=0$;

- $x$ desconhecido;

- $y=1$.

\section{Programa Residual}

$$
\begin{aligned}
& y:=1 * x ; x:=x * x ; \\
& x:=x * x ; \\
& y:=y * x ; x:=x * x ;
\end{aligned}
$$

Pode-se observar claramente que, para o caso específico em que o valor de n é 5 , o programa residual gerado pela Avaliação Parcial produzirá o mesmo resultado que o programa original, para qualquer que seja o valor de $\mathbf{x}$. 0 princípio da computação parcial diz justamente que isto vale para qualquer caso, ou seja, a computação produzida por um programa residual - juntamente com um estado transiente - apresenta o mesmo resultado que a computação produzida pelo programa original junto com o estado de memória inicial.

Pode-se observar também que o programa residual é mais eficiente, pois elimina as avaliações de expressões existentes na execução do programa original. Isto significa que a Avaliação Parcial é uma técnica que pode ser utilizada para gerar programas mais eficientes, especializando um programa geral para um conjunto específico de entrada.

\subsection{Avaliação Parcial em Programação Lógica}

A teoria geral da Avaliação Parcial foi primeiramente desenvolvida para programas escritos em linguagens convencionais, sendo então incorporada ao paradigma da programação funcional [Fujita 87a]. Posteriormente, a técnica de Avaliação Parcial foi introduzida no paradigma da programação lógica [Koromowski 81]. Alguns anos depois, Venken desenvolveu essa teoria para uso prático [Venken 84].

O principal objetivo da Avaliaçào Parcial é transformar o programa fonte em um outro programa semanticamente equivalente, porém com um número reduzido de inferências lógicas. Com isto, a eficiência do programa pode aumentar significativamente [Venken 88]. 


\subsubsection{Conceitos Básicos}

Um Avaliador Parcial é um programa que tem como entrada um procedimento $P$, com argumentos

$$
(X 1, X 2, \ldots, X n)
$$

junto com os valores

$$
(C 1, C 2, \ldots, C m)
$$

onde $m \leq n$, para os primeiros $m$ dos $n$ argumentos, e gera um novo procedimento $P^{\prime}$ tal que

$$
P^{\prime}(X m+1, X m+2, \ldots, X n)=P(C 1, \ldots, C m, X m+1, \ldots, X n)
$$

Neste caso, $P^{\prime}$ é denominado programa residual de $P$ com relação a $(C 1, \ldots, C m)$, ou seja, $P^{\prime}$ é o programa $P$ avaliado parcialmente com relação a $(C 1, \ldots, C m)$ [Beckman 76]. 0 mecanismo de Avaliação Parcial pode ser visto na Figura 6.1.
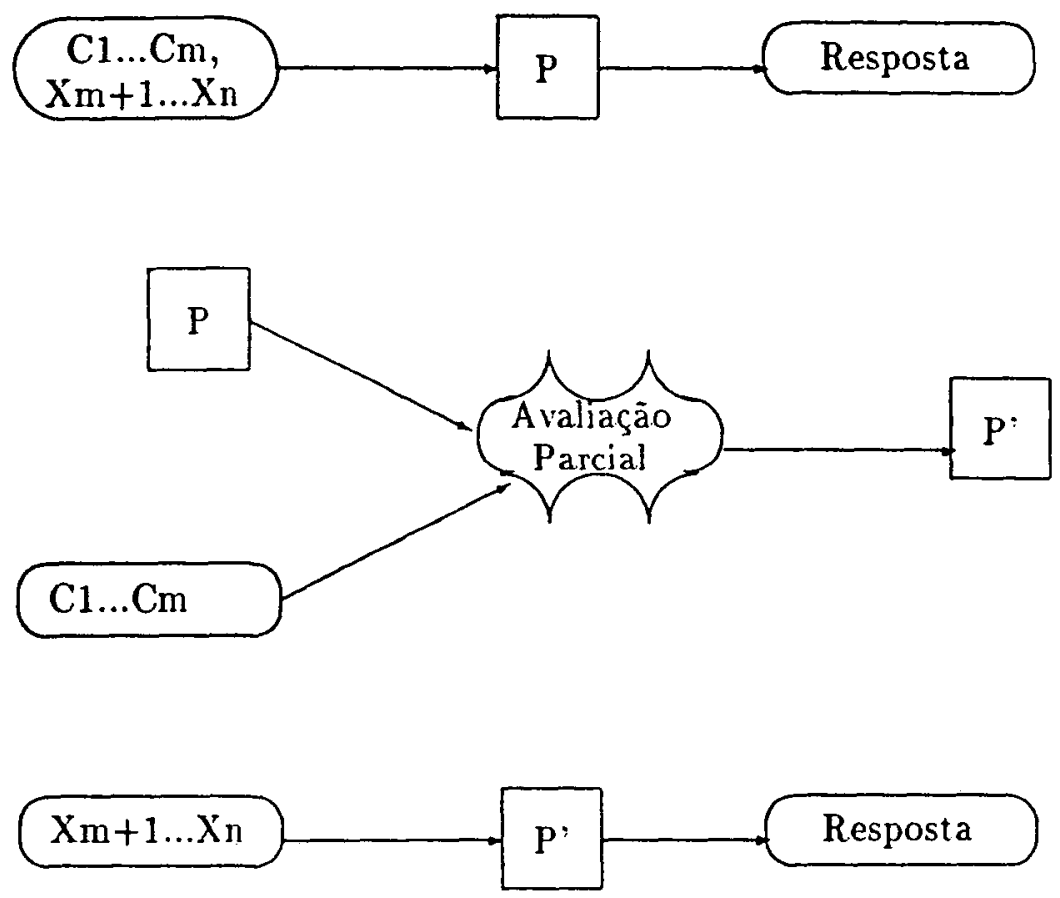

Figura 6.1: Mecanismo de Avaliação Parcial

Conceitualmente, a Avaliação Parcial de um programa lógico puro é muito simples: um programa geral é especializado para uso específico baseado nas informações sobre seu uso, tal como instanciação Parcial de alguns argumentos [Takeuchi 86a]. No caso de 
Prolog, a Avaliação Parcial é mais complexa, já que essa linguagem possui predicados extra-lógicos.

Um sistema de Avaliação Parcial deve seguir o seguinte princípio básico:

- avaliar as partes do programa cujos dados de entrada são suficientes para realizar essa tarefa;

- manter inalteradas as partes restantes.

Para isto, o sistema de Avaliação Parcial tenta aplicar, em tempo de compilação, o mecanismo de execuçāo utilizado por Prolog durante a execução, restrito a não afetar a semântica do programa. Por isto, a Avaliação Parcial pode ser considerada como uma técnica de compilação para programas com dados incompletos, sendo muito útil para computação iterativa, especificação de programas e otimização de meta-programas [Sakama 87].

Na Figura 6.2 pode-se visualisar como funciona um sistema de Avaliação Parcial.

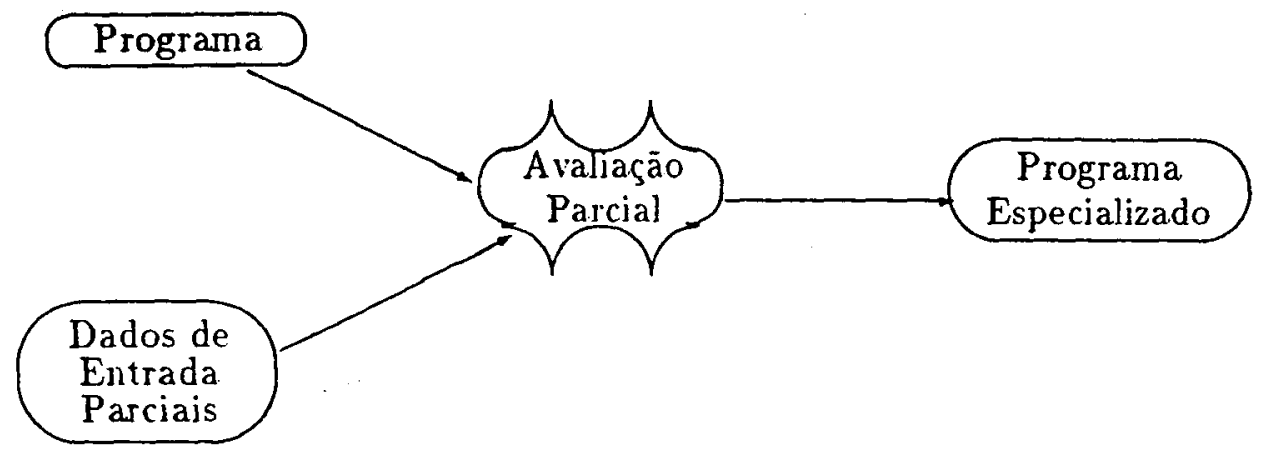

Figura 6.2: Sistema de Avaliação Parcial

\subsubsection{Mecanismos de Avaliação Parcial}

Vários mecanismos tem sido propostos para que a Avaliação Parcial possa ser efetuada[Koromow'shi 81] [Sterling 86] [Yamaki 90]. Basicamente eles se resumem em três:

- poda;

- expansão em linha (incluindo unificação em tempo de compilação);

- avaliação de funções internas (quando possível).

A seguir, cada um destes mecanismos é apresentado com majores detalhes: 
Poda: consiste essencialmente em escolher somente as cláusulas que são efetivamente utilizadas no programa, eliminando aquelas que não são. Para exemplificar este processo, será considerado o seguinte programa:

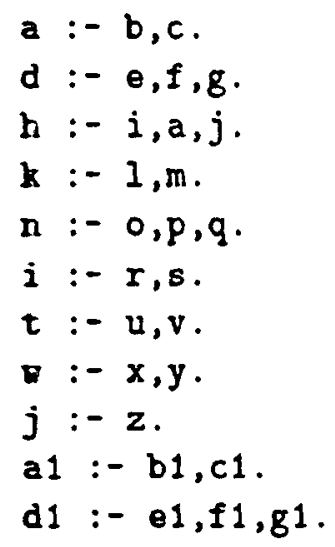

Se for feita a poda com relação a $h$, obtém-se o seguinte programa - equivalente ao anterior com relação a h.

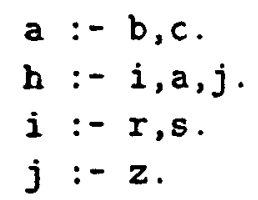

Expansão em linha: consiste em substituir a ativação de uma meta pela corpo da meta [Sawamura 85]. Várias notaçōes Prolog, semanticamente equivalentes, são utilizadas na literatura para representar essas substituições. Neste trabalho, será utilizada a forma que torna mais claros os efeitos da expansão em linha, dependendo do exemplo considerado. Para exemplificar o processo de expansão em linha, será considerado o seguinte programa:

$$
\begin{aligned}
& p:-q, r(X), s(X) . \\
& r(4):-a, b, c .
\end{aligned}
$$

Segue-se o resultado da aplicação do processo de expansão em linha sobre este programa, nas três notaçōes Prolog mais frequentemente utilizadas.

1. Substituir diretamente a meta pelo corpo da meta.

$$
p:-q, a, b, c, s(4) \text {. }
$$

2. Representar explicitamente as unificaçōes de variáveis.

$$
p:-q, x=4, a, b, c, s(x) .
$$

3. Representar explicitamente a unificação da meta com o cabeça da regra envolvida na expansão. 


$$
p:-q, r(x)=r(4), a, b, c, s(x) .
$$

A valiaçāo de funções internas: consiste em substituir uma variável pelo valor correspondente ao valor calculado pela função. Por exemplo, dada a cláusula

$$
h:-x \text { is } 5+4, t(x) \text {, }
$$

a meta $X$ is $5+4$ pode ser avaliada, obtendo-se o seguinte programa equivalente:

$$
\text { h: }:-x=9, t(9) \text {. }
$$

No exemplo a seguir, pode-se observar mais claramente os três mecanismos envolvidos na Avaliação Parcial:

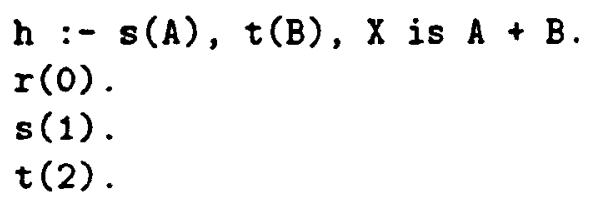

Após a expansão em linha tem-se:

$$
h:-A=1, B=2, X \text { is } 1+2 \text {. }
$$

Neste caso, é possível avaliar a meta $X$ is $1+2$. O programa final equivalente fica da seguinte forma:

$$
h:-A=1, B=2, X=3 \text {. }
$$

Pode-se observar que, como $r(X)$ não faz parte de nenhuma das submetas ativadas durante a Avaliação Parcial, $r(0)$ foi automaticamente eliminado pelo processo de poda.

\subsection{Avaliação Parcial de Programas Prolog}

$\mathrm{Na}$ seção anterior, foram introduzidos os conceitos básicos de Avaliação Parcial para programas lógicos. É claro porém que, no caso de uma implementação prática real, devem ser levados em conta algumas peculiaridades da implementação da linguagem lógica considerada - neste caso Prolog. Estas peculiaridades, ou impurezas, já são bem conhecidas por causar problemas no desenvolvimento de meta-interpretadores, compiladores, interpretadores e transformação de programas em geral. Os problemas mais importantes são causados pelos predicados extra-lógicos (tal como corte). A seguir são considerados alguns destes aspectos. 
Cláusulas Múltiplas: a expansão em linha de um predicado definido em cláusulas múltiplas não pode ser feita simplesmente como uma substituição direta. Neste caso, pode-se substituir a meta pela disjunção das submetas que unificam com essa meta. Portanto, a presença de cláusulas múltiplas causa a construção de disjunçōes explícitas. Por exemplo, dado o programa:

$t(X):-a(X, Y), h(Y)$.

$a(X, Y):-b(X, Y)$.

$a(X, Y):-c(X, Y)$.

a expansào em linha de $a(X, Y)$ gera:

$t(X):-(b(X, Y) ; c(X, Y)), h(Y)$.

Propagação Local de Valores: durante execução, a unificação de valores causa propagação desses valores através do corpo da regra, tanto para frente quanto para trás. A propagação para frente - progressiva - durante a Avaliação Parcial pode ser feita sem causar qualquer problema. Já a propagação dos valores para trás - regressiva - exige certos cuidados. No exemplo a seguir, pode-se ver um caso em que a propagaçào regressiva nào pode ser feita.

$t:-b(X)$, write(ok), $c(X)$.

$c(a)$.

Se fosse feita a expansão em linha e propagação regressiva dos valores, o programa ficaria assim:

$t:-b(a)$, write(ok), true.

Porém, este programa não é equivalente ao original, pois se $b(x)$ unificar com diversos valores distintos, a execução do primeiro programa escreveria "ok", para cada unificação feita, até que a meta $c(X)$ possa ser resolvida. No programa transformado, um único "ok" será impresso. Portanto, a propagação regressiva não pode ser feita neste caso. A transformação correta, neste caso, deve utilizar atribuiçāo explícita, gerando o seguinte programa:

$t:-b(x)$, write(ok), $X=a$.

Em geral, a propagação regressiva não pode ser realizada sobre construçōes que causam efeitos laterajs sem afetar a semântica operacional do programa. Atribuiçōes explícitas são necessárias somente quando a variável ocorre em alguma cláusula anterior dentro da mesma regra.

Quando a propagação progressiva ocorre juntamente com cláusulas múltiplas, ocorre duplicação do código. Por exemplo: 
$t:-a(x), b(x), c(x)$.

a(1).

$a(2)$.

Neste caso, o programa gerado por Avaliação Parcial será:

$t:-X=1, b(X), c(X) ; x=2, b(X), c(X)$.

Esta duplicação representa algum perigo, pois, em alguns casos, isto pode causar explosão do volume do código.

Propagação Global de Valores: a propagação global progressiva consiste em propagar qualquer instanciação parcial dos argumentos de uma meta para suas submetas. A propagação global recursiva consiste em instanciar os argumentos da meta com os valores encontrados durante a Avaliação da submeta. Por exemplo:

I :- $s(X), t(X)$, write $(X)$.

$s(B):-h(A), g(A, B)$.

$h(3)$.

$g(3,4)$.

$t(A):-B$ is $5+A$, write $(B), n l$.

A expansão em linha de $s(X)$ é true, mas deve haver uma propagação regressiva dos valores. Isto significa que, durante o processo de expansão de $s(X), X$ unificou com algum valor. Este valor deve então ser propagado até a meta principal de onde foi feita a expansão em linha e, em seguida, deve ser feita a propagação local dos valores, resultando no seguinte:

I :- true,t(4),write(4).

Agora, na avaliaçào de $t(X)$, o valor $X=4$ é propagado pela submeta, de modo que o resultado final da Avaliação Parcial será:

I :- true, B $=9$,write (9), nl,write(4).

Corte: sem dúvida, o corte representa um grande problema quando se faz a expansão em linha, pois um corte na cláusula original causa um fluxo de controle diferente do corte na cláusula em que foi feita a substituição. No exemplo a seguir, isto pode ser visto claramente. 


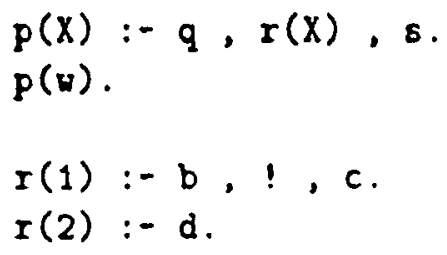

Supondo que, durante a execução, sejam fornecidos os seguintes fatos:

$$
\{q, b, d, \operatorname{not}(c)\}
$$

Neste caso, quando $\mathrm{p}(\mathrm{X})$ é ativado, $\mathrm{q}$ é provado. Em seguida, $\mathrm{r}(\mathrm{X})$ é ativado, unificando com a primeira cláusula. Porém, $c$ falha e, como c está após o corte, $r(X)$ falha. Neste caso $p(X)$ é provado com a segunda cláusula de $p$, ou seja, $p(w)$, como mostrado a seguir:

?- $p(A)$.

$A=->$;

no

Se for feita a expansão em linha, o programa ficará da seguinte forma:

$$
\begin{aligned}
& p(x):-q,(x=1, b, !, c ; x=2, d), s . \\
& p(w) .
\end{aligned}
$$

Neste caso, quando $c$ falha, $p(X)$ também falha, pois o corte está presente no corpo de $\mathrm{p}(\mathrm{X})$.

?- $p(X)$.

no

Recursividade: no caso da substituição em linha para predicados recursivos, dois casos podem ocorrer:

- Se os parâmetros de entrada estão suficientemente instanciados, a expansão pode ser feita completamente, também de modo recursivo. Por exemplo:

$t:-r(R, S)$, append $([a, b, c], R, M)$.

append $([X \mid A], B,[X \mid C]):-\operatorname{append}(A, B, C)$.

append $([], L, L)$.

O programa $t$ transformado deve ficar da seguinte forma:

$t:-r(R, S), M=[a, b, c \mid R]$. 
- Se os parâmetros de entrada nào estão suficientemente instanciados, a expansão em linha pode gerar um loop infinito durante a Avaliaçāo Parcial. Neste caso, somente o primeiro passo da expansão deve ser feito. Por exemplo:

$t:-r(R, S)$, append $(R, S, M)$.

Neste caso, os argumentos não estão suficientemente instanciados para a expansão completa. Expandindo-se uma única vez, tem-se o seguinte programa:

$t:-r(R, S), R=[X \mid R 1], M=[X \mid M 1]$, append $(R 1, S, M 1)$.

No entanto, é um problema em aberto descobrir, através de análise do programa, quando uma meta está ou não suficientemente instanciada para que possa ser expandida.

\subsection{Um Avaliador Parcial Básico para Prolog}

A seguir encontra-se o programa que implementa o algoritmo básico de Avaliação Parcial [Fujita 87a], que é similar ao algoritmo de busca utilizado para encontrar todas as soluçōes de uma dada meta - programa 5.3. Pode-se observar que ele é muito limitado, não levando em consideração os casos de metas não determinísticas - cláusulas múltiplas.

Programa 6.1 Avaliador Parcial Básico

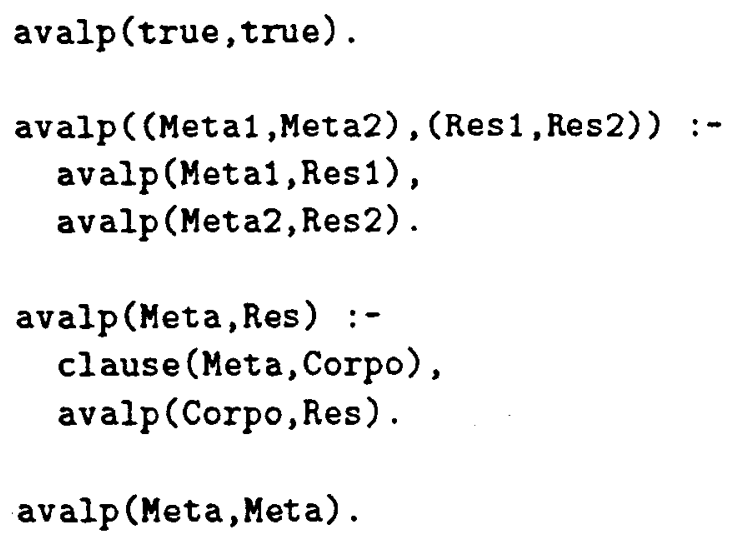

O programa a seguir será utilizado para mostrar como o Avaliador Parcial acima especializa um dado programa Prolog. 
Programa 6.2 Gerador de Relatórios

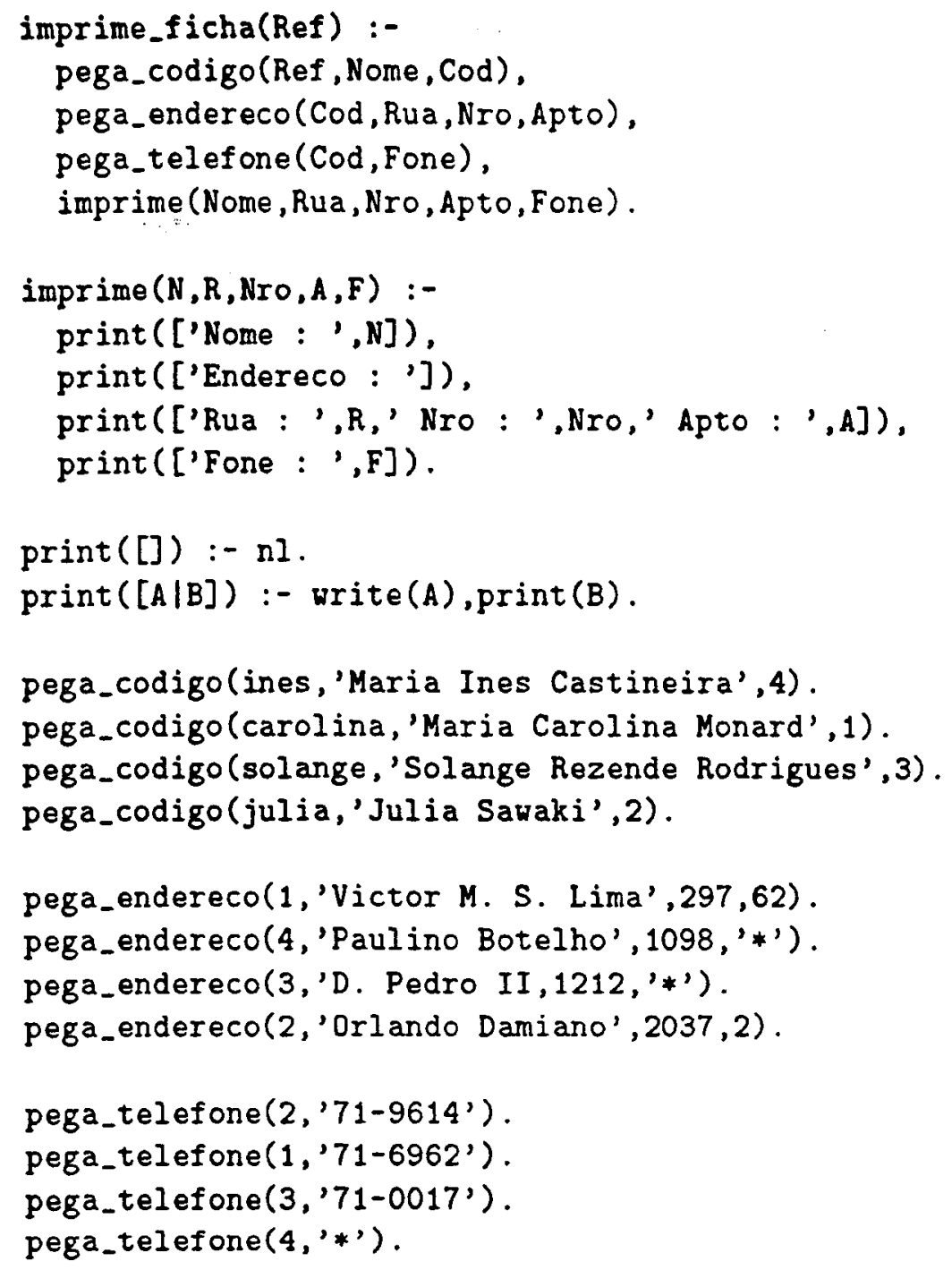

Se o programa acima for avaliado parcialmente por avalp/2 em relação à meta imprime_ficha(solange), os seguintes passos devem ser executados:

Primeiramente, a cláusula imprime_ficha(Ref) é ativada, causando a seguinte unificação: Ref = solange. Em seguida, ocorre a propagação progressiva, deixando a definição de imprime_ficha(solange) da seguinte forma:

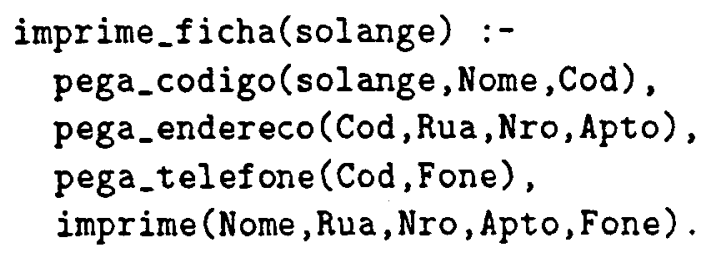

A seguir, a cláusula pega_codigo(solange,Nome, Cod) é ativada, unificando com a seguinte cláusula: 


\section{pega_codigo(solange, 'Solange Rezende Rodrigues', 3).}

Deste modo, Nome unifica com 'Solange Rezende Rodrigues' e Cod unifica com 3. Estes valores são propagados por toda a meta - propagação progressiva - e, em seguida, a meta é substituída pelo corpo da meta, que é true - expansão em linha. Neste caso, obtém-se:

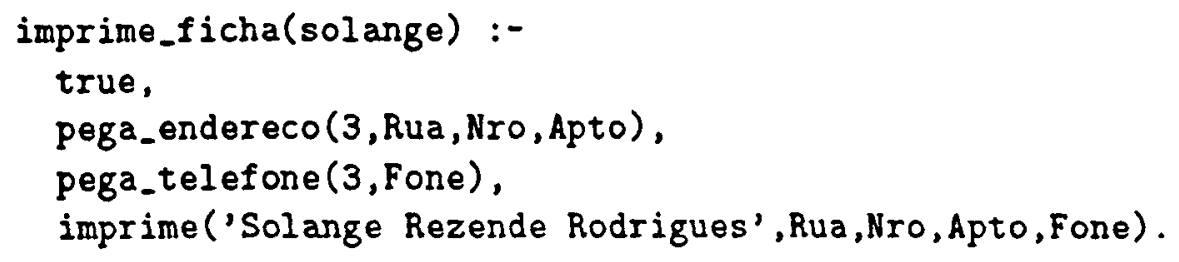

Seguindo o mesmo método, o programa ficará da seguinte forma:

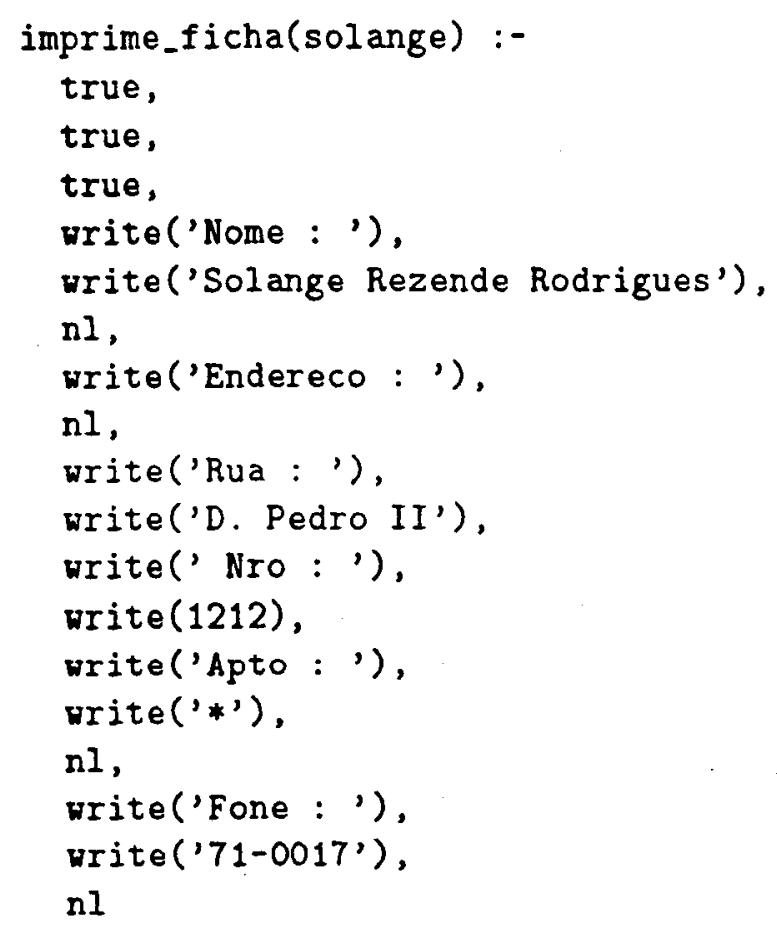

De fato, o resultado da execução de avalp/2 para este caso é:

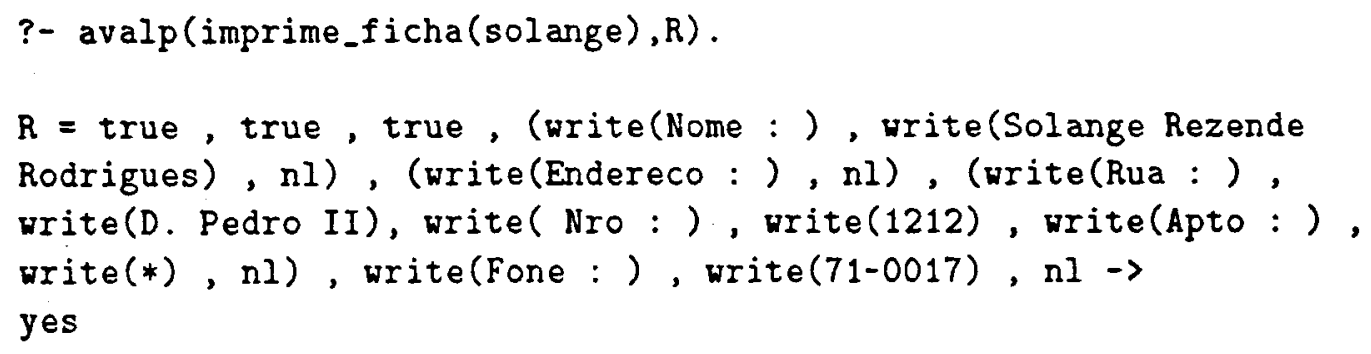


O programa residual acima pode ser melhorado se os átomos true e os parênteses desnecessários forem eliminados. Assim, o programa especializado será:

Programa 6.3 Gemdor de Relatório Especifico

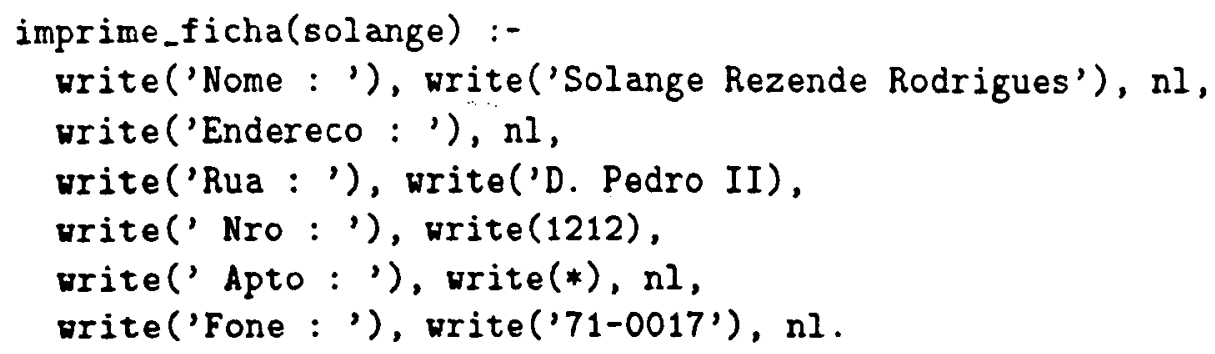

É fácil de se ver que a execução de imprime_ficha(solange) é mais eficiente no programa 6.3 que no programa 6.2 , pois serão realizadas menos inferências lógicas.

\subsection{Decisões de Controle na Avaliação Parcial}

Os efeitos da Avaliação Parcial na performance do programa devem- se, principalmente, ao aumento do determinismo gerado pela substituição da meta pelo corpo da meta [Venken 88]. Numa projeção muito otimista, um sistema de Avaliação Parcial deveria tornar programadores comuns capazes de exibir a mesma habilidade que programadores especialistas na confecção de programas eficientes. Porém, a maioria dos sistemas de Avaliação Parcial implementados necessita da interação humana, e a qualidade do programa especializado por estes sistemas de Avaliação Parcial depende da qualidade da interação humana. Neste caso, a exigência de especialistas em programação é substituida pela necessidade de especialistas em Avaliação Parcial [Takeuchi 88].

Existem sérios problemas en controlar automaticamente Avaliadores parciais gerais, pois eles podem realizar uma série de operações indesejáveis. Sterling identifica quatro resultados primários no controle da Avaliação Parcial [Sterling 86] [Sterling 89]:

- decidir quando expandir ou não uma meta;

- detectar loops infinitos;

- decidir quando uma meta pode ser avaliada;

- tratar programas abertos.

A primeira e mais importante decisão de controle é quando expandir ou não uma meta. Um extremo seria expandir toda meta, convertendo o programa em um conjunto de fatos. Porém, este processo é exponencial e não muito desejável para grandes programas. Takeuchi descreve um esquema que permite ao usuário declarar o conhecimento necessário para controlar o processo de expansão [Takeuchi 86a] [Lakhotia 90]. 
A segunda decisào de controle consiste em detectar loops infinitos, pois mesmo uma computação finita pode causar um loop infinito na Avaliação Parcial, caso os argumentos não estejam suficientemente instanciados.

A terccira decisão de controle diz respeito à avaliabilidade da meta. Em geral, o usuário deve indicar quando uma meta é avaliável por declaraçōes explícitas. Por exemplo, $X$ is $4+3$ é uma meta avaliável, enquanto $A$ is $B+C$ só será avaliável se $B$ e $C$ estiverem instanciadas.

A última decisão de controle relaciona-se a programas abertos. Um programa é aberto se algumas das metas são deixadas intencionalmente indefinidas durante a Avaliação Parcial. Isto pode ser útil no caso de sistemas especialistas, caso alguns dados sejam fornecidos posteriormente pelo usuário do sistema. Em geral, as decisões de controle são feitas explicitamente pelo usuário, e são elas que dificultam a construção de um Avaliador Parcial geral automático. Alguns Avaliadores parciais construídos para uso especifico possuem rotinas que realizam automaticamente as decisões de controle.

\subsection{Considerações Finais}

Neste capítulo foram discutidos os conceitos de Avaliação Parcial de programas, destacando as principais vantagens e as maiores dificuldades na implementação de um Avaliador Parcial.

Foi observado que a Avaliação Parcial pode ser um recurso muito útil como um auxílio a programadores, pois os programas são especializados, eliminando-se os níveis extras de interpretação.

Foram discutidos os mecanismos que podem ser aplicados na Avaliação Parcial, tais como poda, expansão em linha e avaliaşão de funçōes internas.

Mostrou-se que as maiores dificuldades na implementação de um Avaliador Parcial são causadas pela presenşa de predicados extra-lógicos na linguagem Prolog. Alguns aspectos mais importantes foram considerados, tais como: corte, propagação local e global de valores, cláusulas múltiplas e recursividade.

Um Avaliador Parcial básico para Prolog foi apresentado, juntamente com um exemplo que mostra seu funcionamento.

Finalmente, foram destacados os problemas de controle de um Avaliador Parcial, comentando-se sobre as principais decisōes de controle, tais como: quando expandir uma meta, controle de loops infinitos, quando avaliar uma meta, programas abertos. Alguns destes pontos estão ainda sendo pesquisados, enquanto outros serão discutidos com mais detalhes no capítulo seguinte. 


\section{Capítulo 7}

\section{Uso de Avaliação Parcial na Construção de Sistemas Especialistas}

\subsection{Considerações Iniciais}

Como foi visto no Capítulo 5, um dos principais usos de meta-interpretadores é na construção de Sistemas Especialistas. Neste capítulo são discutidos os dois métodos mais utilizados na construção de Sistemas Especialistas. Além disso, é apresentada uma proposta baseada nas técnicas de Avaliação Parcial para aproveitar as vantagens de ambos os métodos, tentando eliminar suas desvantagens.

\subsection{Meta-interpretadores na Construção de Sistemas Es- pecialistas}

Geralmente, um Sistema Especialista é decomposto em Motor de Inferência e Base de Conhecimento. Algumas Bases de Conhecimento podem ser escritas diretamente em Prolog, pois a linguagem Prolog possui seu próprio Motor de Inferência. Neste caso, tem-se uma Base de Conhecimento executável.

Entretanto, existem diversas caracteristicas importantes na implementação de Sistemas Especialistas que não são fornecidas pela linguagem Prolog, tais como mecanismo de explicação ou raciocíno com incerteza [Clocksin 87] [Merrit 89] [Monard 89a], bem como raciocínio não monotônico [Monard 86] [Monard 87].

Uma possível solução para manipular raciocínio com incerteza é incluir estas características diretamente à Base de Conhecimento. Neste caso, alguns argumentos extras são adicionados a cada predicado para armazenar a informação necessária, tal como grau de certeza ou árvore de prova [Monard 89c]. Esta solução mantém a eficiência 
da execuşão, pois a Base de Conhecimento continua sendo uma Base de Conhecimento executável. No entanto, a modularidade e a clareza da Base de Conhecimento são sacrificadas, pois um programa que é puramente declarativo é modificado e passa a conter detalhes procedimentais, como por exemplo o cálculo do fator de certeza, bem como argumentos adicionais que, em geral, tornam as regras um tanto confusas [Walker 87].

Um método alternativo é baseado em meta-programação [Rodrigues 90c]. Neste caso, a Base de Conhecimento é mantida intacta e as características adicionais são incorporadas a meta-interpretadores. Este método mantém a clareza e modularidade da Base de Conhecimento, mas sacrifica a eficiência, pois cada nível de interpretação representa um alto custo na performance do sistema. Entretanto, é possível utilizar Avaliação Parcial para melhorar a eficiência de meta-interpretadores [Takeuchi 86b]. Neste caso, a A valiação Parcial é utilizada para transformar todas as chamadas indiretas via metainterpretador em chamadas diretas, eliminando o nível extra de interpretação imposto pelo uso de meta-programação [Levi 88].

\subsection{Avaliação Parcial de Meta-interpretadores}

Como visto na seção 5.2, um meta-programa é um programa que trata programas como dados. Assin, pode-se dizer que, em um Sistema Especialista, a Base de Conhecimento é o dado de entrada para o Motor de Inferência, que por sua vez é implementado utilizando-se meta-interpretadores. Neste caso, o Motor de Inferência pode ser avaliado parcialmente com relação à Base de Conhecimento, gerando um Motor de Inferência especializado para uma dada Base de Conhecimento [Takeuchi 86a]. Partindo-se deste princípio, é possível escrever um Sistema Especialista baseado em meta-interpretadores e Base de Conhecimento independentes que, após a depuração, com o sistema pronto para ser utilizado, é transformado em um programa eficiente via Avaliação Parcial [Furukawa 89]. Este método incorpora as vantagens da Base de Conhecimento executável e do sistema modular com meta-interpretadores, eliminando suas desvantagens [Sterling 89].

Para exemplificar o método, são utilizados o meta-interpretador Arv-Prova - programa 5.4, página 47- e a Base de Conhecimento Korez - programa 5.1, página 43. Após a Avaliação Parcial do meta-interpretador em relação à Base de Conhecimento, o programa especializado esperado seria o seguinte:

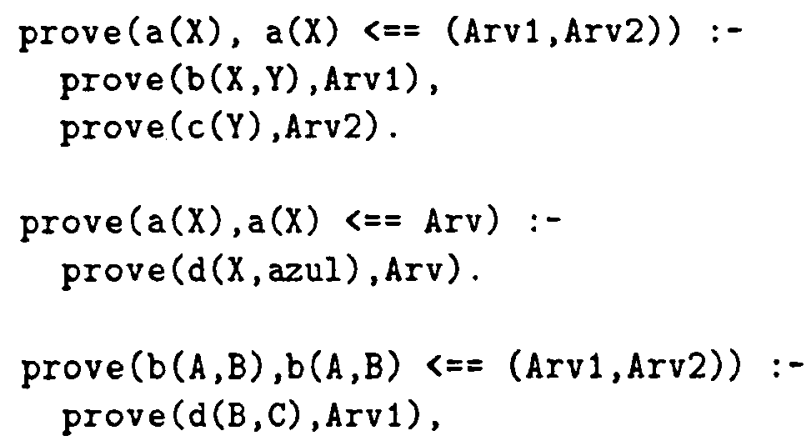




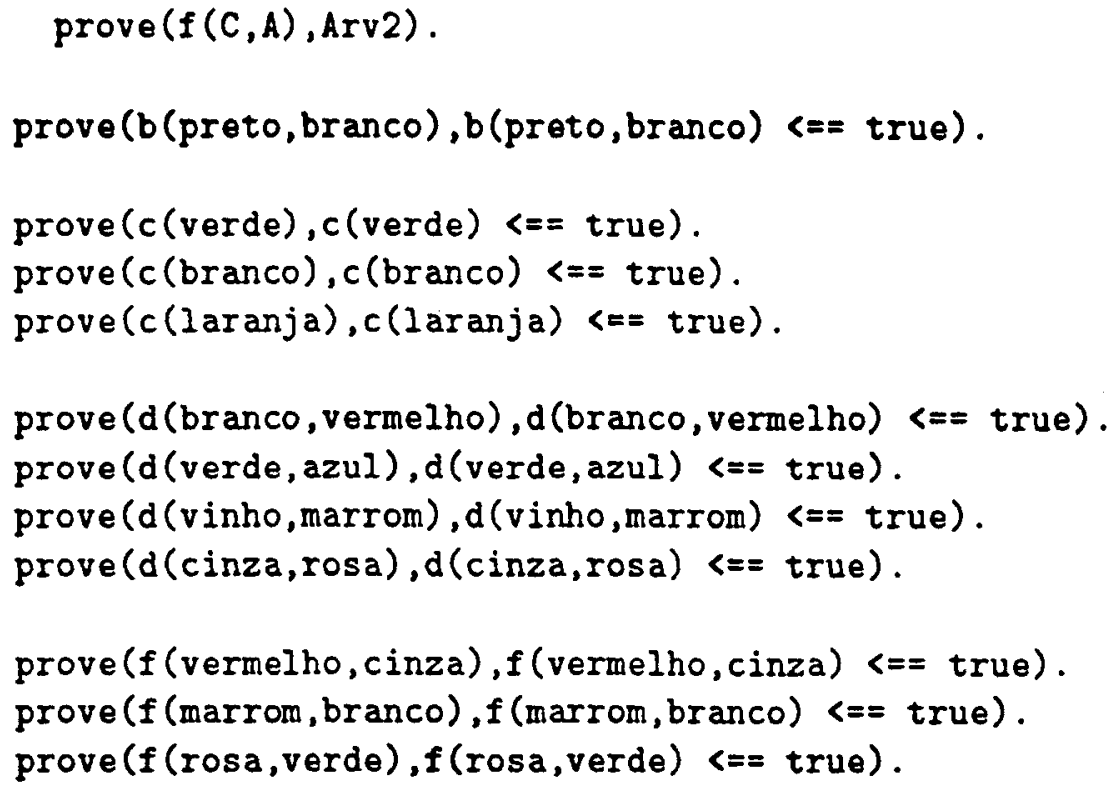

Deve ser observado que, neste caso, a Avaliação Parcial eliminou apenas o nível extra de interpretação imposto pelo meta-interpretador. Deste modo, o programa especializado mostrado acima pode ser novamente avaliado parcialmente, caso haja interesse em eliminar também os níveis de interpretação criados pela forma como a Base de Conhecimento foi escrita. Neste caso, é necessário um Avaliador Parcial geral, que é bem mais complexo que um Avaliador Parcial utilizado para eliminar somente o nivel extra de interpretação, como foi exemplificado acima.

\subsection{Avaliadores Parciais Gerais e Específicos}

Como mencionado no capítulo anterior, a qualidade dos programas especializados por sistemas de Avaliação Parcial que interagem com o usuário dependem da qualidade da interação com o usuário. Por esse motivo, grandes esforços têm sido feitos no sentido de construir Avaliadores Parciais automáticos.

É obvio que um Avaliador Parcial geral é muito difícil de ser automatizado. Porém, um Avaliador Parcial dirigido a uma determinada classe de programas, cujas características sejam bem conhecidas, pode ser satisfatoriamente construído de modo a não exigir intervenção do usuário. Como exemplo de uma classe de programas cujas características são bem conhecidas, pode-se citar os meta-interpretadores, cujas principais características são mostradas no capitulo 5.

Deste modo, pode-se afirmar que um Avaliador Parcial para especializar meta-interpretadores com relação a uma Base de Conhecimento não é tão complexo quanto um Avaliador Parcial geral, já que ele é dirigido a uma classe restrita de programas. A construção de um Avaliador Parcial automático, neste caso, implica em descobrir algumas características que possam ser relacionadas ao controle da Avaliação Parcial.

Sterling [Sterling 86] mostra como solucionar alguns problemas relacionados ao controle 
da Avaliação Parcial na Avaliaçào Parcial de meta-interpretadores. As soluçōes por ele propostas são:

- Quanto ao controle da expansão, seu Avaliador Parcial apresenta uma declarasão deve_expandir/1 que decide quando uma meta deve ser expandida, sem a necessidade da participação do usuário no processo de decisão;

- O controle de loops infinitos é feito mantendo-se uma pilha de metas pendentes. Um loop infinito é detectado quando uma meta a ser avaliada parcialmente é uma instanciação de alguma meta da pilha. Quando um loop é detectado, a meta nāo é mais expandida.

Deve ser observado que o Avaliador Parcial de Takeuchi [Takeuchi 86a] utiliza o mesmo método, mas permite ao Avaliador Parcial continuar a expansão após a deteç̧ão de um loop, caso seja de interesse do usuário.

\subsection{O Controle de Expansão na Avaliação Parcial}

O Avaliador Parcial básico, mostrado no Capítulo anterior, não possui nenhum controle de expansão das metas. Isto significa que toda meta é expandida até que mais nenhuma expansào possa ser feita, gerando um programa composto essencialmente por um conjunto de fatos e de relações de sistema. Em sistemas grandes esta idéia não parece muito satisfatória, pois este processo de expansão pode tornar-se exponencial. O programa abaixo é uma melhoria do Avaliador Parcial do Capítulo 6, incorporando o predicado deve_expandir(Meta), que decide quando uma meta deve ser expandida ou não. Este predicado é a chave para se alcançar o resultado esperado por um sistema de Avaliação Parcial [Lakhotia 90].

Programa 7.1 Avaliador Parcial utilizando critério de expansão.

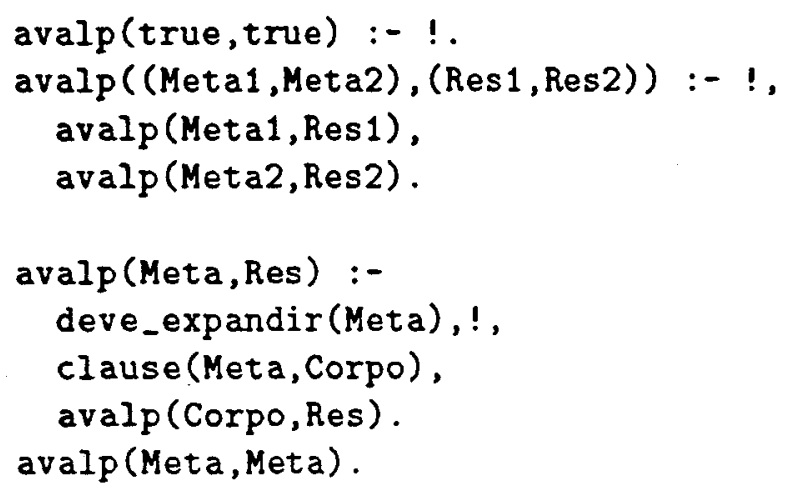

No estágio atual das pesquisas no campo da Avaliação Parcial de programas Prolog, este conhecimento não pode ser extraído através de uma análise do programa, seja 
ela estática ou dinâmica. Este conhecimento deve ser fornecido pelo programador, através de declarasooes explícitas para o programa. No entanto, um estudo sobre o funcionamento dos meta-interpretadores pode fornecer algumas diretrizes que facilitem o trabalho do programador.

\subsubsection{Como Trabalha um Meta-Interpretador}

Um interpretador realiza duas funçōes. Primeiramente, ele analisa a estrutura dos termos de entrada para verificar se ela pertence à linguagem sendo interpretada - ação sintática. Em seguida, ele simula o procedimento operacional associado à estrutura que foj analisada - ação semàntica.

Os meta-interpretadores descritos no capítulo 2 interpretam estruturas que são termos Prolog válidos - regras ou cláusulas de Horn. Estes interpretadores analisam uma regra unificando-a com esqueletos de estruturas aceitáveis pela linguagem, extraindo seus subtermos e analisando-os recursivamente. A fase de análise termina quando um símbolo atômico da linguagem é encontrado, mesmo que a interpretação possa continuar a partir da execução das ações semânticas associadas a este símbolo atômico. Os símbolos atômicos que acarretam interpretação de outras regras são chamados de símbolos não terminais. Os símbolos atômicos terminajs, por sua vez, são aqueles que não acarretam interpretação, como, por exemplo, os predicados pré-definidos do sistema no caso do meta-interpretador Arv-Sistema - programa 5.10. Neste caso, eles são considerados símbolos terminais.

\subsubsection{Critério de Expansão}

O nivel extra de interpretação apresentado pelos meta-interpretadores deve-se, principalmente, à análise da estrutura do programa interpretado durante a execução. Supondo que um meta-interpretador é parcialmente avaliado de modo que toda ação relativa à análise do programa é completamente executada, o residuo, após a Avaliação Parcial, consistirá de ações semânticas associadas a analisar e processar símbolos atômicos. Portanto, neste caso, o resíduo para uma regra teria o mesmo procedimento de execução anterior, mas estaria livre do nível extra de interpretação.

As metas no resíduo que estão suficientemente instanciadas para execução podem ser ainda executadas parcialmente durante o processo de Avaliação Parcial. Como neste caso nāo ocorre nenhum nível extra de interpretação, essa pré-execução pode ser considerada análoga às otimizaçōes feitas por pré-compiladores [Lakhotia 90]. Como já mencionado na seção 6.4 , é um problema em aberto decidir automaticamente quando uma meta está ou não suficientemente instanciada para execução parcial.

$\mathrm{Na}$ especialização de meta-interpretadores, o interesse primário é remover o nível extra de interpretação. As otimizaçōes por pré-execução de ações semânticas, apesar de importantes, são secundárias. Os critérios de expansão descritos a seguir baseiam-se nos efeitos que eles produzem. 


\subsubsection{Alguns Critérios para Remover o Nivel Extra de Interpretação}

A análise da estrutura do programa a ser interpretado é fejta unindo-se estas estruturas aos construtores da linguagem interpretada. A seguir, esta estrutura é decomposta para que seus componentes possam ser analisados recursivamente. Isto significa que o metainterpretador decompõe algumas estruturas durante a fase de análise.

Neste trabalho, os procedimentos que participam da fase de análise são chamados metas ativas. Os argumentos de uma meta ativa são chamados meta-argumentos.

O primeiro critério de expansão para uma meta consiste em expandir somente as metas ativas cujos meta-argumentos estão ligados a uma estrutura que pode ser decomposta pelo meta-interpretador. Este critério pode ser implementado em Prolog da seguinte forma:

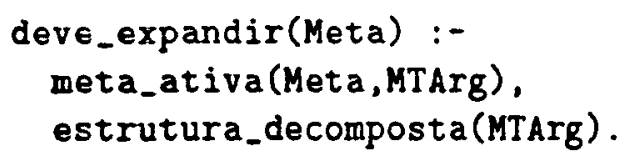

O predicado meta_ativa/2 identifica se uma meta é uma meta ativa, identificando seus meta-argumentos. Para verificar se os meta argumentos pertencem ao conjunto de estruturas que podem ser decompostas pelo meta-interpretados, usa-se o predicado estrutura_decomposta/1. Expandindo somente as metas ativas que carregam argumentos que podem ser decompostos pelo interpretador, evita-se que metas que processam símbolos atômicos sejam expandidas.

As declaraçōes meta_ativa/2 e estrutura_decomposta/1 são definidas explicitamente, dependendo exclusivamente do meta-interpretador que será especializado. Por exemplo, no caso do meta-interpretador Cristalino - programa 5.11 -, as declarações são:

meta_ativa(prove(Meta,Arv), Meta).

estrutura_decomposta(true).

estrutura_decomposta(not $X)$.

estrutura_decomposta $((A, B))$.

\subsubsection{Pré-execução de Símbolos Atômicos}

As regras acima abstêm-se de expandir cláusulas que processam símbolos atómicos que podem acarretar interpretação para outras regras. Porém, nem todo símbolo atômico acarreta interpretação. Assim, pode ser conveniente expandir o processamento dos símbolos atômicos que concluem a interpretação, como mostrado a seguir.

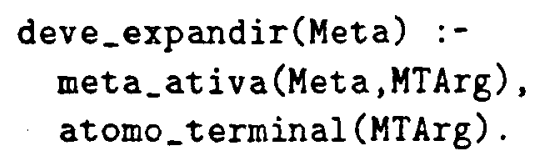


No caso do meta-jnterpretador Cristalino, os átomos terminais são os predicados do sistema e as relaçôes primitivas - declaradas como primitiva(Meta). Neste caso, o conhecimento é indicado para o Avaliador Parcial da seguinte forma:

atomo_terminal (Meta) :- sistema(Meta).

atomo_terminal(Meta) :- primitiva(Meta).

\subsubsection{Cláusulas Múltiplas}

Como citado no capítulo anterior, um dos problemas na expansão ocorre quando uma meta possui mais que uma instanciação para clause(Meta,Corpo), isto é, múltiplas cláusulas definem o mesmo predicado.

A expansāo em cláusulas disjuntas nem sempre é a melhor solução. Para a implementaçào do avaliador parcial desenvol vido neste trabalho, adotou-se o seguinte critério: só serão expandidas as metas cuja expansão é única. Este critério é implementado da seguinte forma:

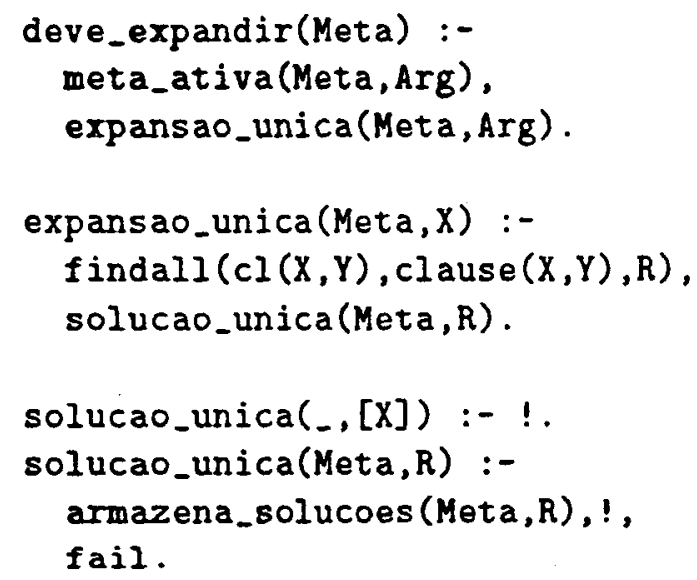

Quando não existe uma única solução, as soluções existentes são armazenadas para que,posteriormente, possam ser expandidas individualmente.

\subsubsection{Como Garantir a Expansão Correta}

Após certificar-se que a meta pode ser expandida, é necessário um mecanismo que realize a expansão correta entre as diversas expansões possíveis, pois muitas cl'ausulas do meta-interpretador podem ser unificadas com uma dada meta.

Quando a meta ativa é uma estrutura decomposta pelo meta-interpretador, a expansão feita é sempre a correta, o que nào ocorre no caso dos átomos terminais. A verificação é feita utilizando o predicado verifica(Meta): 


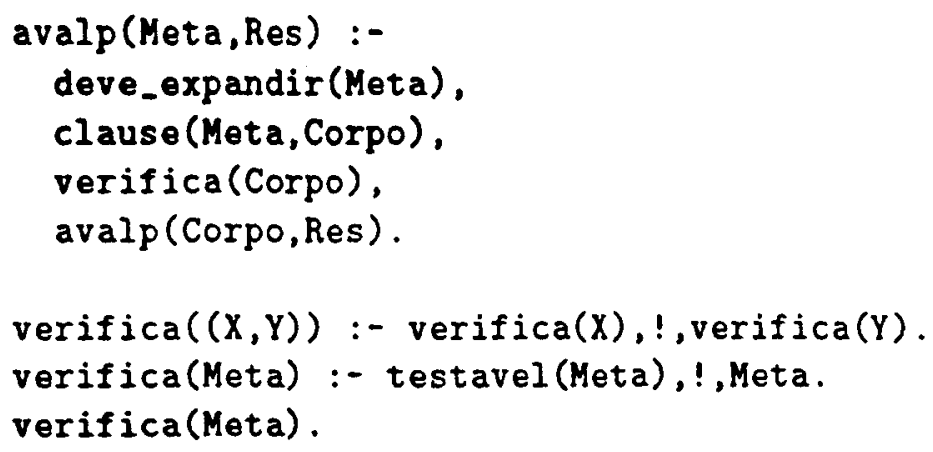

\subsection{Otimizaçōes Durante a Avaliação Parcial}

Caso haja interesse em expandir metas realizando pré-execução das ações semânticas, pode-se utilizar um esquema de anotaçôes explícitas para o Avaliador Parcial semelhante ao proposto por Takeuchi. Neste caso as metas são classificadas em residuais, parcialmente avaliáveis e totalmente avaliáveis. Uma meta residual não deve ser expandida, ou seja, torna-se um resíduo. As metas totalmente avaliáveis podem ser executadas diretamente pelo motor de inferência de Prolog. As metas parcialmente avaliáveis continuam sendo expandidas [Takeuchi 86a].

O esquema de anotaçōes explícitas, neste caso, é feito da seguinte forma. Uma meta residual é declarada como residual (Meta). Uma meta totalmente avaliável é declarada como totalmente_avaliavel (Meta). Uma meta que nào for declarada nem como residual nem como totalmente avaliável é considerada como parcialmente avaliável.

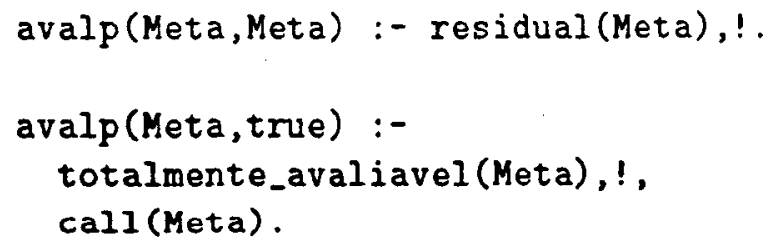

Os predicados pré-definidos do sistema não podem ser definidos como parcialmente avaliáveis, pois eles não podem ser expandidos. Portanto, eles devem ser residuais ou totalmente avaliáveis. Pode-se observar, porém, que estes predicados são independentes do programa que está sendo avaliado, pois são internos a.o sistema. Deste modo, eles podem ser tratados separadamente pelo Avaliador Parcial. Isto pode ser feito mantendose uma base de informaçōes globais sobre o sistema, implementada como declaraçōes executavel/1. Esta declaração informa ao sistema quando um predicado do sistema pode ser executado. A seguir estão alguns exemplos de predicados executáveis.

executavel ( $X$ is $Y+Z$ ) :- nonvar $(X)$, nonvar $(Z)$. executavel (int_text ( $I, T)$ ) :- nonvar(I); nonvar(T).

O Avaliador Parcial apresentado anteriormente pode ser incrementado para conter estas novas características, ficando da seguinte forma: 
Programa 7.2 Avaliador Parcial Completo

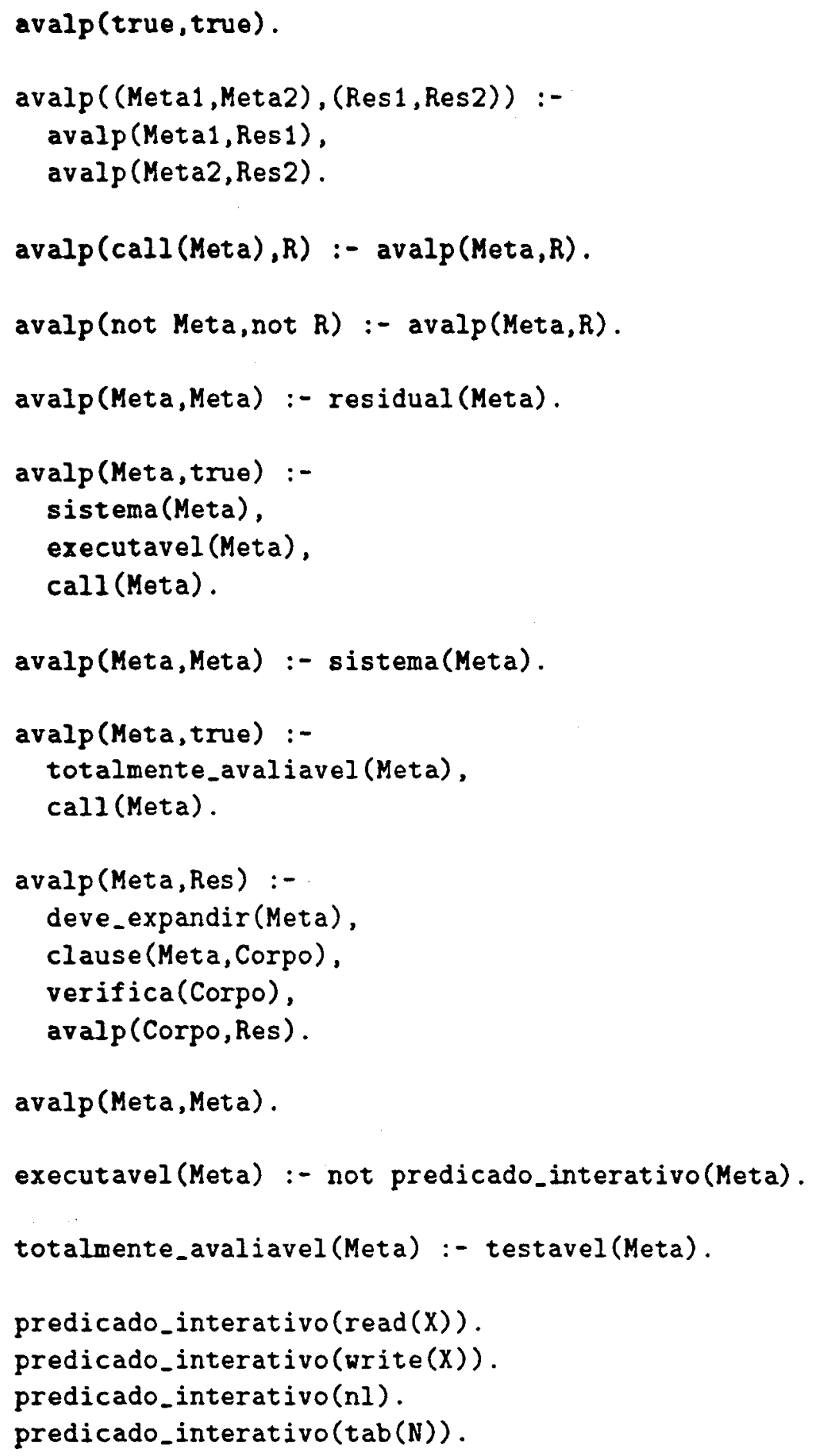




\subsection{Exemplo de Especificação para o Avaliador Parcial}

Nesta seção, será mostrado como o avaliador parcial descrito na seção anterior pode ser utilizado com um meta-interpretador específico.

Para isto, utiliza-se o meta-interpretador a seguir, que constitui um subconjunto do Núcleo de Sistemas Especialistas Geral [Monard 89b].

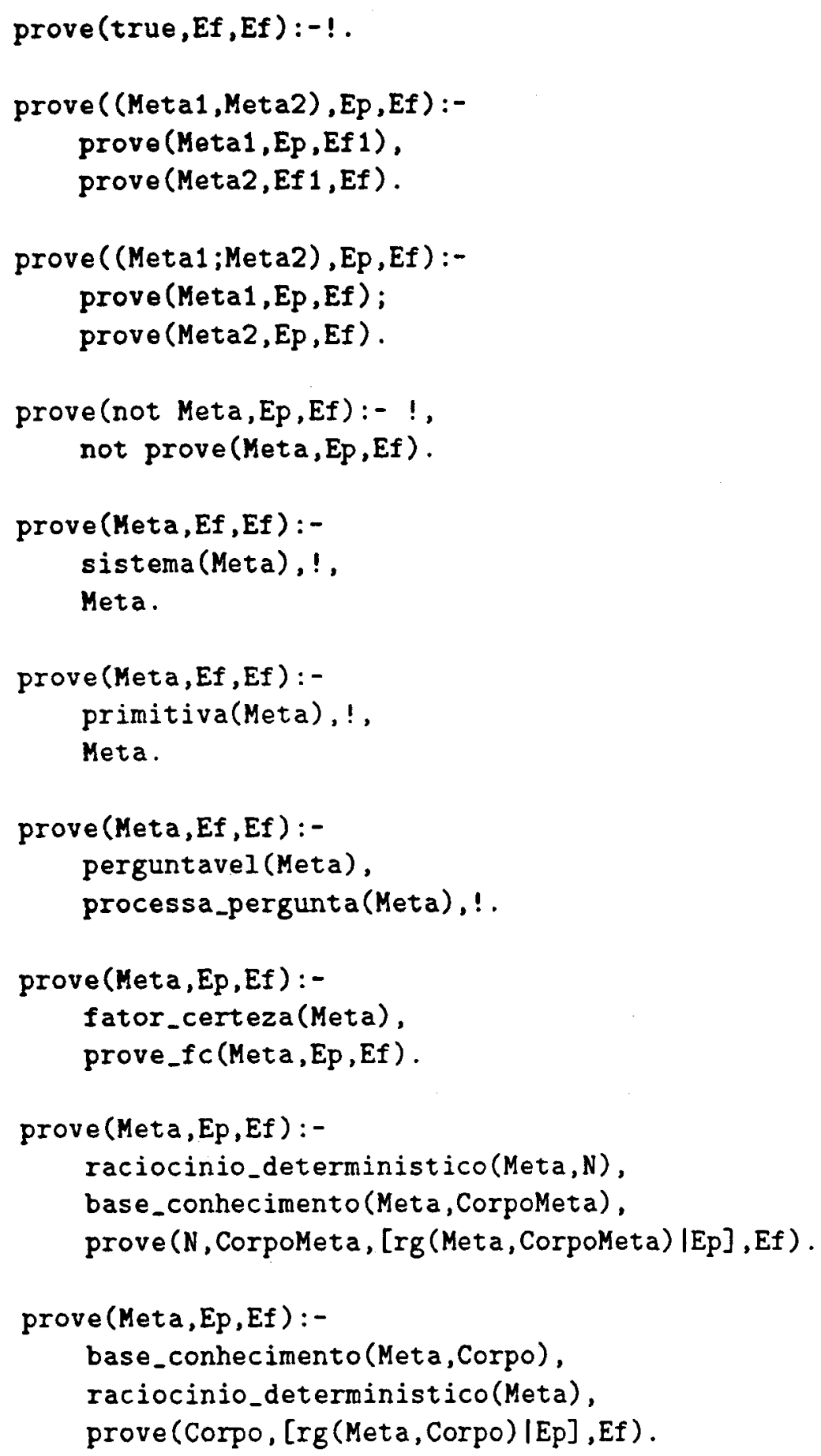


Para que o avaliador parcial possa ser utilzado com este meta-interpretador, devem ser definidas as estruturas decompostas, os átomos terminais, as metas residuais e os predicados sujeitos a verificação, que geralmente estão ligados aos átomos terminajs.

- identificaçào dos meta-argumentos

meta_ativa(prove(Meta,.,., ), Meta).

- estruturas decompostas pelo meta-interpretador

estrutura_decomposta(true).

estrutura_decomposta $((A, B))$.

estrutura_decomposta $((A ; B))$.

estrutura_decomposta(not $X)$.

- atomos terminais

atomo_terminal (Meta) :- primitiva(Meta).

atomo_terminal (Meta) :- sistema(Meta).

atomo_terminal (Meta) :- perguntavel(Meta).

atomo_terminal (Meta) :- fator_certeza(Meta).

- metas residuajs

residual(Meta) :- primitiva(Meta).

- predicados testáveis

testavel (sistema $(X))$.

testavel (primitiva( $(X)$ ).

testavel (perguntavel $(X)$ ).

testavel (fator_certeza( $X)$ ).

testavel (raciocinio_deterministico $(X)$ ).

testavel (raciocinio_deterministico $(X, N)$ ).

\subsection{Eliminação do Meta-Interpretador}

Um passo adicional que pode ser adicionado à avaliação parcial é a eliminação do metainterpretador, retirando seus meta-argumentos e transformando-os no nome da cláusula, do mesmo modo que a base de conhecimento original antes da avaliação parcial.

Este processo é simples e pode ser feito utilizando-se o programa a seguir. O predicado elimina_mti tem quatro parâmetros. Os dois primeiros são respectivamente a cabeça e o corpo da meta; os dois últimos são os primeiros com a eliminação do meta-interpretador. A eliminação do meta-interpretador é feita individualmente pelo predicado elimina_meta, elimina o meta-interpretador nas metas em que ele aparece e não altera as demais metas. 


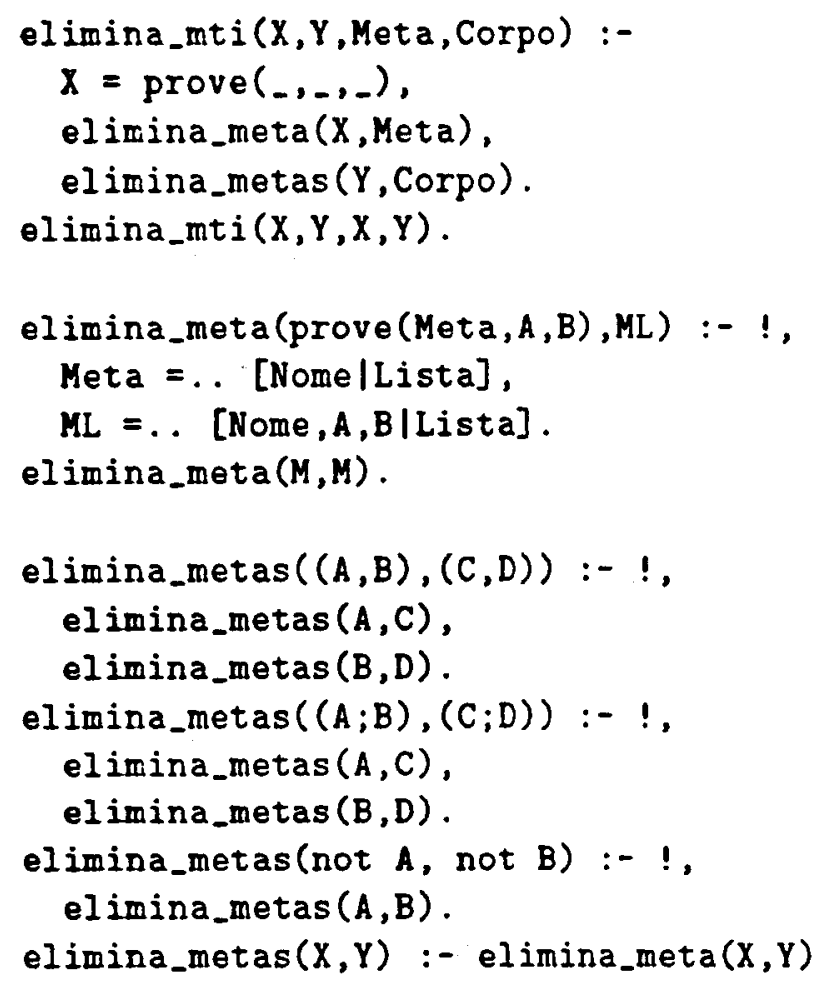

\subsection{Exemplo de Utilização}

Para um melhor entendimento de como trabalha o avaliador parcial, sāo mostrados alguns exemplos ${ }^{1}$ :

Exemplo 1 : Neste primeiro exemplo, utiliza-se a Base de Connhecimento Korez programa 5.1 , página 43.

Após a Avaliação Parcial em prove $(\mathrm{a}(\mathrm{X}),[]$, Arv), o resultado é:

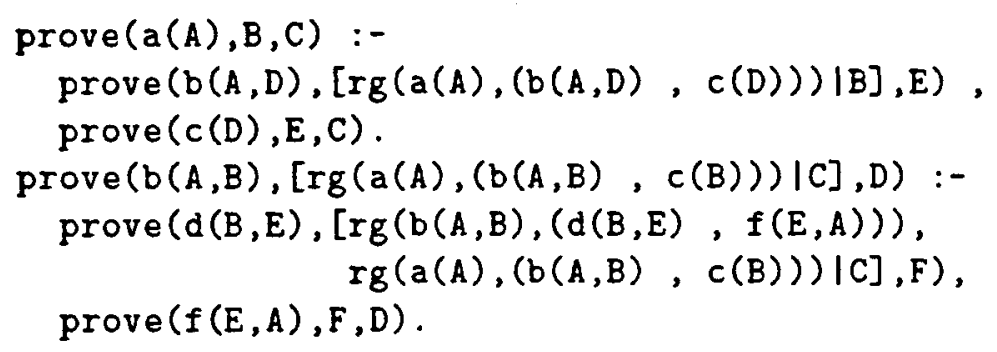

\footnotetext{
${ }^{1}$ Nos exemplos aqui apresentados, para facilitar a compreensâo, são utilizadas Bases de Conhecimento que não fazem interaçào com o meio externo
} 
prove (b(preto,branco), [rg(a(preto), (b(preto,branco), $c$ (branco))

)$[A],[r g(b$ (preto, branco), true), rg (a (preto), (b (preto,branco), $c($ branco $))(A]):-$

true.

prove (c(verde), $A,[r g(c(v e r d e)$, true $) \mid A]):-$ true.

prove (c(branco), $A,[$ rg $(c($ branco $)$, true $) \mid A]):-$ true.

prove (c(laranja), $A,[r g(c(\operatorname{laranja})$, true $) \mid A]):-$ true .

prove (d (branco, vermelho), [rg ( $b$ ( $A, b r a n c o),(d$ (branco, vermelho), $f($ vermelho, $A))), \operatorname{Ig}(a(A),(b(A, b r a n c o), c(b r a n c o))) \mid B]$, [ Ig (d (branco, vermelho), true), Ig ( $b$ ( $A, b r a n c o),(d$ (branco, vermelho $), f($ vermelho, $A))), \operatorname{rg}(a(A),(b(A, b r a n c o)$, $c($ branco $)\})(B]):-$

true.

prove (d(verde, azul),$[\operatorname{Ig}(b(A, v e r d e),(d(v e r d e, a z u]), f(a z u l, A)))$, Ig(a(A), (b(A,verde), $c($ verde $))) \mid B],[$ rg (d(verde, azul), true $)$, $\operatorname{rg}(b(A, v e r d e),(d(v e r d e, a z u l), f(a z u l, A))), r g(a(A),(b(A$, verde), $c($ verde) )) $\mid B])$ :-

true.

prove (d (vinho, marrom), $[\mathrm{rg}(b(A, v i n h o),(d$ (vinho, marrom), f (marrom, $A))), \operatorname{rg}(a(A),(b(A, v i n h o), c(v i n h o))) \mid B],[r g(d(v i n h o$, marrom), true $), \mathrm{rg}(b(A, v i n h o),(d(v i n h o$, marrom) , f(marrom, A)) $), \operatorname{Ig}(a(A),(b(A$, vinho $), c($ vinho $)))(B]):-$

true.

prove (d(cinza, rosa), $[\mathrm{rg}(b(A, c$ inza),$(d(\operatorname{cinza}$, rosa $), f(\operatorname{ros} a, A)))$, $\operatorname{rg}(a(A),(b(A, c i n z a), c(c i n z a))) \mid B],[r g(d(c i n z a$, rosa $)$, true $)$, $\operatorname{rg}(b(A, c i n z a),(d(\operatorname{cinza}$, rosa $), f(\operatorname{ros} a, A))), r g(a(A),(b(A$, cinza), $c($ cinza)) ) $\mid B])$ :-

true.

prove (f (vermelho, cinza), $A,[\mathrm{rg}(f($ vermelho, cinza), true) $\mid A]):-$ true. prove (f (marrom,branco), A, [rg(f(marrom,branco), true)|A]) :- true. prove (f(rosa,verde), $A,[r g(f(r o s a, v e r d e), t r u e) \mid A]):-$ true.

Após a eliminação do meta-interpretador, obtém-se o seguinte programa:

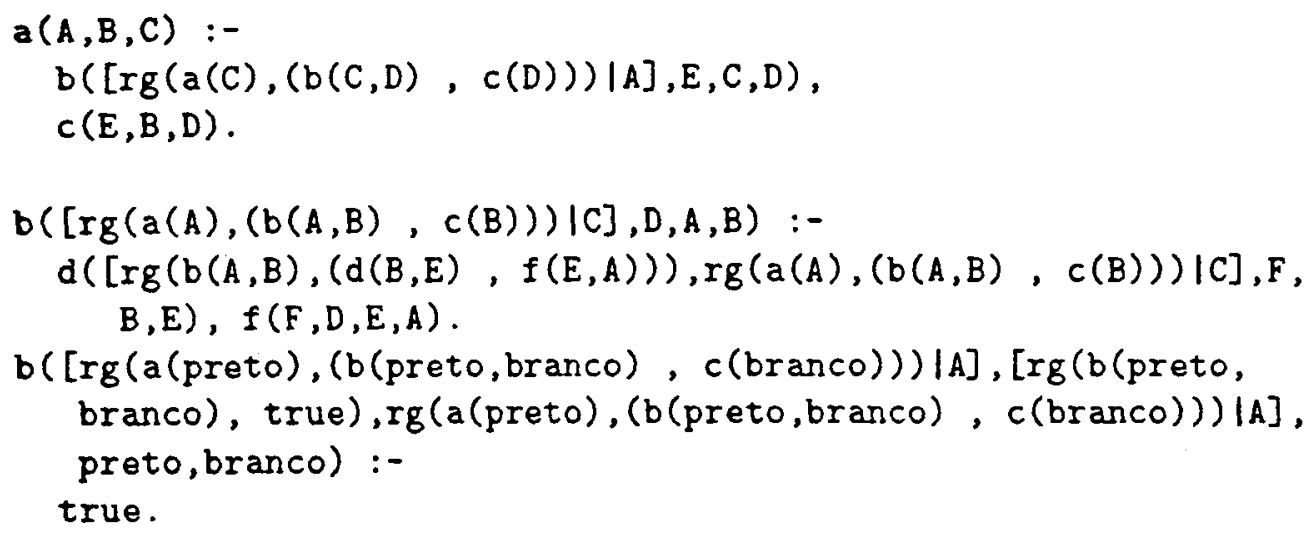




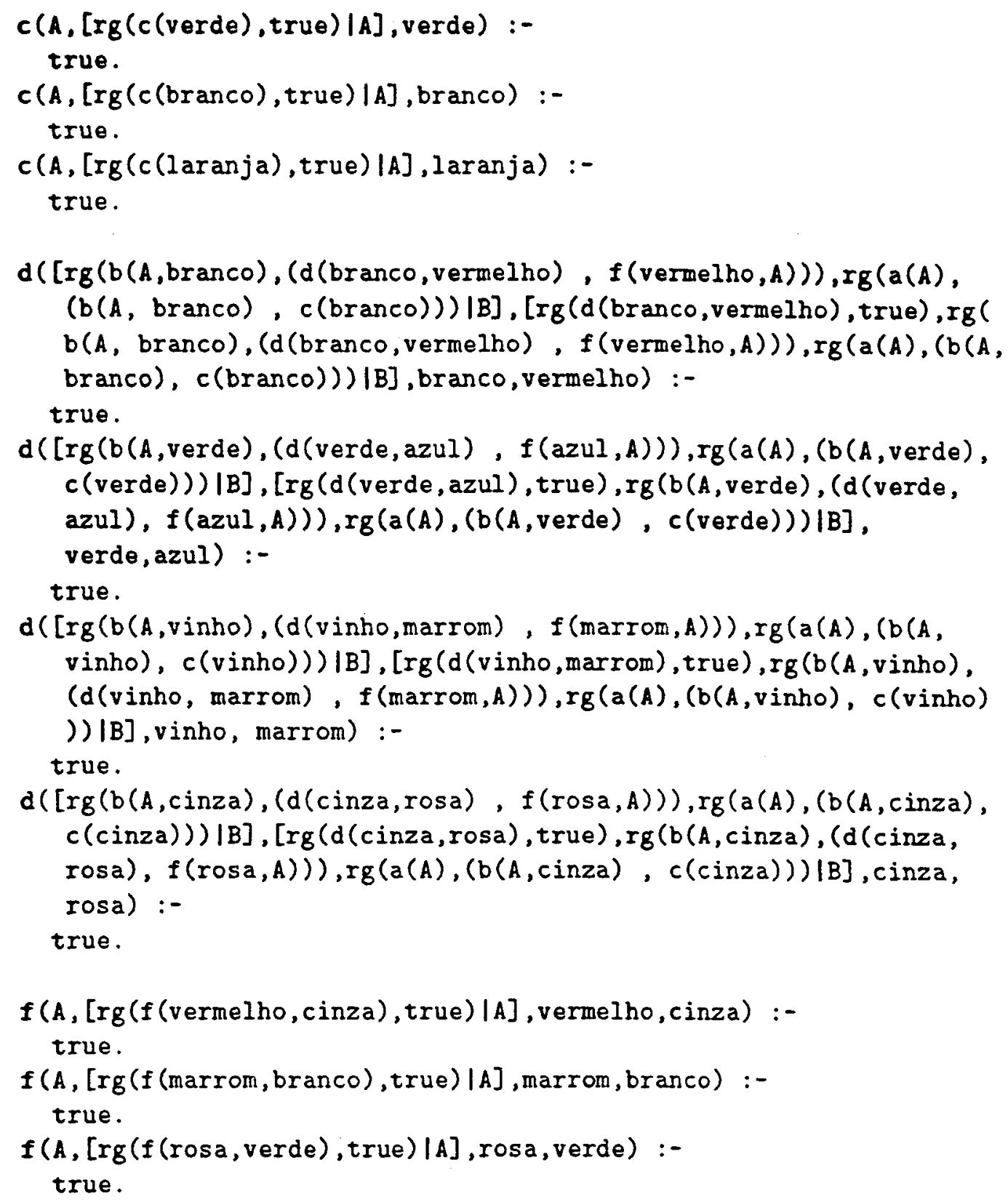

Exemplo 2 : Como segundo exemplo, será utilizada o seguinte programa como Base de Conhecimento, contendo relaçōes primitivas e do sistema:

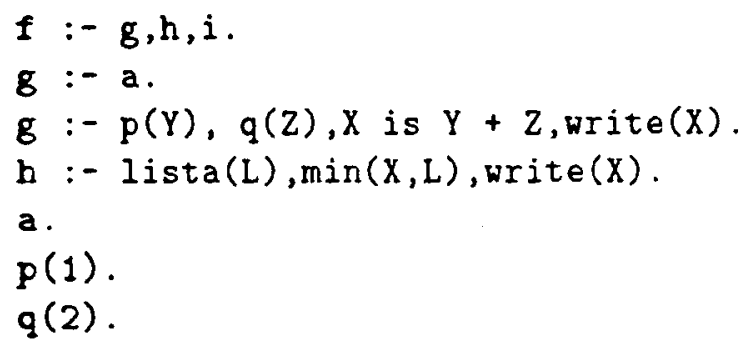




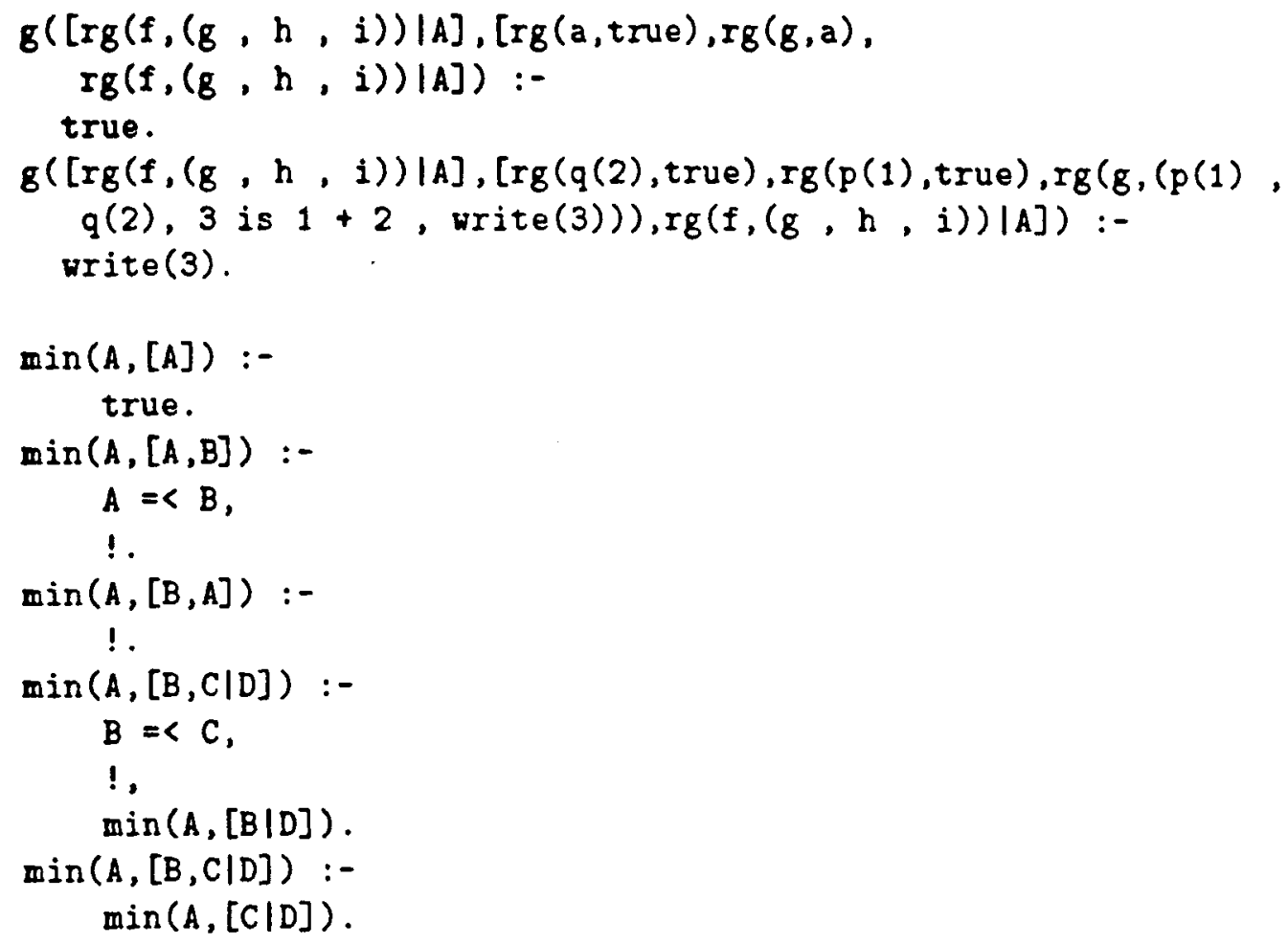

\subsection{Considerações Finais}

Neste capítulo discutiu-se como a Avaliação Parcial pode ser utilizada para aumentar a eficiência de Sistemas Especialistas, principalmente quando se utiliza de meta-interpretação para manter a Base de Conhecimento independente do Núcleo que a manipula.

Foram apontados os principais critérios que podem ser utilizados para decidir quando uma meta deve ser expandida ou não. Foi dada maior ênfase na eliminação do nível extra de interpretação introduzido pela utilização de meta-interpretadores, mas as otimizaçōes que podem ser obtidas com pré-execuçōes de açōes semânticas não foram deixadas de lado.

Foi proposto um Avaliador Parcial de meta-interpretadores e mostrou-se um exemplo mostrando o que deve ser feito para que esse Avaliador Parcial possa ser utilizado em um meta-interpretador específico.

Finalmente, mostrou-se como eliminar o meta-interpretador, retirando-se os meta-argumentos da cláusula.

A dificuldade de aplicar o método da avaliação parcial em meta-interpretadores está diretamente ligada à classificação dos meta-interpretadores (seção $5.4-$ pag. 66). Em geral, os meta-interpretadores com aumento estrutural ou contextual não apresentam problemas na Avaliação Parcial. Entretanto, há certa dificuldade na Avaliação Parcial de meta-interpretadores com aumento procedimental, principalmente quando ele pode alterar a Base de Conhecimento. 


\section{Capítulo 8}

\section{Conclusões}

\subsection{Considerações Iniciais}

Neste trabalho foram discutidos alguns métodos para aumentar a eficjência de programas Prolog, dentre os quais foi dado major ênfase aos Sistemas Especialistas desenvolvidos usando meta-interpretadores.

Os métodos aqui discutidos - Especialização de Programas e Avaliação Parcial - não devem ser comparados aos métodos de otimização de programas convencionais, pois seus objetivos são um tanto distintos. Na verdade, ambos são métodos que permitem a construção de programas gerais para posteriormente torńa-los específicos, de modo a facilitar a confecçào de um programa sem perder sua eficiência.

A Especialização de Programas Prolog consiste em eliminar de um programa as cláusulas que não são necessárias a uma determinada aplicação. Deste modo, é possível construir um programa abrangente em uma determinada área de aplicação e, para sua real utilização, utilizar o método de Especialização de Programas para gerar um programa com um menor número de cláusulas e, portanto, mais eficiente que o programa original.

A Avaliação Parcial também pode ser considerada um método de especializar programas gerais, embora com uma filosofia um tanto distinta. A Avaliação Parcial trabalha sobre um programa geral onde a entrada para sua execução é uma base de dados específica. Utilizando o programa geral e esses dados, a Avaliação Parcial gera um programa específico com uma razão de eficiência maior que o programa original, pois neste último, os dados estão inseridos dentro do programa, eliminando, no processo de execução do programa, a busca e interpretação desses dados.

\subsection{Análise do Avaliador Parcial}

A implementação de um sistema de Avaliação Parcial é uma tarefa um tanto complexa. Neste trabalho, procurou-se mostrar como construir um Avaliador Parcial para eliminar 
o nível extra de interpretasão quando utiliza-se meta-interpretadores.

A implementaçào de um Avaliador Parcial para um meta-interpretador específico, feita neste trabalho, foi importante para mostrar quão complexa é a utilização dessa metodologia.

A seguir encontram-se algumas características do Avaliador Parcial que merecem algum destaque:

- o Avaliador Parcial ignora os cortes (!) existentes no meta-interpretador. No entanto, considerando-se que o Avaliador Parcial toma somente uma das regras do meta-interpretador para montar o programa especializado, o sistema resultante tem um funcionamento equivalente ao original.

- o meta-interpretador deve ter algumas características que permitam ao Avaliador Parcial determinar qual das regras será utilizada em cada passo da Avaliação Parcial. Por este motivo, o meta-interpretador original [Monard 89b] - que forma a base do Núcleo Geral - foi transformado em um meta-interpretador equivalente, mas que elimina algumas ambiguidades. O Avaliador Parcial foi construído sobre o meta-interpretador modificado.

- o Avaliador Parcial é específico para um dado meta-interpretador, mas ele é independente da Base de Conhecimento, que pode ter até mesmo multiplicidade de cláusulas na definiçào uma única meta.

Apesar da complexidade da implementação de um Avaliador Parcial, e também das limitasooes encontradas, os resultados apresentados pelo Avaliador Parcial mostram que a Avaliação Parcial pode se tornar uma ferramenta muito poderosa, principalmente quando utilizada com meta-interpretadores.

\subsection{Avaliação do Sistema $G E \mathcal{N} E S E$}

GENESE é um sistema baseado na filosofia da Especialização de Programas feito para gerar núcleos específicos de Sistemas Especialistas. Ele trabalha com o núcleo geral descrito em [Rodrigues 90a].

$\mathrm{Na}$ verdade, a construção de um sistema para Especialização de Programas pode ser considerada uma tarefa simples, pois consiste tão somente em:

- verificar as cláusulas que se aplicam a um procedimento específico

- perguntar ao usuário do sistema se sua aplicação utilizará esse procedimento

- eliminar esse conjunto de cláusulas desnecessárias.

Em princípio este fato pode até ser considerado verdadeiro, caso o programa seja estático, isto é, um sistema que não sofra alteraçōes depois de pronto. Deste modo, 
um sistema utilizado para especializar um determinado programa deve ser de fácil alteração, para que possa ser facilmente adaptável ao programa sempre que este sofra alteraçōes.

Considerando os aspectos delineados no parágrafo anterior, o sistema GENESE - por nós proposto e implementado - pode ser considerado muito versátil, pois sua concepção permite que ele se adapte a alterações do núcleo geral - sobre o qual ele trabalha sem que seu código seja alterado. Isto é possível porque a relação entre as cláusulas do núcleo geral e as aplicasooes específicas de cada conjunto de cláusulas é feita de forma explicita, ou seja, o GENESE não traz essa informação em seu código. Essa informação encontra-se em uma base de dados e pode ser facilmente alterada - através do Módulo de Interface com o Implementador do Núcleo Geral.

Um sistema de especialização baseado nas idéias apresentadas acima pode ser cosiderado muito versátil; porém, na implementação do sistema GENESE a partir dessa filosofia encontramos alguns obstáculos, principalmente no que diz respeito a interação com o usuário:

- em muitos casos, a interação com o usuário é feita através de menus que apresentam ao usuário uma lista de opçōes, permitindo ao usuário escolher uma delas. Infelizmente, os recursos apresentados pelo Arity Prolog - caixas de diálogo dificultam a implementação desse modelo de interação com o usuário

- o conjunto dos elementos que compõem a lista de opçōes dos menus é constantemente modificado. Esse dinamismo torna praticamente inviável a utilização de caixas de diálogo na implementação do sistema GENESE

- o desconhecimento de um outro sistema para a geração de Núcleos de Sistemas Especialistas específicos, ou de qualquer sistema geração de programas específicos semelhante, tornou a tarefa de definir o sistema GEN'ESE um tanto árdua, pois no início da implementação tínhamos somente uma idéia um tanto vaga do objetivo final e quase nada em relação ao caminho a ser trilhado.

Para solucionar o problema da inflexibilidade das caixas de diálogo do Arity Prolog, construimos um sistema de menus mais flexível e muito mais fácil de ser utilizado.

Quanto ao sistema implementado, os resultados obtidos superaram nossas expectativas; realmente, esperava-se que o $G E \mathcal{N} E S E$ fosse um sistema transparente ao Implementador da Base de Conhecimento. Entretanto, conseguimos implementar um sistema que também é transparente ao Implementador do Núcleo Geral [Franco 92]. 


\subsection{Trabalhos Futuros}

A seguir são apresentadas algumas sugestões de trabalhos que podem ser desenvolvidos baseados nos resultados econtrados neste trabalho:

\subsubsection{Avaliação Parcial}

A Avaliação Parcial, bem como outros métodos de transformação de programas, constituem um campo muito vasto para estudos futuros. Aliás, mesmo nas instituições de pesquisas mais avançadas, existem diversos problemas que ainda não foram solucionados. Além disso, algumas das soluções existentes não são completamente satisfatórias.

Em termos de implementação, existem algumas sugestões para melhorar o Avaliador Parcial implementado e apresentado neste trabalho:

1. permitir a existência de cláusulas ambíguas no meta-interpretador, isto é, quando o Avaliador Parcial encontrar mais de uma cláusula que soluciona uma dada meta, ele deverá trabalhar com as duas em paralelo. Na verdade, isto não é vantajoso em termos de eficiência, pois duplicaria alguns trechos do código, mas tornaria o Avaliador Parcial mais versátil.

2. construir um módulo de interação com o usuário para que ele possa definir com maior facilidade as características de seu meta-interpretador sem alterar o Avaliador Parcial.

3. definir um Avaliador Parcial que possa ser utilizado com meta-interpretadores que encontram majs de uma solução para uma mesma meta.

\subsubsection{Especialização de Programas}

Apesar do sistema GENESE ter sido desenvolvido especificamente para trabalhar na geraçāo de núcleos especificos a partir de um núcleo geral, pode-se observar que, devido às características da linguagem Prolog, ele pode ser utilizado para especializar qualquer programa Prolog.

Assim, além da sugestão óbvia de utilizar GENESE para trabalhar com outros núcleos distintos daquele aqui apresentado, pode-se também sugerir o uso de GENESE em sistemas mais gerais, dirigidos a sistemas de bases de dados, programas dirigidos a aplicações mais convencionais, e até mesmo programas dirigidos a problemas de Inteligência Artificial distintos de Sistemas Especialistas. 


\subsection{Considerações Finais}

A grande diferença entre a tecnologia brasileira em relação aos países do primeiro mundo torna-se uma grande barreira para as pesquisas mais avançadas, principalmente em uma área como Cjências da Computação, área em que os avanços são cada vez maiores.

Apesar disso, a comunidade científica brasileira tenta acompanhar a evolução das pesquisas internacionais, usando muita criatividade para superar essas deficiências.

Neste traballıo foram discutidas algumas metodologias de transformação de programas que podem ser utilizadas para aumentar sua eficiência. Apesar da teoria não ser tão recente, somente nos últimos anos esses métodos começaram a ser utilizados. Afinal, a Avaliação Parcial mereceu destaque no ICOT Journal [Furukawa 90], mostrando a importáncia da construção automática de programas específicos a partir de programas gerais no projeto Quinta Geraçào. 


\section{Bibliografia}

[Alty 84] Alty, J.C.; Coombs, M.J. Expert Systems: Concepts and Examples. NCC Publications, 1984.

[Amble 87] AMBLE, T. Logic Programming and Knowledge Engineering. Addison-Wesley, 1987.

[Arity 88] Arity Corporation. The Arity/Prolog Programming Language. CSA Press, Massachussets, 1988.

[Beckman 76] Beckiman, L.; Haraldson, A.; Oskarsson, Ö.; Sandewall, E. A Partial Evaluator, and its Use as a Programming Tool. Artificial Intelligence 7, $\mathrm{pp}$ 319-357, 1976.

[Bowen 82] Bowen, K.; Kowalski R. Amalgamating Language and Metalanguage in Logic Programming. Logic Programming Clark,K. and Tärnlund S. (Eds) ; Academic Press, 1982.

[Bratko 90] Bratko, 1. Prolog Programming for A.I. Addison-Wesley, 2a. Ed., 1990.

[Bulyonkov 90] Bulyonkov, M. Mized Computation and Compilation: New Approaches to Old Problems. Theoretical Computer Science 71, pp 209$226,1990$.

[Carnota 88] Carnota, R.J.; Tezkiewiz, A.D. Sistemas Expertos y Representación del Conocimiento. Editora Ebai, 1988.

[Casanova 87] Casanova, M.A.; Giorno, F.A.C.; Furtado, A.L. Programação em Lógica e a Linguagem Prolog. Editora Edgard Blücher, 1987

[Clocksin 87] Clocksin, W.F.; Mellish, C.S. Programming in Prolog. SpringerVerlag, 3a. Ed. , Germany, 1987.

[Ershov 77] Ershov, A. P. On the Partial Computation Principle. Information Processing Letters, Vol. 6, No2, pp 38-41, A pril 1977.

[Ershov 82] Ershov, A. P. Mixed Computation: Potential Applications and Problems for Study. Theoretical Computer Science, Vol. 18, pp 41-67, North-Holland Publishing Company, 1982. 
[Ford 87] Ford, N. How Machines Think. John Wiley and Sons, 1987.

[Franco 92] Franco, J. L. GENESE - Um Gerador de Núcleos Específicos de Sistemas Especialistas. ICMSC-USP, 1992 - Em Preparação.

[Fujita 87a] Fujita, H.; Furukawa, K. A Self Applicable Partial Evaluation and its Use in Incremental Compilation. ICOT Technical Report: TR-258, May 1987.

[Fujita 87b] Fujita, H. An Algorithm for Partial Evaluation with Constraints. ICOT Technical Memorandum TM-0367, August 1987.

[Fujita 88] Fujita, H.; Okumura, A.; Furukawa, K. Partial Evaluation of GHC Programs Based on UR-set with Constraint Solving. ICOT Technical Report: TR-344, February 1988.

[Furukawa 89] Furukawa, K.;Fujita, H. Deriving an Efficient Production System by Partial Evaluation. ICOT Technical Report: TR-456, March 1989.

[Furukawa 90] Furukawa, K.;Fujita, H. On Partial Evaluation. ICOT Journal, No28, pp 4-15, 1990.

[Gallaire 82] Gallaire, H.; Lasserre, C. Metalevel Control for Logic Programs. Logic Programming, Clark,K. and Tärnlund S. (Eds); Academic Press, 1982.

[Hayes-Roth 83] Hayes-Roth, F.; Waterman, D.A.; Lenat, D.B. (Eds). Building Expert Systems. Addison-Wesley Publishing Company, 1983.

[Jackson 86] JACison, P. Introduction to Expert Systems. Addison-Wesley Publishing Company, 1986.

[Jones 88a] Jon Es, N. D. Scientific Foreword New Generation Computing, 6, pp $87-90,1988$.

[Jones 88b] Jon es, N. D. Challenging Problems in Partial Evaluation and Mixed Computation New Generation Computing, 6, pp 87-90, 1988.

[Koromowski 81] Koromowski, H. J. A Specification of an Abstract Prolog Machine and Its Application to Partial Evaluation. Linkoping Studies in Science and Technology Dissertations, No. 69, Software Systems Research Center, Linkoping University, Sweden, 1981.

[Lakhotia 90] Lakhotia, A.; Sterling, L. How to Control Unfolding when Specializing Interpreters. New Generation Computing, 8, pp 61-70, 1990.

[Levi 88] Levi, G.; SARDU, G. Partial Evaluation of Metaprograms in a "Multiple Worlds" Logic Language. New Generation Computing, 6, pp $227-247,1988$.

[Michie 82] MICHIE, D. (ED) Introductory Readings in Expert Systems. Gordon and Brach, 1982. 
[Marcus 86] Mancus, C. Prolog Programming - Applications for Database Systems, Expert Systems and Natural Language Systems. AddisonWesley Publishing Company, 1986.

[Merrit 89] MERRIT, D. Building Expert Systems in Prolog. Springer-Verlag, 1989.

[Monard 86] Monard, M. C. Um Sistema de Representação de Conhecimento e Raciocinio por Default. Tese de Livre Docência, ICMSC-USP, 1986.

[Monard 87] Monard, M. C.,Hebihara, S. M. Um Sistema que Utiliza Raciocinio por "Default". Anais IV SBIA, pp 143-156, Outubro 1987.

[Monard 89a] Monard, M. C.; Prado, A.H.A. Uso de Incerteza em Sistemas Baseados em Conhecimento. ILTC, Maio 1989.

[Monard 89b] Monard, M. C.; Rodrigues, S. R. Implementação Lógica de um Motor de Inferência com Raciocinio Backward Chaining para a Construçioo de Sistemas Especialistas. Notas do ICMSC-USP, No51, 1989

[Monard 89c] Monard, M. C.; Rodrigues, S. R. Desenvolvimento de Sistemas Especialistas em Prolog. ILTC, Julho 1989.

[Monard 90] Monard, M. C.; Franco, J. L. Uso de Programação Lógica no Desenvolvimento de Compiladores. Relatório Técnico do ICMSC-USP, No8, 1990

[Monard 91] Monard, M. C.; Rodrigues, S. R. An Environment for Developing Expert System's Shells. Aceito no "The World Congress on Expert Systems, Orlando, Florida USA, 1991.

[Nilsson 82] NıLson, N. J. Principles of Artificial Intelligence. Spring-Verlag, 1982.

[Pearl 86] Pearl, J. Bayes Decision Methods. Technical Report CSD-850023. University of California at Los Angeles, January 1986

[Rodrigues 89] Rodrigues, S. R.; Monard, M. C. Um Subsistema de um Núcleo de Sistemas Especialistas para Interrogar o Usuário Admitindo Diversas Categorias de Perguntas. Anais do 6oSimpósio Brasileiro em Inteligência Artificial, pp 78-93, 1989.

[Rodrigues 90a] Rodrigues, S. R. Um Ambiente para Auxiliar a Construção de Núcleos de Sistemas Especialistas. Tese de Mestrado, ICMSC-USP, 1990.

[Rodrigues 90b] Rodrigues, S. R.; MONARD, M. C. Implementação Lógica de um Módulo Coletor de Dados para a Construção de Sistemas Especialistas. Notas do ICMSC-USP, NQ63, 1990. 
[Rodrigues 90c] Rodrigues, S. R.; Monard M. C. Uso de Meta-Interpretadores no Desenvolvimento de Núcleos de Sistemas Especialistas. ILTC, Agosto 1990.

[Sakama 87] Sakama, C.; ItoH, H. Partial Evaluation of Queries in Deductive Databases. ICOT Technical Report: TR-302, September 1987.

[Sawamura 85] Sawamura, H.; Takeshima, T. Source-Level Optimization Techniques for Prolog. IC.OT Technical Memorandum TM-0091, January 1985.

[Sawaki 91] SaWAKI J. Um Sistema Baseado em Conhecimento para Apoio aos Usuários da Biblioteca NAG. Tese de Mestrado, ICMSC-USP, 1991.

[Shell 85] Shell, P.S. Expert Systems: A Practical Introduction. McMillan Publishers Ltd., 1985.

[Shortliffe 76] Shortulffe, E.H. Computer-Based Medical Consultation Mycin. American Elsevier, New York, 1976.

[Sterling 84] Sterling; L. Logical Levels of Problem Solving. Journal of Logic Programming, No2, pp 151-163, 1984.

[Sterling 86] Sterling, L.; Beer, R. Incremental Flavor-Mixing of MetaInterpreters for Expert System Construction. Proceedings Symposium on Logic Programming, pp 20-27, 1986.

[Sterling 87] Sterling, L. ; Shapiro, E. The Art of Prolog. The Mit Press, 1987.

[Sterling 89] Sterling, L. Meta Interpreters for Expert System Construction. The Journal of Logic Programning, 1989.

[Takeuchi 86a] Takeuchi, A.; Furulawa, K. Partial Evaluation of Prolog Programs and its Application to Meta Programming. ICOT Technical Memorandum TM-0164, September 1986.

[Takeuchi 86b] TAKEUCHI, A. Affinity between Meta Interpreters and Partial Evaluation. ICOT Technical Report: TR-166, April 1986.

[Takeuchi 88] Takevchi, A.; Fujita, H. Competitive Partial Evaluation. New Generation Computing, 6, pp 259-277, 1988.

[Venken 84] Venken, R. A Prolog meta-interpreter for partial evaluation system and its application to source-to-source transformation and query optimisation. Proceedings of ECAI '84, Pisa, North-Holland, 1984.

[Venken 88] Venken, R.; Demoen, B. A Partial Evaluation System for Prolog: some Practical Considerations. New Generation Computing, 6, pp 279-290, 1988. 
[Walker 87] W'Alker, A. (Ed.); MCCord, M.; Sowa, J. E.; Wilson, W. G. Knowledge Systems and Prolog. A Logical Approach for Expert Systems and Natural Language Processing. Addison-Wesley, 1987.

[Waterman 86] Waterman, D.A. A Guide to Expert Systems Addison-Wesley, 1986.

[White 85] Withe, A.P. Inference Deficiencies in Rule-based Expert Systems Research and Development in Expert Systems, Cambridge University Press, pp 39-50, 1985.

[Winston 84] Winston, P. H. Artificial Intelligence Addison-Wesley, 1984.

[Yamaki 90] YamakI, C. K. Combinando Avaliação Parcial e Introdução Automática de Controle para Aumentar a Eficiência de Sistemas Especialistas. Tese de Mestrado, IMECC, Unicamp, 1990. 